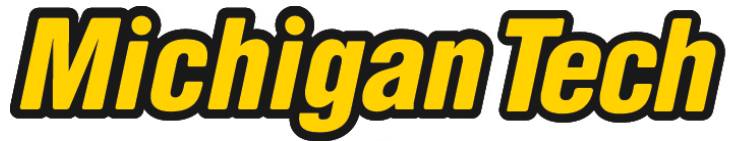 \\ Michigan Technological University Create the Future Digital Commons @ Michigan Tech
}

Dissertations, Master's Theses and Master's Reports - Open

Dissertations, Master's Theses and Master's

Reports

2011

\section{Micro combined heat and power laboratory development}

Thomson Varghese

Michigan Technological University

Follow this and additional works at: https://digitalcommons.mtu.edu/etds

Part of the Mechanical Engineering Commons

Copyright 2011 Thomson Varghese

\section{Recommended Citation}

Varghese, Thomson, "Micro combined heat and power laboratory development", Master's report, Michigan Technological University, 2011.

https://doi.org/10.37099/mtu.dc.etds/560

Follow this and additional works at: https://digitalcommons.mtu.edu/etds

d. Part of the Mechanical Engineering Commons 


\title{
Micro Combined Heat and Power Laboratory Development
}

\author{
By
}

Thomson Varghese

A REPORT

Submitted in partial fulfillment of the requirements of the degree of

MASTER OF SCIENCE IN MECHANICAL ENGINEERING

MICHIGAN TECHNOLOGICAL UNIVERSITY

2011

(C) 2011 Thomson Varghese 
This report, "Micro Combined Heat and Power Laboratory Development” is hereby approved in partial fulfillment of the requirements for the Degree of MASTER OF SCIENCE IN MECHANICAL ENGINEERING

Department of Mechanical Engineering-Engineering Mechanics

Signatures:

Report Advisor

Dr. Jeffrey D. Naber

Department Chair

Dr.William Predebon

Date 


\section{$\underline{\text { Abstract }}$}

Micro Combined Heat and Power (Micro-CHP) system produces both electricity and heat required for residential or small business applications. Use of Micro-CHP in a residential application not only creates energy and economic savings but also reduces the carbon foot print of the house or small business. Additionally, micro-CHP can subsidize its cost of operation by selling excess electricity produced back to the grid. Even though MicroCHP remains attractive on paper, high initial cost and optimization issues in residential scale heat and electrical requirement has kept this technology from becoming a success. To understand and overcome all disadvantages posed my Micro-CHP system, a laboratory is developed to test different scenarios of Micro-CHP applications so that we can learn and improve the current technology.

This report focuses on the development of this Micro-CHP laboratory including installation of Ecopower micro-CHP unit, developing fuel line and exhaust line for Ecopower unit, design of electrical and thermal loop, installing all the instrumentation required for data collection on the Ecopower unit and developing controls for heat load simulation using thermal loop. Also a simulation of Micro-CHP running on Syngas is done in Matlab.

This work was supported through the donation of 'Ecopower' a Micro-CHP unit by Marathon Engine and through the support of Michigan Tech REF-IF grand. 


\section{Acknowledgements}

I would like to take this opportunity to thank everyone who provided support and encouragement to ensure the success of this report.

First and foremost, I would like to thank my research advisor, Dr. Jeffrey Naber, for his invaluable guidance, support, and encouragement throughout my research project. His enthusiasm and immense knowledge has yielded a rewarding and successful research and graduate school experience. I also like to thank Dr. Jeffery Allen, Dr. Wayne Weaver and Dr. Dana Johnson for their invaluable guidance in this project.

I would like to thank Marathon Engines for donating the Ecopower unit and Michigan Tech for funding the lab development work. I would also like to thank all the engineers in Marathon Engines who helped me with this project.

I would also like to thank my friends and family for their encouragement through this process. I thank my Mom and Dad for their financial and emotional support during this process.

Thank you all,

Thomson 


\section{Table of Contents}

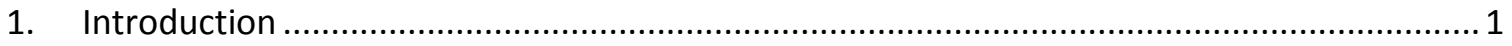

1.1. Comparison of CHP to conventional power generation .............................................. 3

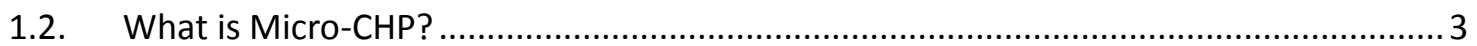

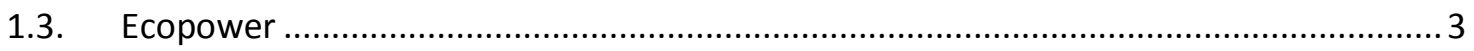

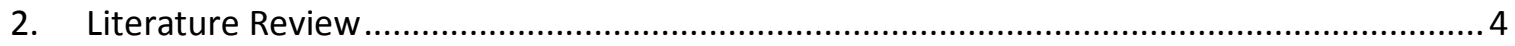

2.1. Micro-CHP Setup for residential application ......................................................... 4

2.2. Optimal sizing of Micro-CHP setup for maximum Economy.......................................... 4

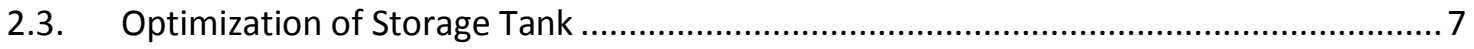

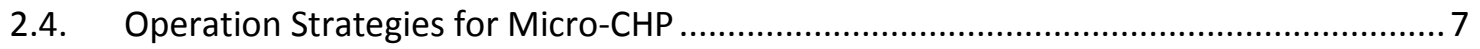

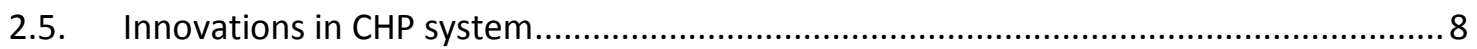

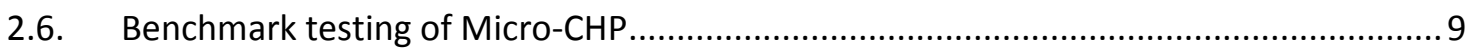

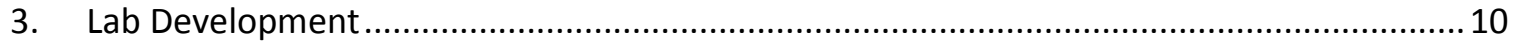

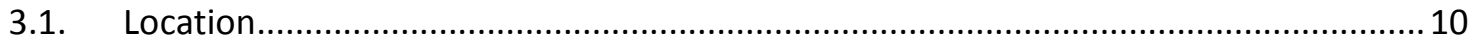

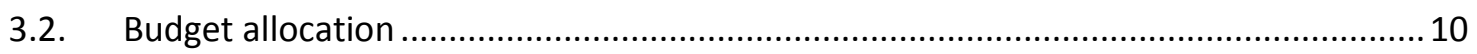

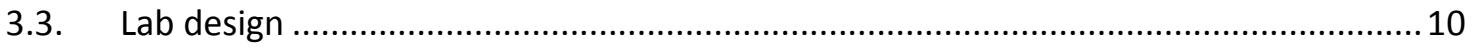

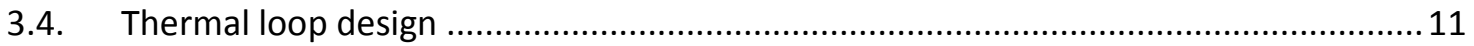

3.4.1. Water recirculation mode (1 to 9 shown in figure 3.1 ) ...................................... 11

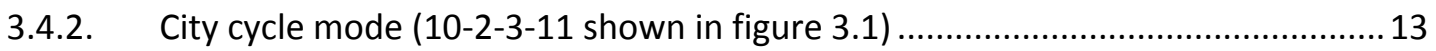

3.4.3. Thermodynamic validation of the thermal loop:................................................... 14

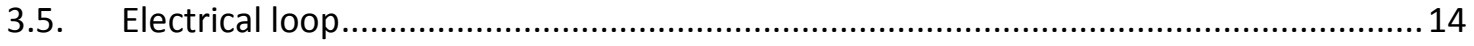

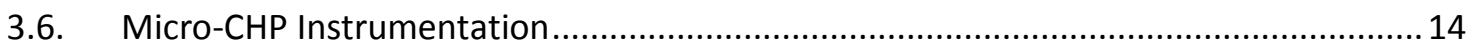

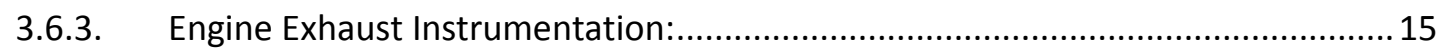

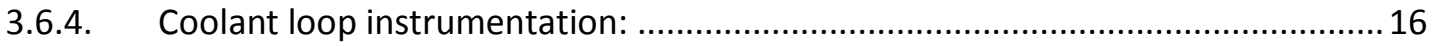

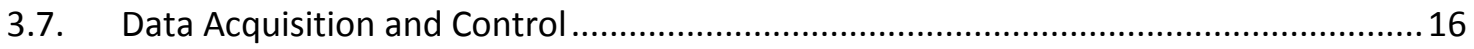

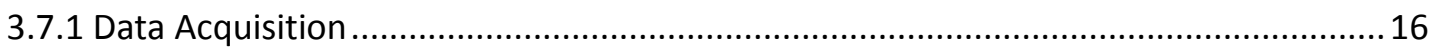

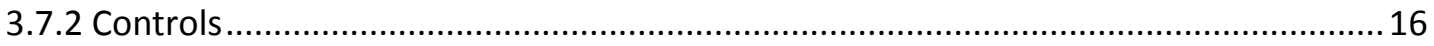

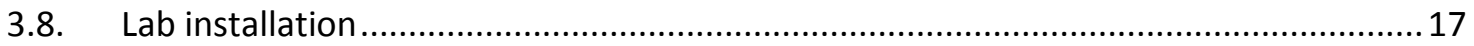

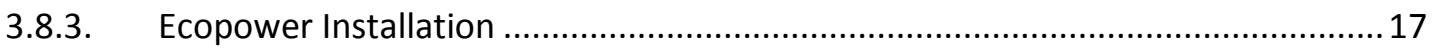

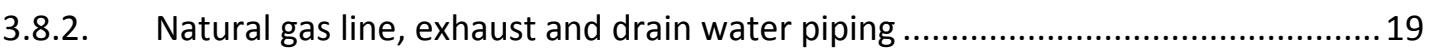

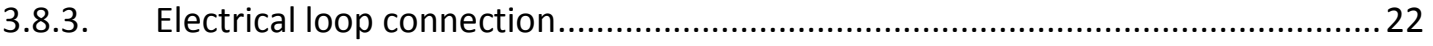

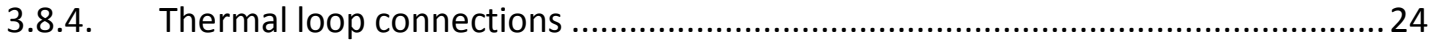




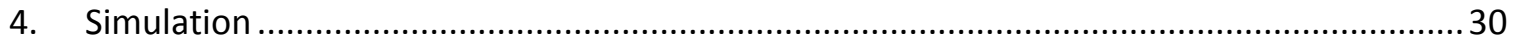

4.1. Design of Biomass run Micro-CHP system ....................................................... 30

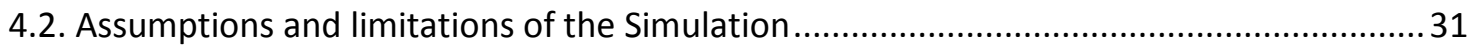

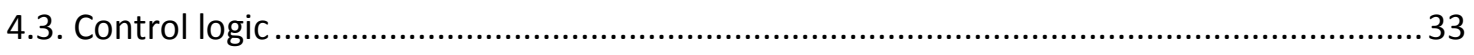

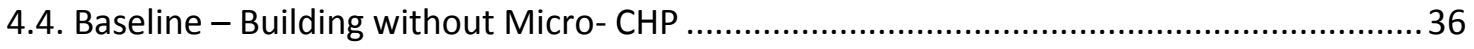

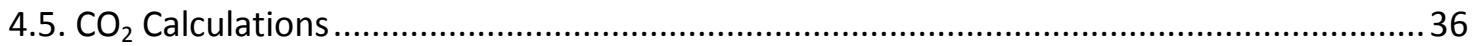

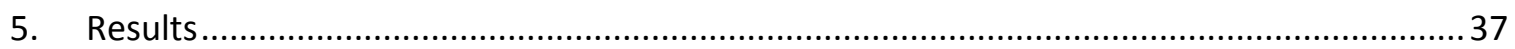

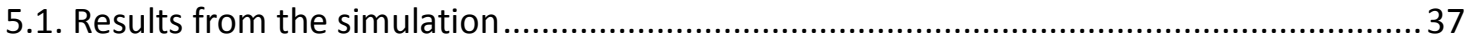

5.1.1. System efficiency comparison between CHP and baseline run system ...................37

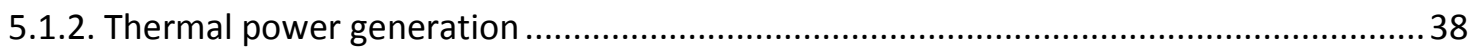

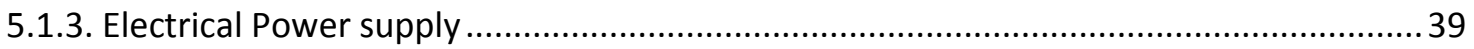

5.1.4. $\mathrm{CO}_{2}$ emission comparison between a Syngas operated Micro-CHP system and a baseline

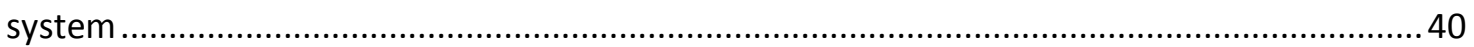

5.1.5. Fuel mass flow rate for CHP system ........................................................... 41

5.1.6. Fuel mass flow rate for Baseline System ................................................. 42

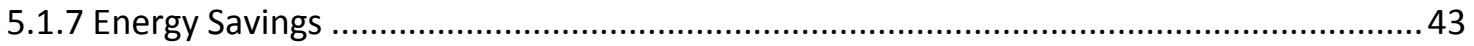

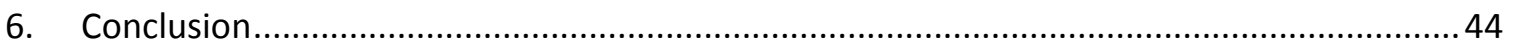

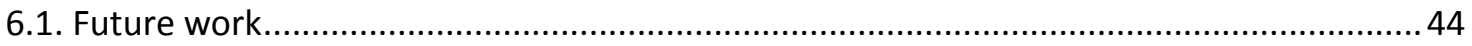

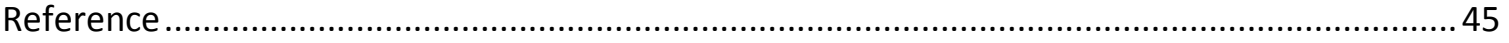

Appendix A: Matlab code for simulation .................................................................46

Appendix B: EES program for thermodynamic analysis of the Thermal Loop..........................55

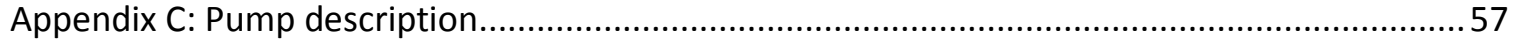

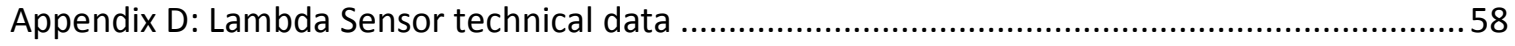

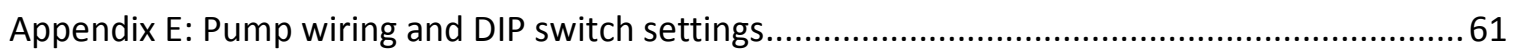

Appendix F: Belimo Three way, Characterized Control Valve ...........................................64

Appendix G: Micro CHP Project spending report ...................................................67

Appendix H: Instructions to run Micro-CHP Lab .................................................... 70

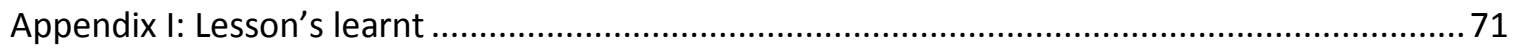




\section{Introduction}

Combined Heat and Power (CHP) systems involves the production of heat and electricity both from the same energy source [1]. CHP is also known as a cogeneration plant. A normal electrical generator unit uses only a fraction of the chemical energy of the fuel to generate electricity and the rest of the energy is converted into low quality heat which is wasted. In a CHP system this waste heat is utilized for space heating, water heating, process heating etc. A CHP system produces up to $90 \%$ efficiency as compared to a conventional power plant efficiency of about 55\%. The advantages of using CHP compared to conventional power plants are [2]:

- Increased total thermodynamic efficiency

- Reduced fuel consumption

- Reduced overall facility energy consumption cost

- Reduced dependability on the grid for electricity

- Reduced $\mathrm{CO}_{2}$ emissions

- Improved facility reliability

- Freedom to use different types of fuels including carbon neutral fuels like biofuels.

Use of CHP is commonly seen in hospitals, district energy systems, municipal centers, commercial campuses, large commercial buildings, data centers, jails and prisons, oil refineries, waste water treatment plants, pharmaceutical industries, industries requiring heating processes and residential systems [2].

Fuels typically used in CHP are fossil fuels, natural gas, biomass, ethanol, biodiesel, biogas and municipal wastes [2].

CHP systems are typically installed on sites where there is a simultaneous requirement of electrical and thermal load. Other than the requirement of electricity and heat, additional considerations before installing the CHP are the price and availability of electricity, capital investment required to install a CHP system and the return on investment after installing [2]. CHP's are usually operated parallel to the grid, supply excess electricity generated to the grid. In some cases, a CHP system is designed to operate separately from the grid and is known as "island mode" [2].

When a CHP runs parallel with utility power and supplies excess electrical power into the grid, utility companies compensate for this electrical power in their grid in the form of retail credit, a process called net metering. Net metering is important for a CHP user as it partially pays for the fuel used in the CHP. Net metering by the utility company is governed by the law of the land. In the United States, each state has different laws on net metering. State law dictates compensation rates for the electricity dumped into the utility grid and it also gives a limit on power allowed to be transferred to the grid under net metering scheme. Laws of each state in USA can be found on "Database of State Incentives for Renewables \& Efficiency" (www.dsireusa.org). Laws for Michigan and Wisconsin and four other states known for being most favorable for net metering are given in Table 1.1. Only four states, Alabama, Mississippi, South Dakota and Tennessee do not allow net metering. 
Table 1.1: Net metering laws for states

\begin{tabular}{|c|c|c|c|}
\hline State & $\begin{array}{l}\text { System Capacity } \\
\text { Limit }\end{array}$ & $\begin{array}{c}\text { Aggregate Capacity } \\
\text { Limit }\end{array}$ & Net Excess Generation \\
\hline Michigan & $150 \mathrm{~kW}$ & $\begin{array}{l}0.75 \% \text { of utility’s } \\
\text { peak load during } \\
\text { previous year }\end{array}$ & $\begin{array}{l}\text { Credited to customer's } \\
\text { next bill at retail rate for } \\
\text { systems } 20 \mathrm{~kW} \text { or less }\end{array}$ \\
\hline Wisconsin & $20 \mathrm{~kW}$ & No limit specified & $\begin{array}{l}\text { Generally credited to } \\
\text { customer's next bill at } \\
\text { retail rate for renewable } \\
\text { and avoided-cost rate for } \\
\text { non-renewable }\end{array}$ \\
\hline Colorado & $\begin{array}{c}\text { IOU:120\% of the } \\
\text { customer's average } \\
\text { annual } \\
\text { consumption } \\
\text { Municipality and } \\
\text { co-op customers: } \\
\text { 10kW for } \\
\text { residential } \\
\text { application }\end{array}$ & No limit specified & $\begin{array}{l}\text { Credited to customer's bill } \\
\text { at retail rate }\end{array}$ \\
\hline Maryland & $2 \mathrm{MW}$ & $\begin{array}{c}1500 \mathrm{MW} \text { ( 8\% of } \\
\text { peak demand) }\end{array}$ & $\begin{array}{l}\text { Credited to customer's } \\
\text { next bill at retail rate }\end{array}$ \\
\hline New Jersey & $\begin{array}{l}\text { No limit specified, } \\
\text { but total energy } \\
\text { production should } \\
\text { not exceed } \\
\text { customer's annual } \\
\text { on-site energy } \\
\text { consumption. }\end{array}$ & No limit specified & $\begin{array}{l}\text { Credited to customer's } \\
\text { next bill at retail rate }\end{array}$ \\
\hline Pennsylvania & $\begin{array}{l}50 \mathrm{~kW} \text { for } \\
\text { residential } \\
\text { application }\end{array}$ & No limit specified & $\begin{array}{l}\text { Credited to customer's } \\
\text { next bill at retail rate }\end{array}$ \\
\hline
\end{tabular}

* Source: www.dsireusa.org

* IOU: Investor-owned utilities

* In above list, only Wisconsin, Maryland and Pennsylvania explicitly mentions $\mathrm{CHP} /$ Cogeneration as a technology considered for net metering 


\subsection{Comparison of CHP to conventional power generation}

Conventional power plants are not as efficient as a CHP system. This is because conventional power plant produces only one form of useful energy (electricity) and it is limited by Carnot efficiency. Whereas the efficiency of CHP is increased because waste heat produced along with electricity is utilized for different heating requirement and is considered as useful energy.

\subsection{What is Micro-CHP?}

CHP systems usually are $50 \mathrm{~kW}$ (electrical output) [2] and above and is set up to cater large electricity and heating load demand, whereas a Micro-CHP system can produce anywhere between $1 \mathrm{~kW}$ to $10 \mathrm{~kW}$ of power and is aimed at residential application where heat and power requirements are low. Micro-CHP units are installed in homes or small businesses where the electricity is either consumed in the location or sold back to the utility to subsidize the cost of fuel for CHP. The heat is utilized for room heating and water heating applications. Various prime movers used for Micro-CHP are I.C Engine, Sterling Engine, Turbines and Fuel Cells.

\subsection{Ecopower}

Ecopower is an I.C Engine based Micro CHP system produced by Marathon Engines. It is designed to use Natural Gas as its fuel. Ecopower uses Marathon Engine developed by Gas Research Institute and is designed to run continuously for 4000 hours between maintenance cycle which includes change of ignition cable, spark plug, oil and filters. In Ecopower the engine is manufactured and assembled by Marathon Engine Systems and the electronic control loop is sourced from Vaillant (a German company). Specifications of the Ecopower system are as follows (www.marathonengines.com):

\author{
Electrical Power \\ Thermal Output \\ Gas Consumption \\ Overall efficiency \\ Electrical/Thermal output \\ Engine \\ Exhaust Gas Figures (at 5\% $\mathrm{O}_{2}$ ) \\ Grid Feed (Single Phase) \\ Power Factor \\ Sound Level \\ Dimensions (in inches) \\ Weight
}

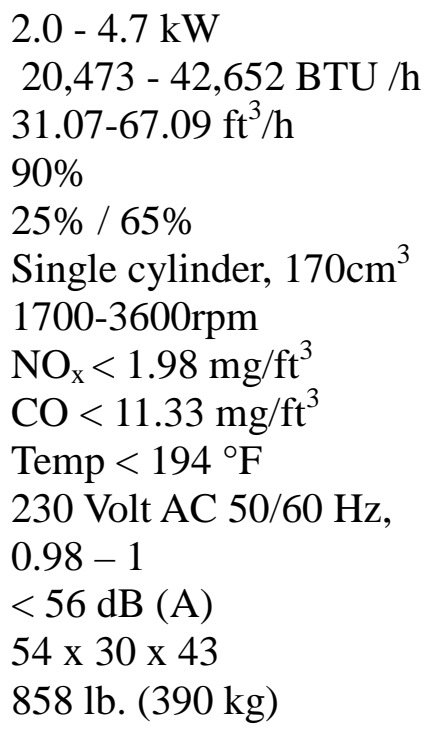




\section{Literature Review}

A literature review was undertaken to understand the development and application of micro-CHP.

\subsection{Micro-CHP Setup for residential application}

The setup of Micro-CHP in residential house for the heating, cooling and electrical power requirement is explained in detail in references [3] and [4] and is shown in figure 2.1. Micro-CHP system is connected parallel to the grid in residential houses to meet the electrical demand. If the peak thermal demand of the house is higher than CHP's peak thermal output, an additional boiler is installed to supplement the thermal load. Surplus electricity produced by the Micro-CHP is sold back to the grid and surplus heat produced by the Micro-CHP is stored in a thermal storage tank as shown in figure 2.1.

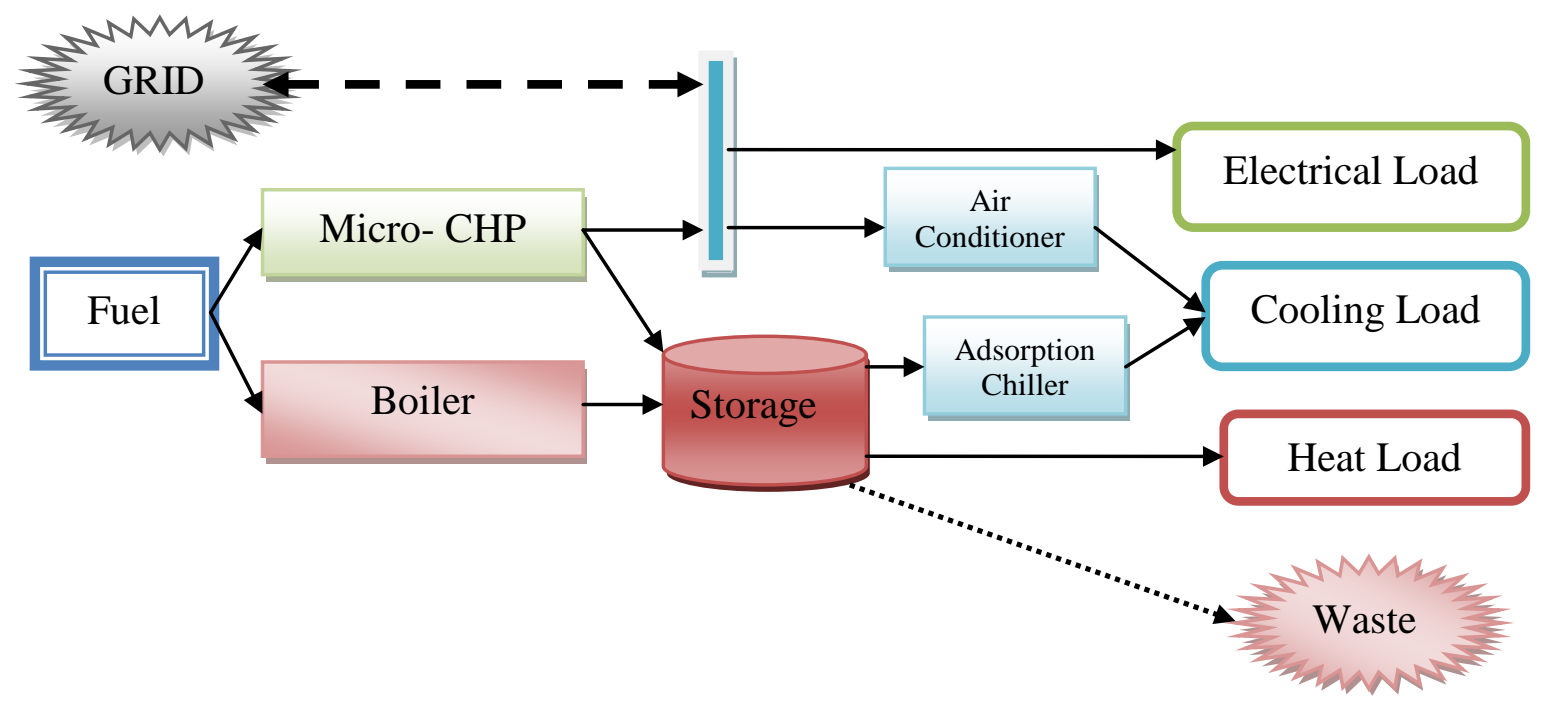

Figure 2.1: Micro-CHP energy flow diagram for residential application [3]

\subsection{Optimal sizing of Micro-CHP setup for maximum Economy}

To obtain the most economical advantage after installing the Micro-CHP in a house, references [4] and [5] has given the following objective function:

Minimize $\left\{\mathrm{C}_{\text {Total }}=\mathrm{C}_{\text {Utility }}+\mathrm{C}_{\mathrm{CHP}}+\mathrm{C}_{\text {Boiler }}+\mathrm{C}_{\mathrm{CHP} \_ \text {inv }}+\mathrm{C}_{\text {Boiler_inv }}+\mathrm{C}_{\mathrm{ctax}}-\mathrm{C}_{\text {Utility_sale }}\right\} \quad$ eq 1

Where $\mathrm{C}_{\text {Total }}=$ Total Cost

$\mathrm{C}_{\text {Utility }}=$ Cost of buying electricity from the Utility

$\mathrm{C}_{\mathrm{CHP}}=$ Cost of running the CHP 
$\mathrm{C}_{\text {Boiler }}=$ Cost of running the auxiliary Boiler

$\mathrm{C}_{\mathrm{CHP} \_ \text {inv }}=$ Total investment made on CHP

$\mathrm{C}_{\text {Boiler_inv }}=$ Total investment made on Boiler

$\mathrm{C}_{\text {ctax }}=$ Cost for carbon emission

$\mathrm{C}_{\text {Utility_sale }}=$ Income from selling electricity generated by CHP to the Grid

While minimizing eq 1 , the following constraints must be enforced:

- Electric power balance

O $\quad \mathrm{E}_{\text {Utility }}+\mathrm{E}_{\mathrm{CHP}} \geq \mathrm{E}_{\text {Load }}+\mathrm{E}_{\text {Air_Conditioner }}$

eq 2

Where $\mathrm{E}_{\text {Utility }}=$ Electricity imported from Grid

$\mathrm{E}_{\mathrm{CHP}}=$ Electricity produced my Micro-CHP

$\mathrm{E}_{\text {Load }}=$ Electric Load of the House

$\mathrm{E}_{\text {Air_Conditioner }}=$ Electric load produced by the Air Conditioner

- Heat Balance

o $\quad \mathrm{H}_{\text {CHP }}+\mathrm{H}_{\text {Boiler }} \geq \mathrm{H}_{\text {Space }}+\mathrm{H}_{\text {Water }}$

eq 3

Where $\mathrm{H}_{\mathrm{CHP}}=$ Heat produced by the CHP

$\mathrm{H}_{\text {Boiler }}=$ Heat produced by the Boiler

$\mathrm{H}_{\text {Space }}=$ Heating required for Space heating (or cooling using adsorption chiller)

$\mathrm{H}_{\text {Water }}=$ Heat required for Water heating

- Constrain on performance characteristics of Micro-CHP unit

O $\mathrm{E}_{\text {CHP }} \leq \mathrm{CHP}_{\text {Capacity }}$

eq 4

O $\quad$ CHP Capacity $\geq \mathrm{CHP}_{\text {Min_Capacity }}$

eq 5

Where CHP Capacity = Electrical capacity of the CHP

$\mathrm{CHP}_{\text {Min_Capacity }}=$ Minimum size of CHP available in the market

- Additional Constraints are required to ensure the operation of the storage tank. These constraints are given in reference [4]

Once we know the sizing of the micro-CHP we can follow the algorithm shown in figure 2.2 to obtain optimal energy dispatch. Different operational strategies based on figure 2.2 are given in section 2.4. 


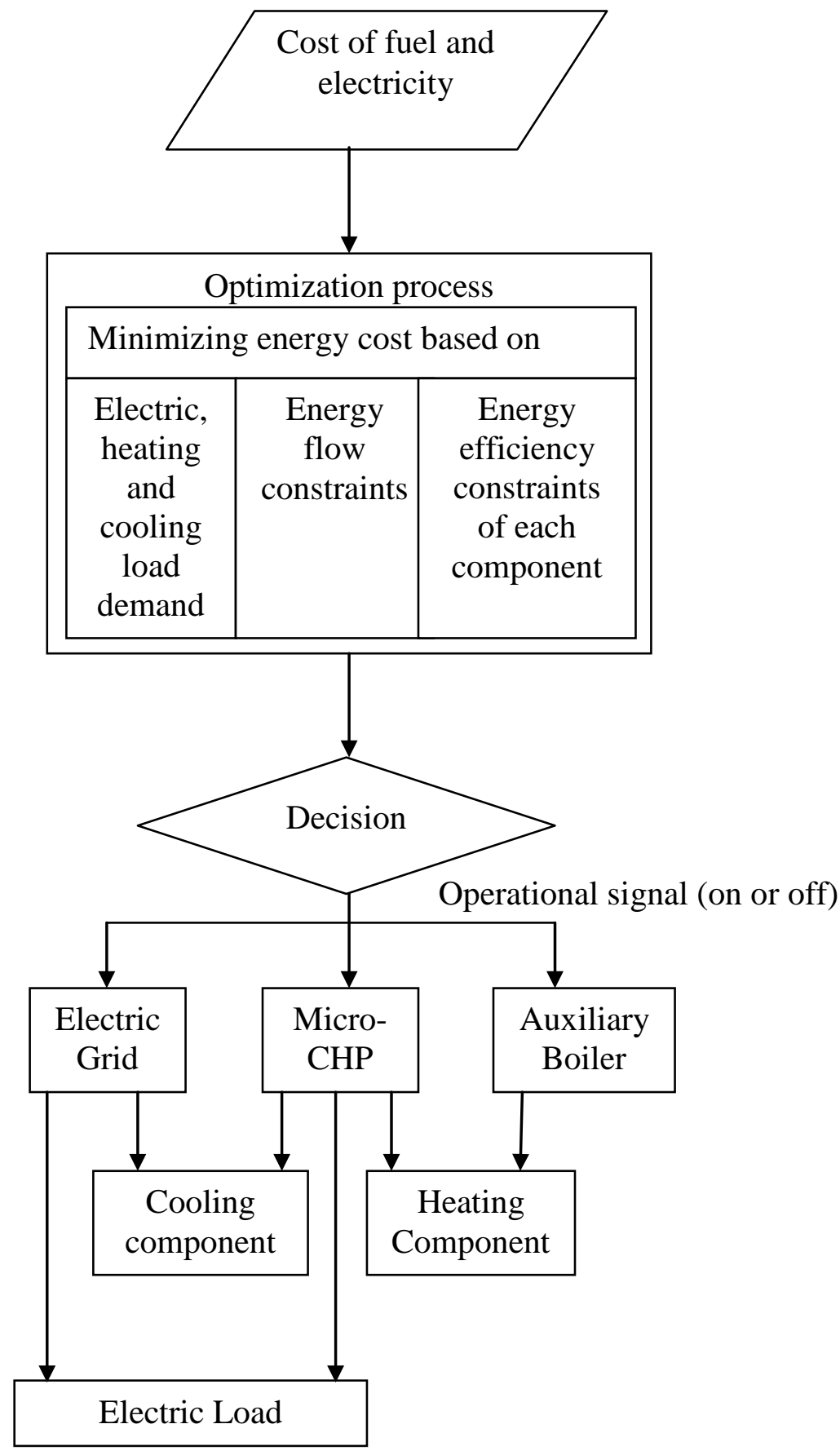

Figure 2.2: Flow chart of the optimal energy dispatch algorithm [5] 


\subsection{Optimization of Storage Tank}

A large storage tank allows for flexible storage management but loses more heat to the surroundings. On the other hand, a small tank has less heat dissipation to the surrounding but not enough room to store the water [4]. Storage tanks not only reduce the fluctuation of heat load imposed on CHP but it can also store excess heat produced by CHP and allow the CHP to operate longer even when the heat demand is low. When we keep increasing the size of the storage tank, the run time of the CHP increases until a certain value and then it decreases as the storage tank gets bigger. The optimal size of the storage tank gives the maximum cost saving and runs the CHP for about $12 \%$ longer than in the case of no storage tank for reference [4]. Also at optimal storage tank capacity the cost associated for grid electricity and the natural gas for auxiliary boiler are minimum.

\subsection{Operation Strategies for Micro-CHP}

Electrical load and heat load does not peak at the same time of the day. But the microCHP's Heat to Power Ratio remains constant. Therefore an operation strategy is required to control the CHP's electrical and thermal output. Different kinds of operation strategies used are as follows [3]:

2.4.1. Following heat demand: The CHP is run to meet the heat load of the residential unit. If excess electricity is produced in the process by the CHP then it is sold back to the grid and if electricity demand is not met, then electricity is sourced from the grid.

2.4.2. Following electricity demand: The CHP is run to meet the electric load of the residential unit. The heat load is achieved by either producing excess heat required to meet the load by the auxiliary boiler or by wasting the excess heat produced by the CHP.

2.4.3. Continuous Operation: The CHP is run for a fixed amount of time irrespective of the energy demand. This strategy is used for some engines which are not able to run in partial load conditions.

2.4.4. Peak Shaving: The CHP is operated to cover a predefined part of the electric load during the peak electric load conditions. This strategy allows the user to reduce peak power bought from the grid. This strategy is especially useful when the utility company charges a premium during the peak load condition on the grid.

2.4.5. Base load operation: The CHP is run to cover the base load of the residential unit. All the additional electricity required is bought from the grid.

2.4.6. Aggregate load control (ALC): Reference [6] explains that running micro-CHP in individual houses will save money and help reduce the carbon foot print for that particular house. But if the majority of houses in the local grid start using micro-CHP systems then there will be unpredictable load on the grid. This will cause the Utility company financial losses and will increase the total carbon emission in the grid due 
to idling of the generator used to power the grid. To avoid this, reference [6] suggests an aggregate load control on all the micro-CHP systems attached to the grid. The number of CHP systems activated in the grid assuming all are of the same size is given by:

\begin{tabular}{|c|c|c|}
\hline \multirow{5}{*}{ Where } & \multicolumn{2}{|r|}{$\mathbf{N}=(\mathbf{E}-\mathbf{P a}) / \mathbf{P o e}$} \\
\hline & $\mathrm{N}$ & $=$ No. of micro-CHP activated in the local grid \\
\hline & $\mathrm{E}$ & $=$ Aggregate electrical demand on the local grid (in $\mathrm{kW}$ ) \\
\hline & $\mathrm{Pa}$ & $\begin{aligned}= & \text { Aggregate load threshold above which a number of } \\
& \text { Micro-CHP in the local grid will be activated }\end{aligned}$ \\
\hline & Poe & = Rated electrical power of single micro-CHP unit \\
\hline
\end{tabular}

In ALC control methodology, micro-CHP in the house experiencing thermal load requirement is given priority to be activated when the opportunity arises in the grid. By using ALC, thermal demand in the participating houses may not always be met by Micro-CHP. Therefore an auxiliary boiler will supplement the additional thermal load. Also, under ALC there can be instances when thermal energy will be wasted in some houses so that grid electric demand can be met [6].

\subsection{Innovations in CHP system}

\section{Use of Adsorption Heat Pump:}

A new CHP system is developed in reference [7] to increase the total thermal output of the CHP system and therefore increase the system efficiency. The new CHP configuration consists of an I.C Engine, Adsorption Heat Pump (AHP) and a Condensate Heat Exchanger (CHE). This configuration is shown in figure 2.3.

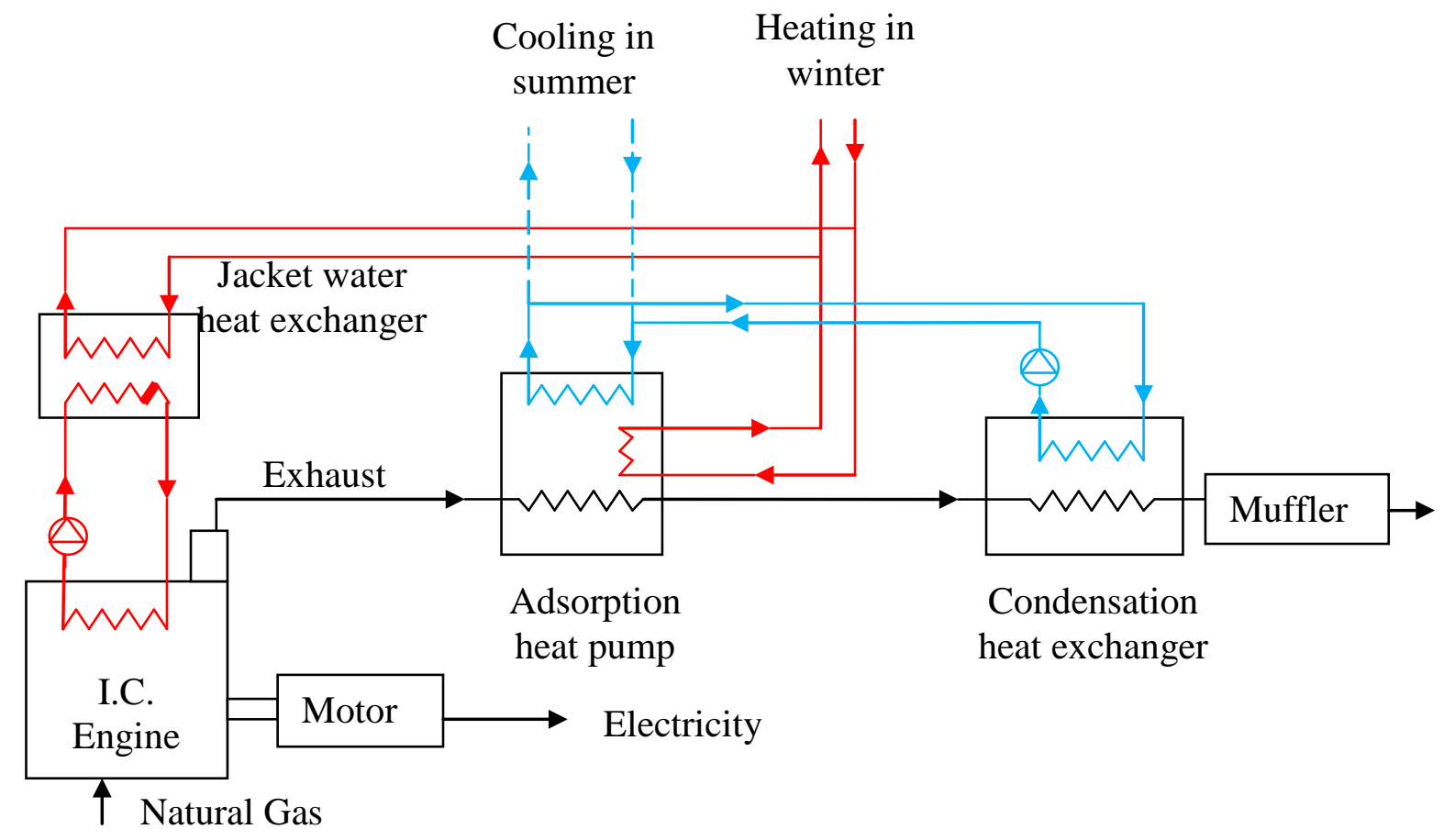

Figure 2.3: Schematic of CHP with Adsorption Heat Pump 
In winter, the exhaust gas of the I.C Engine is used to run AHP and exhaust from the AHP goes into CHE before emitting it to the atmosphere. On the evaporator side of AHP cold water from CHE which is heated by the exhaust acts as a low grade heat source. On the condenser side of AHP the water is heated, and along with water from the jacket water heat exchanger, is used for space heating. In summer the heat in the exhaust is utilized in AHP to produce chilled water [7].

\subsection{Benchmark testing of Micro-CHP}

Paper [8] and [9] tested different Micro-CHP systems available in the market and have done comparison test. The Micro-CHP units investigated for the comparison test were:

- SenerTec “Dachs": It's a Micro-CHP unit producing 5.5kW of electrical power and $12.5 \mathrm{~kW}$ of thermal power. It comes with an otto engine (for natural gas) and diesel engine (for liquid fuels like biodiesel and heating oil).

- SOLO Stirling161: It consists of a 2 cylinder sterling engine with a swept volume of $160 \mathrm{~cm}^{3 .}$ It uses helium as the working fluid. It can produce $2-9 \mathrm{~kW}$ electric and 8-26kW thermal power.

- Ecopower: It produces $4.7 \mathrm{~kW}$ electric and $12.5 \mathrm{~kW}$ thermal energy when running on full load. It has a four stroke $272 \mathrm{~cm}^{3}$ engine. The main advantage of Ecopower is that the engine is coupled to a synchronous generator thus allowing speed variations. This speed variation allows varying the output engine speed between 1200 to 3600rpm. The variable output power from Ecopower varies from 1.3 to $4.7 \mathrm{~kW}$ electric and $4-12.5 \mathrm{~kW}$ thermal power.

- Whispergen: It's a four cylinder Stirling engine which produces $1 \mathrm{~kW}$ electric and 7.5 to $12 \mathrm{~kW}$ thermal power.

Paper [8] discussed about Idatech fuel cell and paper [9] discusses Micro-CHP SM5A, a pre production prototype at Danish Technical University. Since both of these micro-CHP are not available for purchase in the market, they are not considered in this comparison.

The efficiency and the emission comparison for the above mentioned four MicroCHP models are given in table 2.1.

Table 2.1: Efficiency and emission comparison of leading Micro-CHP units

\begin{tabular}{|c|c|c|c|c|c|c|}
\hline & \multicolumn{2}{|c|}{ Full load } & \multicolumn{2}{|c|}{$50 \%$ load } & \multirow{2}{*}{$\begin{array}{c}\mathrm{CO} \\
5 \% \mathrm{O}_{2} \\
\mathrm{mg} / \mathrm{Nm}^{3}\end{array}$} & \multirow{2}{*}{$\begin{array}{c}\mathrm{NO}_{\mathrm{x}} \\
5 \% \mathrm{O}_{2} \\
\mathrm{mg} / \mathrm{Nm}^{3}\end{array}$} \\
\hline & $\square_{\text {electrical }}$ & $\bar{Q}_{\text {thermal }}$ & $\square_{\text {electrical }}$ & $\bar{Q}_{\text {thermal }}$ & & \\
\hline SenerTec & 27.7 & 60.8 & \multicolumn{2}{|c|}{$\begin{array}{l}\text { Does not operate in } \\
\text { partial load condition }\end{array}$} & 0 & $500-600$ \\
\hline SOLO & 26.8 & 71.7 & 24.8 & 70.3 & 191 & 105 \\
\hline Ecopower & 24.7 & 64.2 & 24.0 & 60.5 & 0.1 & 8.4 \\
\hline Whispergen & 12.0 & 80.0 & NA & NA & NA & NA \\
\hline
\end{tabular}




\section{Lab Development}

\subsection{Location}

Micro-CHP test bed is integrated into a cold room in the Alternate Energy Research Building (AERB). The cold room is equipped to control the inside temperature and humidity precisely at a user defined value between $-30^{\circ} \mathrm{F}$ to $130^{\circ} \mathrm{F}$. The purpose of setting the test bed inside the cold room is to run the CHP unit is to understand the impact of input air temperature on unit operation.

\subsection{Budget allocation}

The Micro-CHP project is funded by Michigan Tech and has provided a total of $\$ 34,000$ for the project. The fund allocations are as follows:

- $\$ 24,900$ for test bed development and instrumentation

- $\$ 6,600$ for personnel and fringe costs for staff research engineer

- $\$ 2,500$ for domestic travel

\subsection{Lab design}

The Micro - CHP lab is designed to accommodate the following research topics:

- California emissions standard for CHP: Testing and modifying the CHP to meet California emission standards for CHP.

- CHP System with Integrated Adsorption Cooler: Design, analysis, operation and system optimization.

- Systems Level Real-Time Optimization: Implement model based control logic that optimizes the balance between electrical, coolant, and exhaust energy based on real-time utility pricing and thermal and electrical demands and storage capacity.

To accommodate the above mentioned research, a unique test bed is designed which is capable of running a CHP unit and producing results required for addressing these research topics. For this research we have obtained an I.C. Engine based Micro-CHP system named 'Ecopower' from Marathon Engines System. The specification of Ecopower was given in section 1.3. The design of the test bed is made around the Ecopower unit's specification. The test bed design can be split into four major sections:

- Thermal loop design

- Electrical loop design

- Micro CHP Instrumentation

- Data Acquisition and Control 


\subsection{Thermal loop design}

The main aim of thermal loop is to control the inlet temperature and mass flow rate of water flowing through the micro-CHP's heat exchanger. Controlling the inlet temperature and mass flow rate of water irrespective of temperature output by the CHP's heat exchanger gives us the capability of testing the CHP for different heat loads with one simple control loop. The different kind of heat loads imposed on a Micro-CHP unit include hot water for residential applications, room heating, and adsorption based air conditioning systems. These heat loads can be simulated using the thermal loop controls. Design of thermal loop is shown in Figure 3.1.

Example: Assume we want to test the performance of Ecopower unit to support the heat requirement of adsorption based chiller for room air conditioning. To do the test we will conventionally hook up the chiller to Ecopower unit and find the results. However with the Thermal loop we can practically simulate the adsorption chiller by creating an equivalent heat load on the Ecopower unit and obtain the results.

The thermal loop is designed to run in two different modes, water recirculation mode and city cycle mode. In water recirculation mode we can run the CHP unit with water being circulated in a closed loop (1 to 9 shown in figure 3.1). This helps in controlling on the mass flow rate as well as temperature at point 2 . Whereas in city cycle mode (10-2-3-11 shown in figure 3.1), we run city water through the CHP unit so as to absorb the heat from CHP at city water temperature. Basic working of both modes of thermal loop is explained as follows:

\subsubsection{Water recirculation mode ( 1 to 9 shown in figure 3.1$)$}

For water recirculation mode we keep Valve 1 and 4 open and Valve 2 and 3 closed. Water circulation for this mode is explained with respect to figure 3.1:

1. From 1 to 2: Water is pumped using a variable flow rate pump to the input of Micro-CHP's Heat Exchanger. Let us consider the amount of water pumped to be $\mathrm{m}_{1}$. An accumulator is installed to absorb any sudden pressure or mass flow rate changes. A flow meter is installed in series to measure the flow rate produced by the pump and this data is used in a PID controller to get a precise control on the pump (see Control Center Design). A thermocouple and pressure gauge is installed to measure the temperature and pressure at the input of Micro-CHP's Heat Exchanger.

2. From 2 to 3: Water flows through the Micro-CHP's Heat Exchanger and absorb the heat produced by the Micro-CHP unit.

3. From 3 to 4: Water flows through the output of Micro-CHP's heat exchanger to the input of Chiller's $30 \mathrm{~kW}$ Heat Exchanger. Thermocouple and pressure gauge are installed for data collection. 


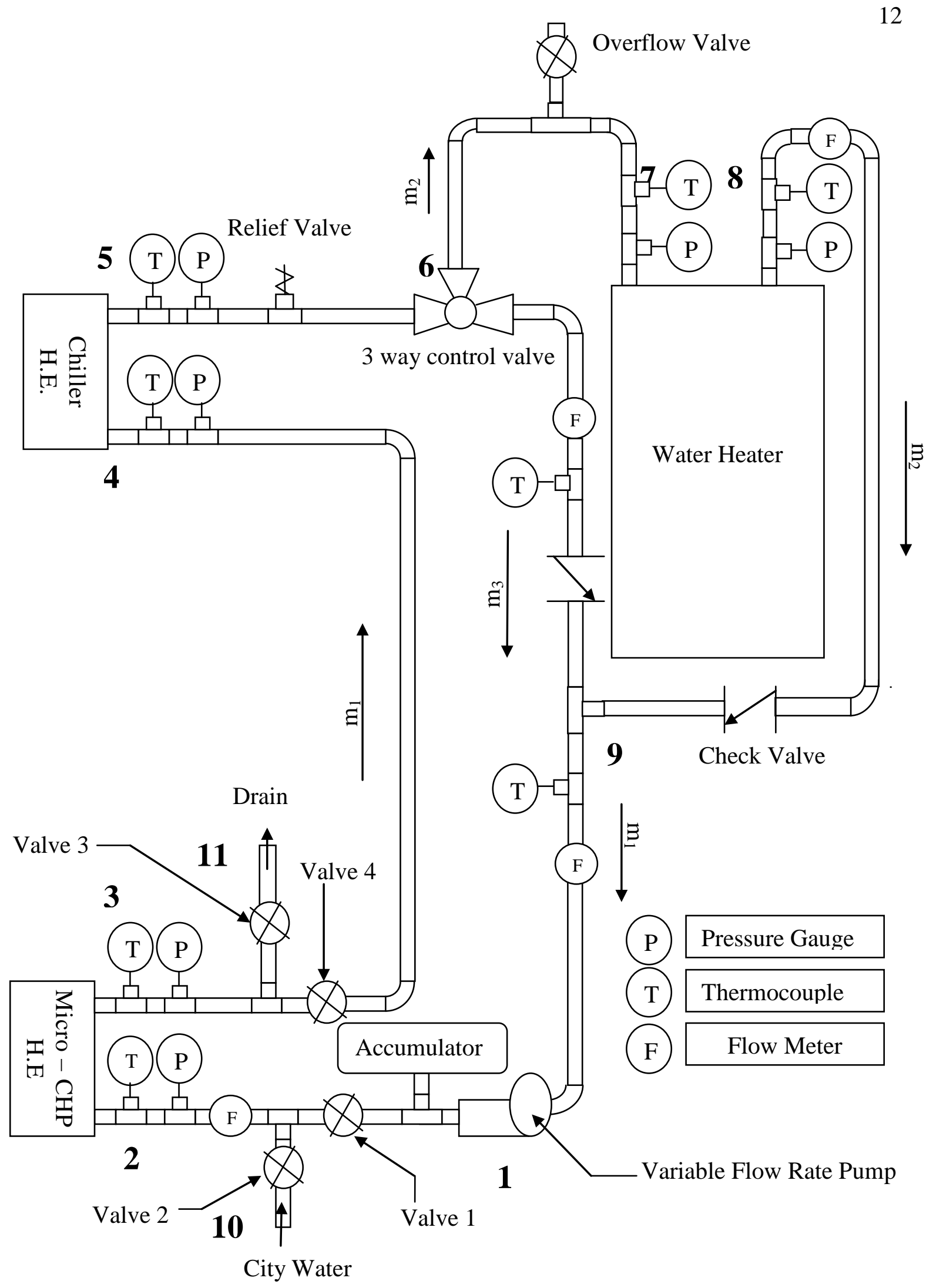

Figure 3.1: Thermal loop design 
4. From 4 to 5: Water flows through the Chiller H.E and cools down to a desired temperature set on the Chiller's controller. Chiller is capable of absorbing up to $30 \mathrm{~kW}$ of heat and act as a heat load. The Chiller has the capabilities to cool down the water to $45^{\circ} \mathrm{F}\left(7.2^{\circ} \mathrm{C}\right)$.

5. From 5 to 6: Cold water from the chiller flows to the 3 way control valve. There is a thermocouple and pressure gauge installed in the line for data collection. A pressure relief valve is installed to safe guard the thermal loop from extensive back pressure.

6. At 6: We have a 3 way proportional control valve which is controlled by a DAQ system and can split the flow of water into two streams with mass flow rate of $\mathrm{m}_{2}$ and $m_{3}$. The $m_{2}$ stream of water flows through the water heater and attains a preset temperature set on the water heater before flowing to point 9. Water stream with flow rate $\mathrm{m}_{3}$ flows through a non return valve (check valve) to point 9 . Thus at point 9 the water stream $\mathrm{m}_{2}$ and $\mathrm{m}_{3}$ mixes to form the new stream $\mathrm{m}_{1}$ with a new temperature. Thus we get a mixture of water with predefined temperature. The ratio at which the water is spilt at point 6 is a function of temperature of water at point 5 , temperature of water after passing through the water heater (that is temperature of water at point 8) and the desired temperature at point 9.

7. From 6 to 7: A portion of the water flow from the chiller is diverted towards the water heater. An overflow valve is attached in this section to vent any air present in the loop while priming it with water. Thermocouple and pressure gauge is attached to check the input parameters to the water heater.

8. From 7 to 8: Water flows through the water heater and absorbs heat and the water temperature reaches the pre-set value.

9. From 8 to 9: Water flows from the water heater to point 9. We have a flow meter, thermocouple and a pressure gauge to check the output of the water heater. Before reaching point 9 , water flows through a non return valve (check valve) which avoids any back flow of water to the water heater.

10. From 6 to 9: Water with a flow rate of $m_{3}$ flows from the mixing valve through a non return valve (check valve) to point 9.

11. At 9: Water from the water heater (flow rate $\mathrm{m}_{2}$ ) and from the line mixing valve (flow rate $\mathrm{m}_{3}$ ) mixes at point 9 and attains a new temperature. This is the desired temperature required at the micro-CHP's heat exchangers input.

12. From 9 to 1: Water flows from 9 to pump at 1 through a flow meter that measure the flow rate of water to the pump.

\subsubsection{City cycle mode (10-2-3-11 shown in figure 3.1$)$}

For city cycle mode, valve 1 and 4 are closed and valve 2 and 3 are opened. In city cycle mode, water flows from the city water line. There is no control over the temperature on the water to the Micro-CHP's Heat Exchanger. 
1. From 10 to 2: Water flows from the city line to the input of the Micro-CHP's heat exchanger. A flow meter thermocouple and pressure gauge are installed in the line for data collection.

2. From 2 to 3: Water flows through the Micro-CHP's Heat Exchanger and absorb the heat produced by the Micro-CHP unit.

3. From 3 to 11: Hot water from Micro-CHP's heat exchanger flows to the drain. Thermocouple and pressure gauge are installed for data collection.

\subsubsection{Thermodynamic validation of the thermal loop:}

The final desired outcome from the thermal loop is to control the inlet temperature and mass flow rate to the input of the Micro-CHP. This loop is thermodynamically validated using an EES program. The program is attached in Appendix 7.1.

\subsection{Electrical loop}

Electrical connections are designed to transmit all the power to the grid. Figure 3.2 shows the basic electrical configuration for the CHP unit. In the future we can add electric load to control the electrical load demand on the CHP unit. Electrical load was not considered in this design because of financial limitations.

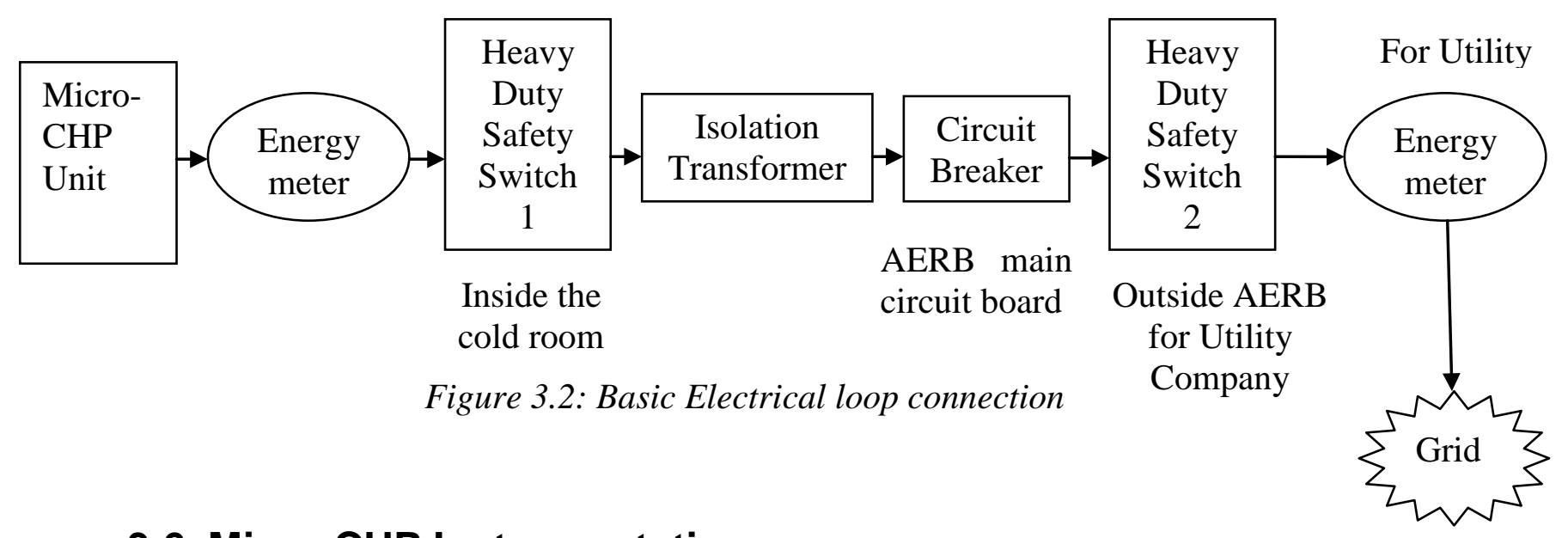

\subsection{Micro-CHP Instrumentation}

For the Micro-CHP project we have received the Ecopower unit from Marathon Engines. The specification of this unit was given in section 1.3. Ecopower is installed on a trolley so that we can move it and give way for other Micro-CHP systems Michigan Tech acquires. Design of the trolley is given in figure 3.3.

Instrumentation designed for the Engine and the coolant loop is shown in figure 3.3. 


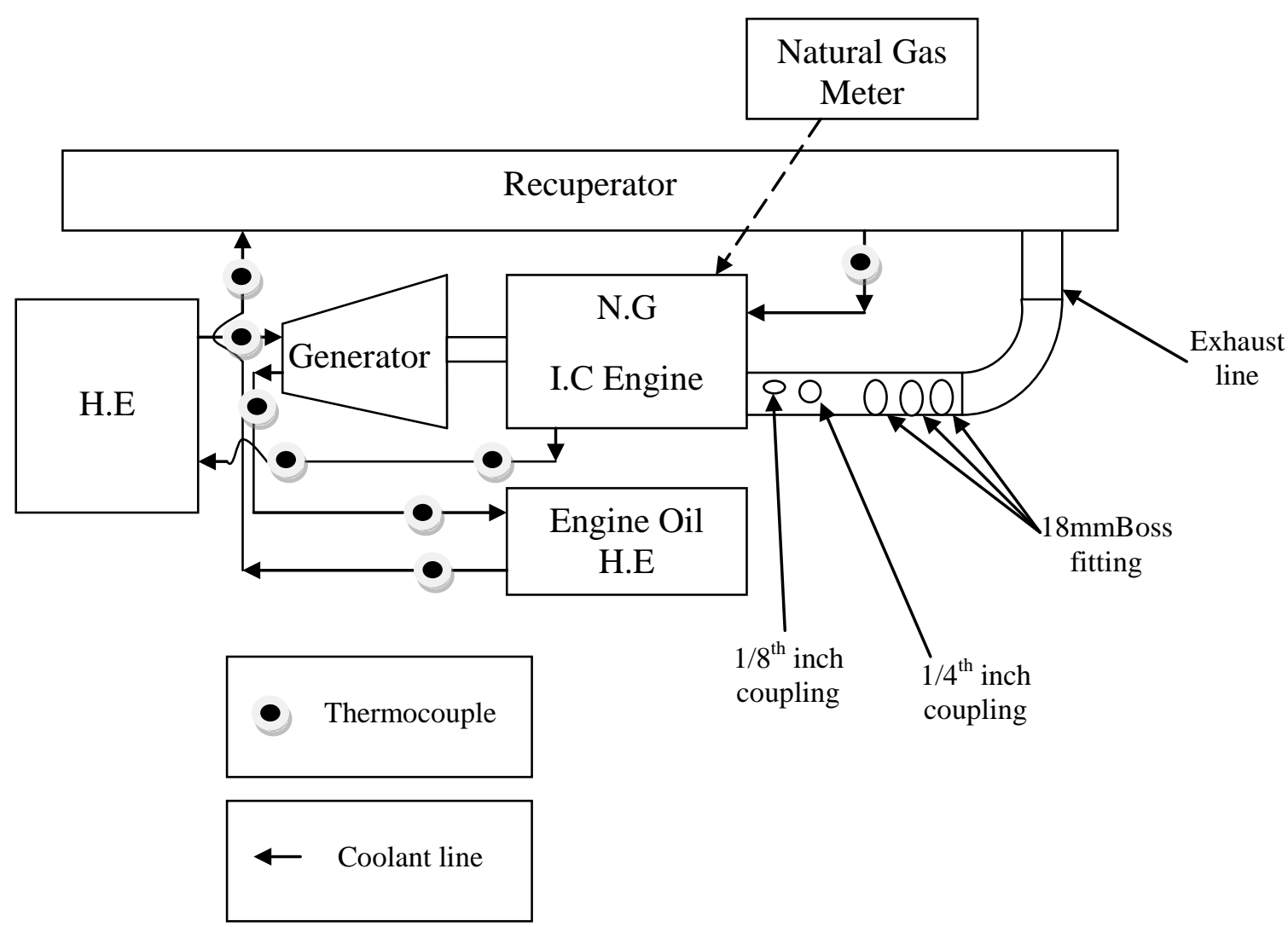

Figure 3.3: Instrumentation diagram of Ecopower unit

\subsubsection{Engine Exhaust Instrumentation:}

In Ecopower, the engine exhaust line is made up of steel. Ecopower comes with its own boss fitting and a lambda sensor. Additional ports are added to help accumulate data on the engine exhaust.

- $\quad \mathbf{1} / \mathbf{8}^{\text {th }}$ inch coupling: This port is meant to attach a $1 / 16^{\text {th }}$ inch thermocouple over a $1 / 8^{\text {th }}$ inch compression fitting

- $\quad \mathbf{1} / 4^{\text {th }}$ inch coupling: This port is provided to add a pressure sensor in the future. Currently this port is closed with a quarter inch plug.

- 18mm Boss fitting for Lambda sensor (Ecopower): An 18mm boss fitting with lambda sensor is provided by Ecopower to obtain data to the Ecopower's control unit

- 18mm Boss fitting for Lambda sensor: An $18 \mathrm{~mm}$ Boss fitting is provided to attach ETAS LA4 Lambda Meter to the exhaust line. Specs for the Lambda meter can be found in the Appendix D.

- 18mm Boss fitting for Emission Analyzer: An 18mm Boss fitting is provided as a sampling point for future emissions test. This fitting is currently closed using a plug. 
- Thermocouples: 3 inch long and $1 / 16^{\text {th }}$ inch diameter $\mathrm{K}$ type thermocouples are installed using $1 / 8^{\text {th }}$ inch compression fitting.

\subsubsection{Coolant loop instrumentation:}

In the coolant loop of the Ecopower unit thermocouples are attached at 8 locations as shown in figure 3.3. The data from these thermocouples will help us accurately determine the change in temperature of coolant when it flows from coolant heat exchanger to generator to engine oil heat exchanger to recuperator to engine and back to coolant heat exchanger.

\subsection{Data Acquisition and Control}

NI Compact DAQ based data acquisition and control is designed as explained below:

\subsubsection{Data Acquisition}

Data generated by all the instrumentation including thermocouple, flow meters, lambda sensors, etc are connected to NI Compact DAQ's Thermocouple and Voltage input modules. This data can be then post processed in LabVIEW or Matlab.

\subsubsection{Controls}

In the thermal loop the pump flow rate and the 3-way control valves are controlled by the DAQ system.

\subsubsection{Control for Pump flow:}

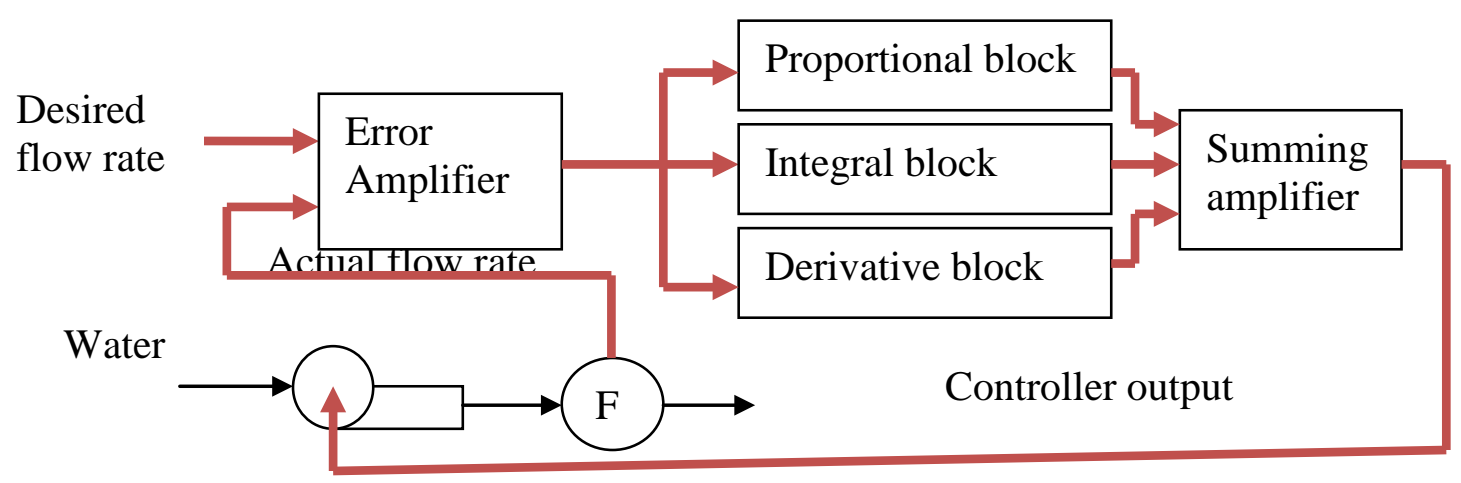

Figure 3.4: PID controller for the Pump

As shown in figure 3.4, the pump can be controlled to give desired flow rate using a PID controller with flow meter acting as a feedback signal.

\subsubsection{Control for 3 way control valve:}

Control for the 3 way control valve will be exactly the same as shown figure 3.4, except instead of controlling the pump, controller's output will go to the 3 way control valve. 


\subsection{Lab installation}

The lab installation can be categorized as following:

- Ecopower installation

- Natural gas line, exhaust and drain water piping

- Electrical loop connections

- Thermal loop connections

- DAQ connections

\subsubsection{Ecopower Installation}

3.8.1.1 Trolley: Ecopower is installed on a moving trolley of dimension 26.5”x38.5”. The trolley is manufactured using steel angles as shown in figure 3.5. In the middle of the trolley is a sheet metal tray for collecting leaked oil. The CAD diagram of the tray is shown in figure 3.5. The tray is equipped with a drain plug. The front of the trolley has two 8" swivel casters with brakes. The rear of the trolley has two 8" rigid casters. All four castors used in the trolley have $500 \mathrm{lb}$. maximum capacity each. The picture of the final trolley is shown in figure 3.6.
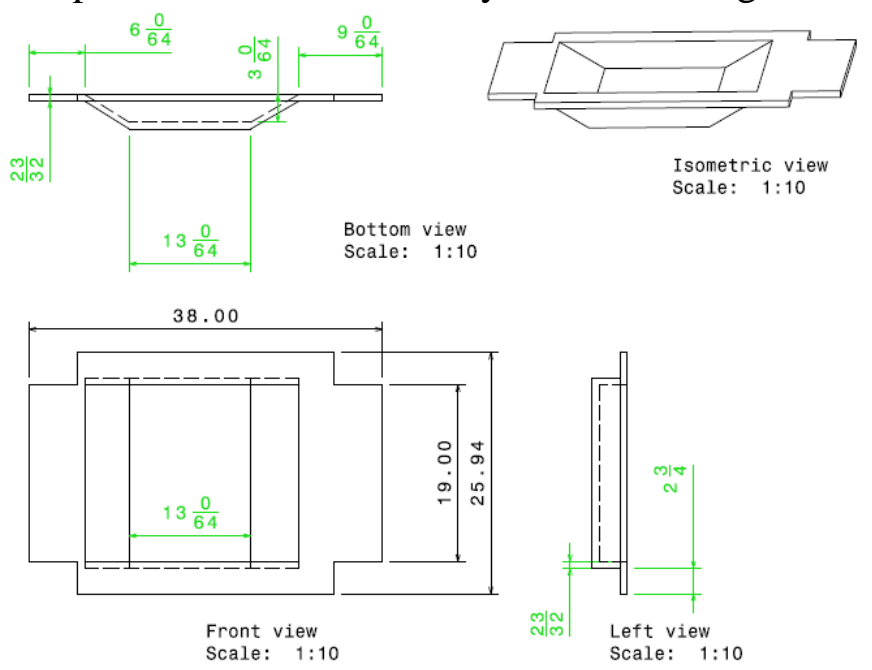

Figure 3.5: $C A D$ diagram of tray installed in the trolley

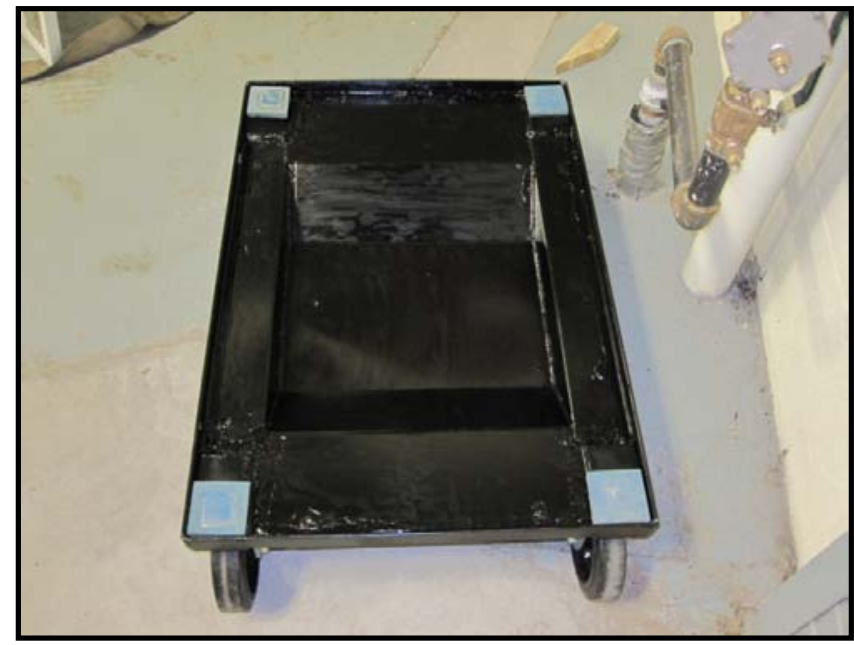

Figure 3.6: Trolley for Ecopower unit 
3.8.1.1. Exhaust line modification: To incorporate the instrumentation in the exhaust line of Ecopower as shown in figure 3.3, the exhaust line is milled and modified to have a $1 / 8^{\text {th }}$ inch coupling for thermocouple fitting, $1 / 4^{\text {th }}$ inch coupling for pressure sensor and two $18 \mathrm{~mm}$ boss fittings for lambda sensor and emission analyzer. A picture of the modified exhaust line is shown in figure 3.7.

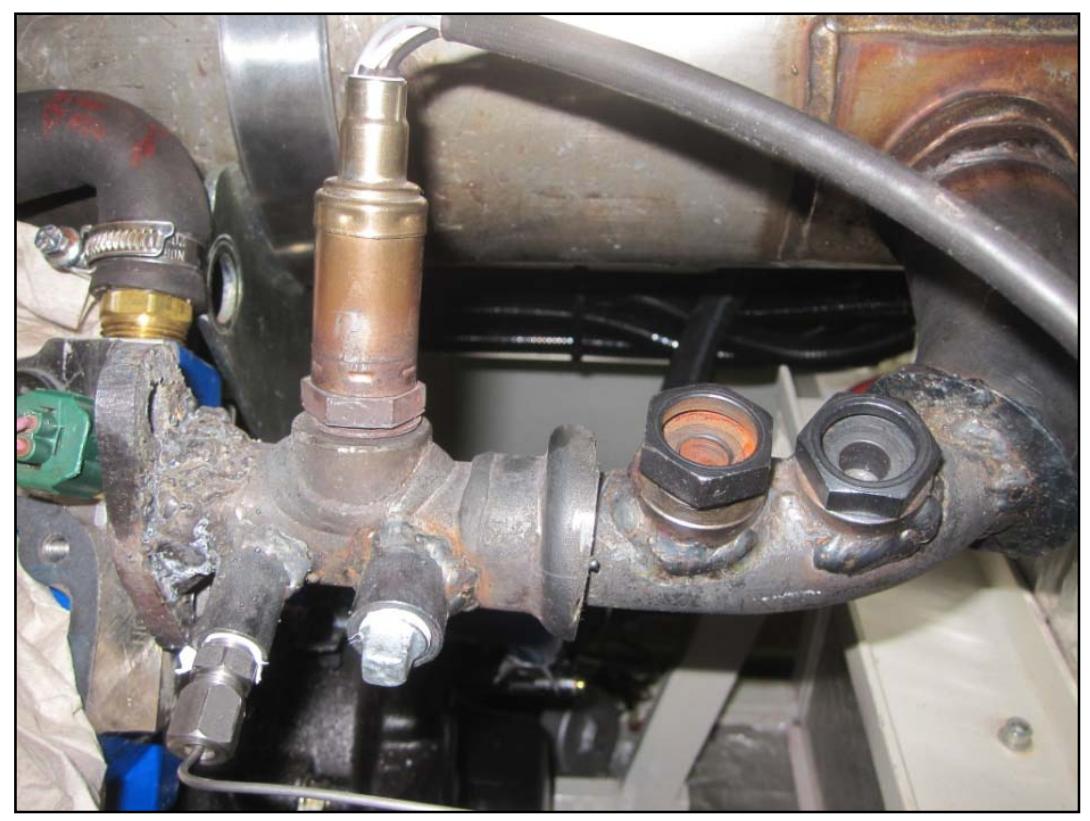

Figure 3.7: Modified exhaust line

ETAS LA4 Lambda meter is used for measuring the $\mathrm{O}_{2}$ in the exhaust gas. The specification of the Etas lambda is given in Appendix D.

3.8.1.2. Thermocouple installation in coolant line: Thermocouples are installed at 8 different locations in the coolant loop of the Ecopower unit. A picture of the thermocouple fitting is shown in figure 3.8.

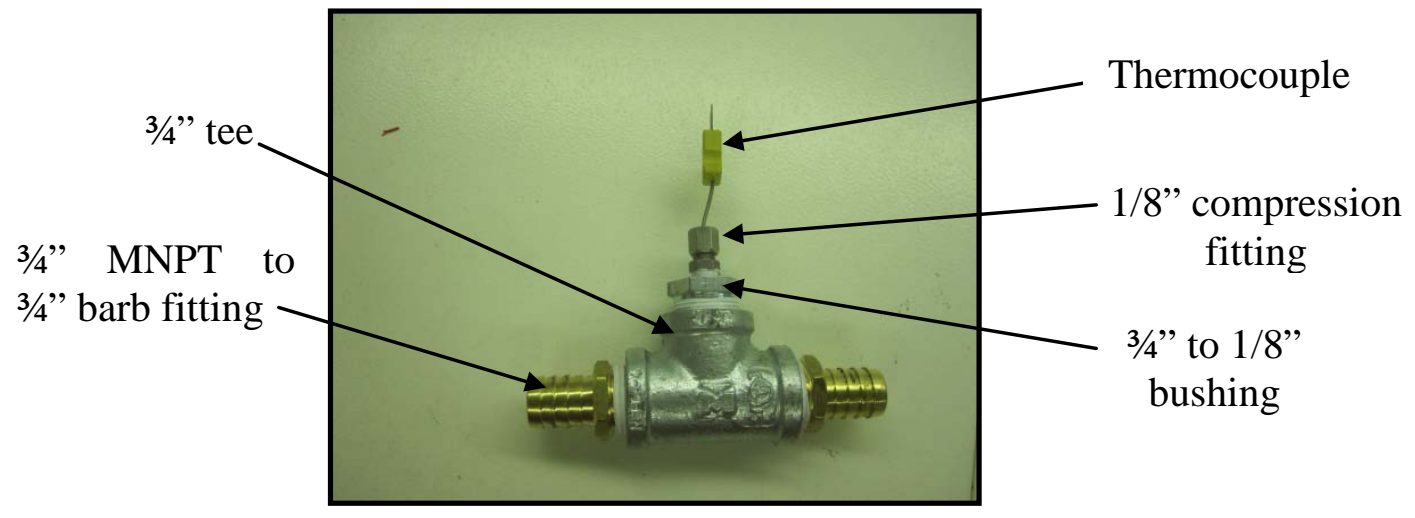

Figure 3.8: Thermocouple installed in a 3/4" tee for coolant loop.

The 3/4" tee has barb fittings on either side to mate with coolant hose and the top end has $3 / 4$ " to $1 / 8$ " bushing which hosts a compression fitting with a thermocouple in it. The coolant loop installation is shown in figure 3.9. 


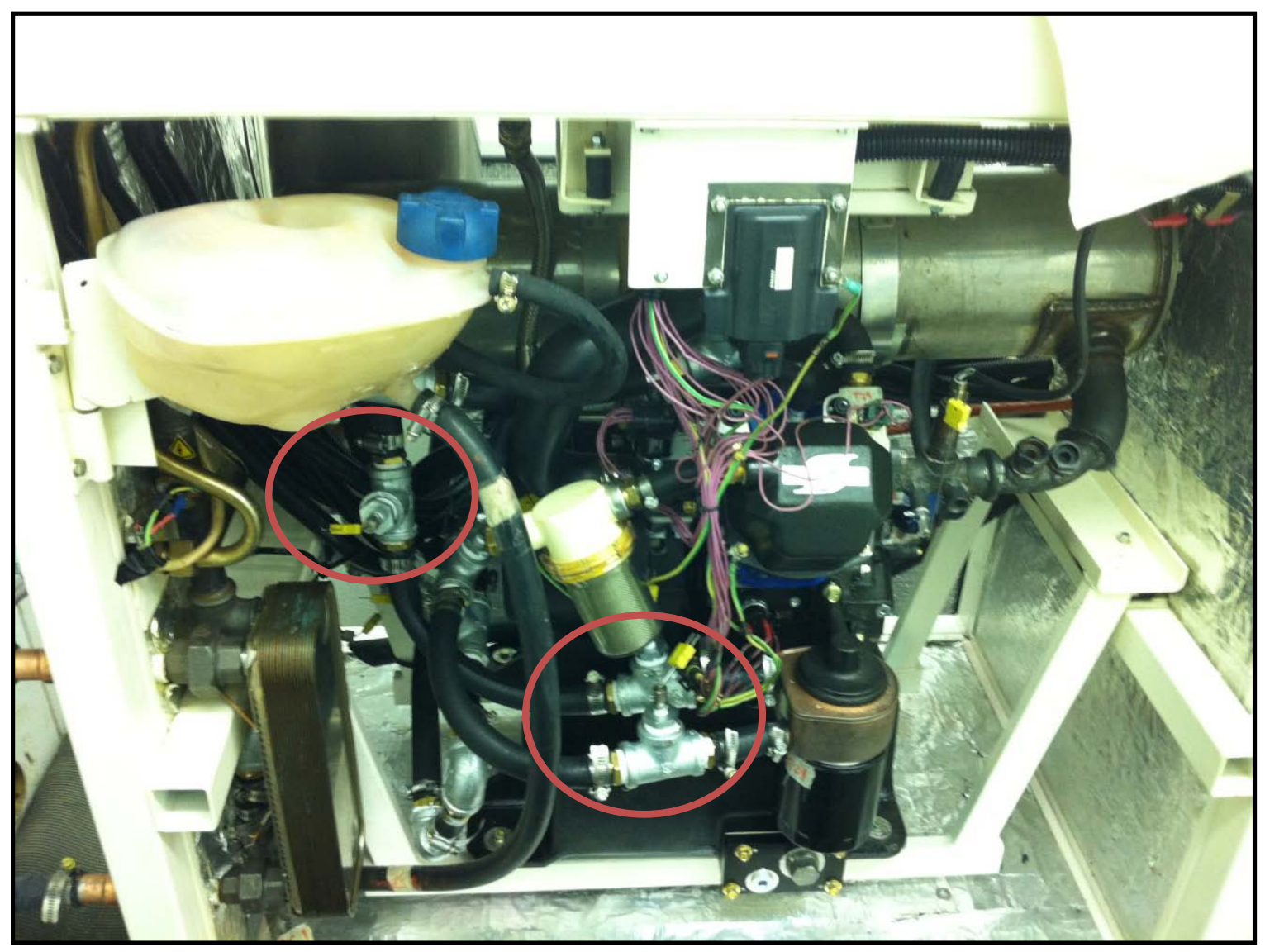

Figure 3.9: Coolant loop thermocouple installation

\subsubsection{Natural gas line, exhaust and drain water piping}

3.8.2.1. Natural gas connection: For operation of Ecopower unit we require 15 to $50 \mathrm{mbar}$ (6 to 20 inch of water column) of gas pressure. Natural gas is supplied to the AERB building by Semco Energy. The gas line coming into the AERB had enough pressure but lacked the volume required to sustain all the NG based instruments at the same time. Therefore, the gas pressure in the incoming line is increased from 7 in to 8 in of water column by adjusting the screw on the gas meter by SEMCO employee. Now, we have 8 inches of Natural Gas pressure but it is still not sufficient to run Ecopower and the heated air ventilation system for the CV Lab at the same time. We can still run the Ecopower unit when the CV lab ventilation is off.

Suggestion: For uninterrupted gas pressure for Ecopower, it is recommended to request SEMCO to increase the orifice diameter of its Gas Meter behind the AERB from $1 / 8$ " to $1 / 4^{\text {th }}$ inch".

Natural gas coming into Cold Room passes through a valve and goes to a Gas Meter capable of sending an analog signal for every cubic feet of gas flowing through it. The gas meter is shown in figure 3.10. 


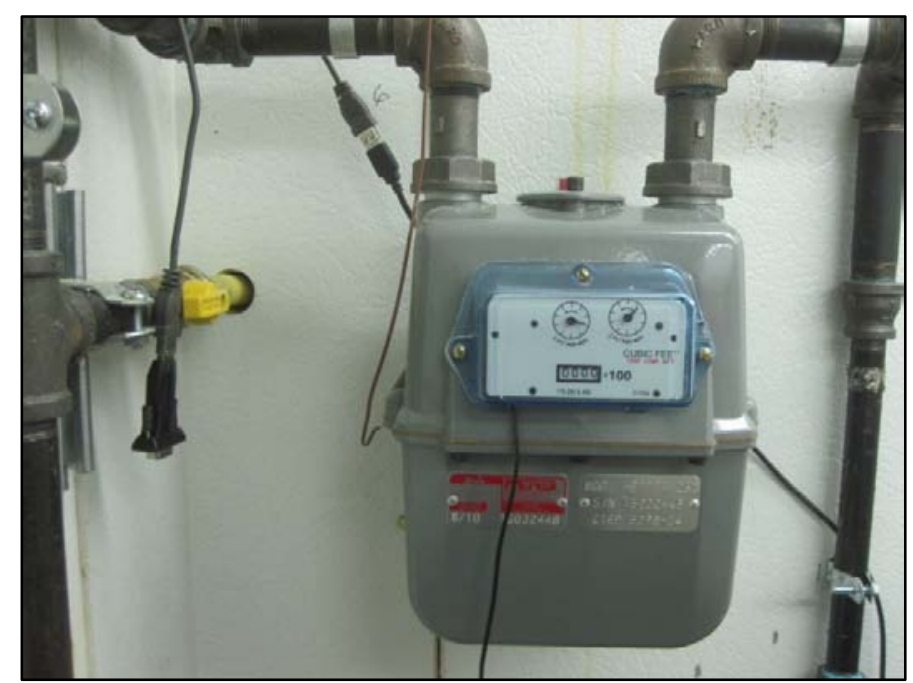

Figure 3.10: Gas Meter to measure the Natural Gas flow to Ecopower unit

From the gas meter the gas goes to another valve before ending up at the Ecopower unit. Picture of gas line from gas meter to Ecopower unit is shown in figure 3.11.

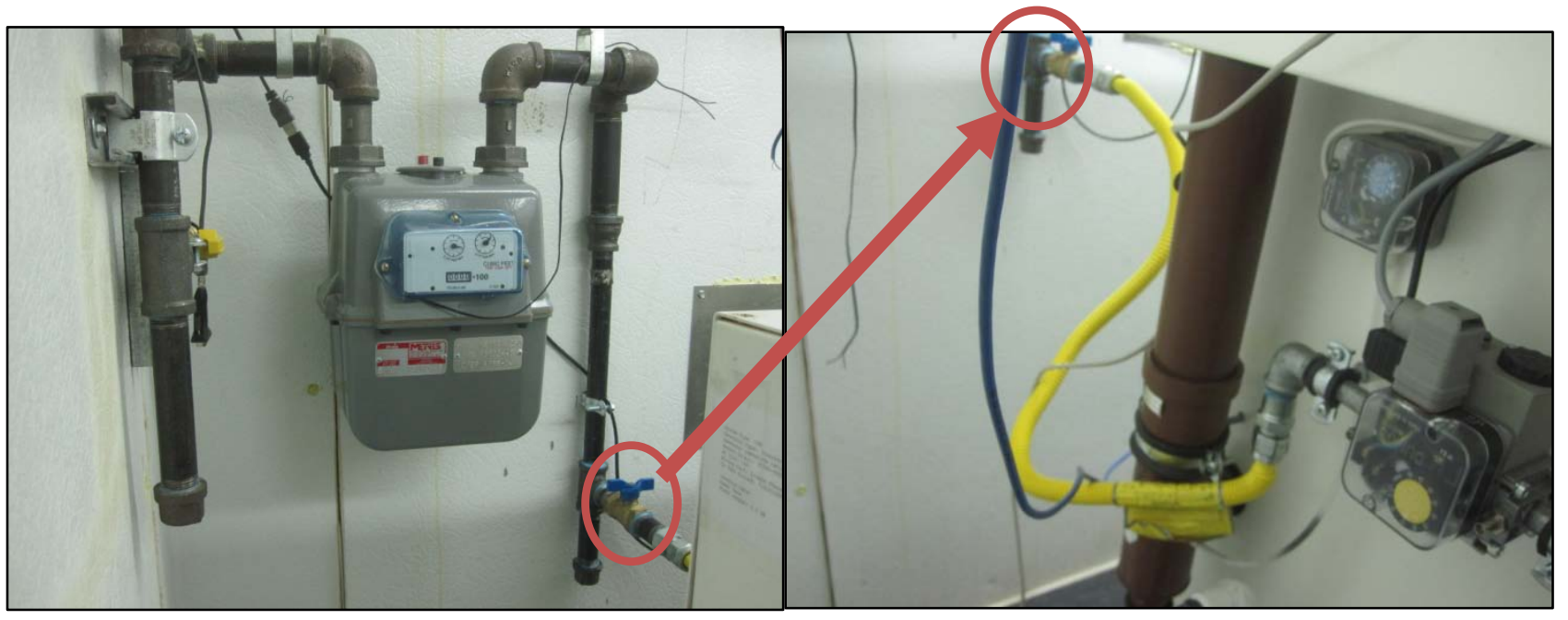

Figure 3.11: Gas line from gas meter to Ecopower unit 
3.8.2.2. Exhaust gas piping: Exhaust gas exists the building through an air tight duct as shown in figure 3.12

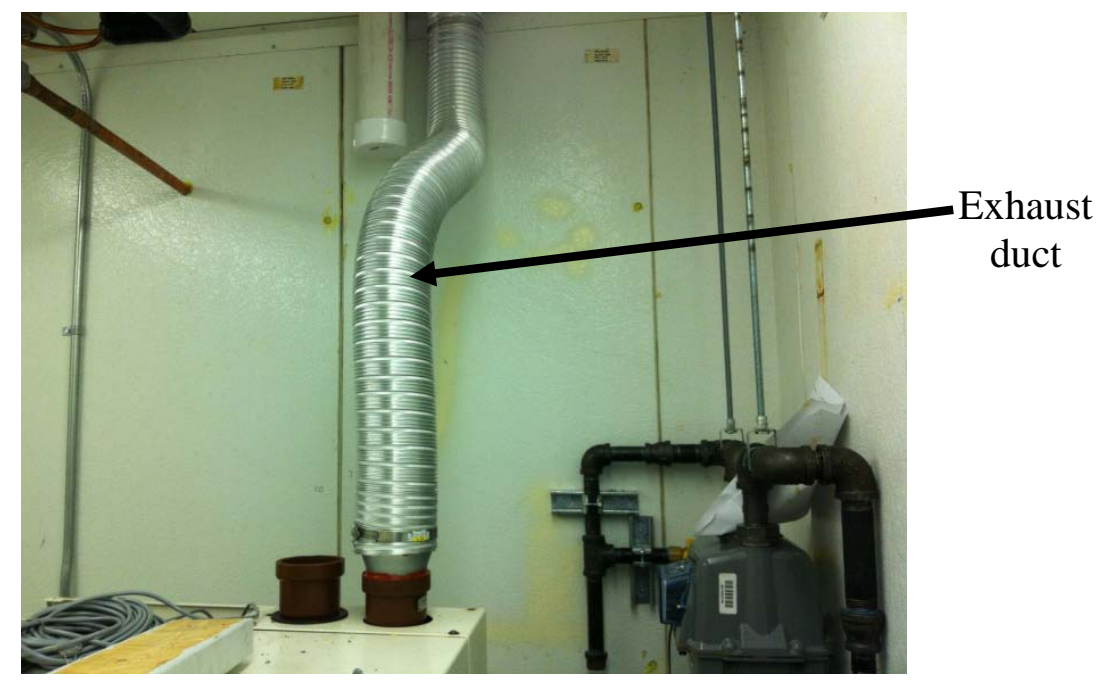

Figure 3.12: Exhaust line from Ecopower heading out of AERB

3.8.2.3. Exhaust drain piping: Exhaust of the engine is at a lowperature as most of the heat from the exhaust is transferred to coolant in the recuperator. Cold exhaust means water vapor present in the exhaust will condense and will collect in the exhaust line. To drain this water way, a condensate drain trap is provided in Ecopower's exhaust line. Figure 3.13 shows the drain trap connection for Ecopower.

Note: The condensate drain trap should always have some amount of water or else there is a risk of intoxication in the lab due to effusing exhaust gas. Exhaust gas contains $\mathrm{CO}$ which is odorless, colorless and a deadly poison.

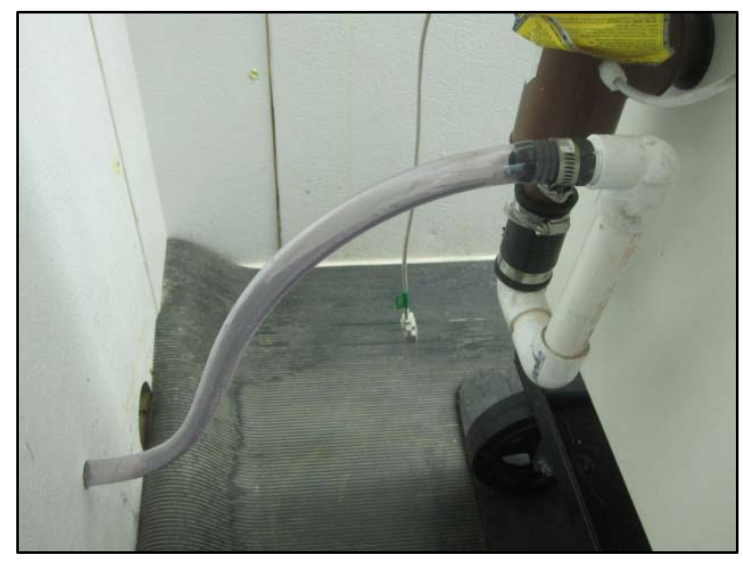

Figure 3.13: Condensate drain trap connection 


\subsubsection{Electrical loop connection}

Electrical connection diagram is shown in figure 3.2. Individual parts used are described below:

3.8.3.1. Energy Meter: Energy meter from Itron is attached to the $230 \mathrm{~V}$ single phase line coming from Ecopower unit. It will measure all electrical energy transferred by Ecopower into the grid. Figure 3.14 shows the energy meter installed inside the cold room.

3.8.3.2. Heavy Duty Safety Switch 1 (inside Clod Room): A heavy duty safety switch is provided inside the cold room to be used as a control switch for the user doing experiments with the Ecopower unit. Figure 3.14a shows the heavy duty safety switch inside the cold room.

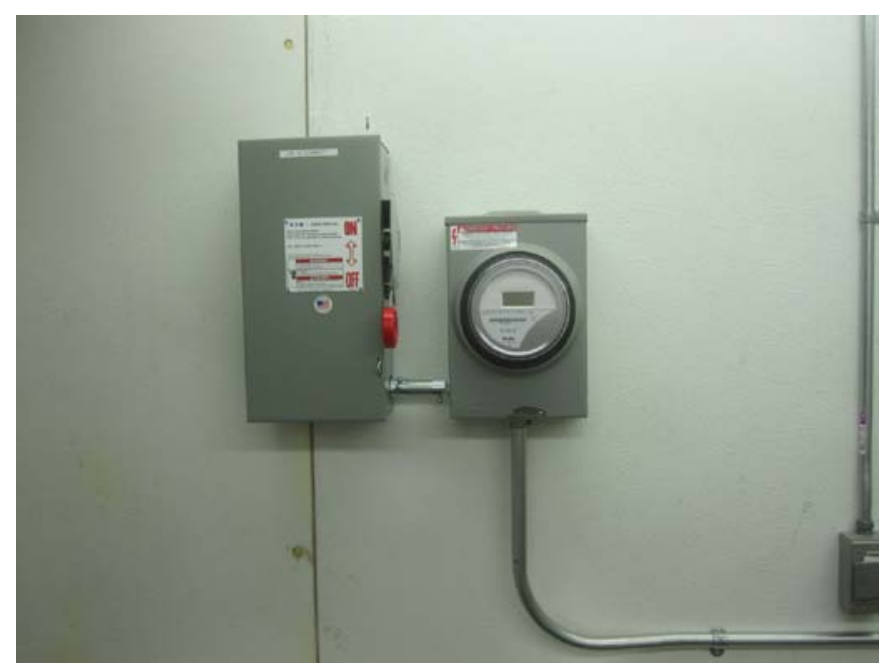

Figure 3.14.a: Energy meter and Heavy Duty Safety Switch inside Cold Room

3.8.3.3. Isolation Transformer: A $240 \mathrm{~V}$ to $240 \mathrm{~V}$ Isolation transformer is installed to isolate the Ecopower unit from the grid for safety. It provides galvanic isolation and helps block interference caused by ground loop. The picture of the isolation transformer installed in AERB is shown in Figure 3.14b.

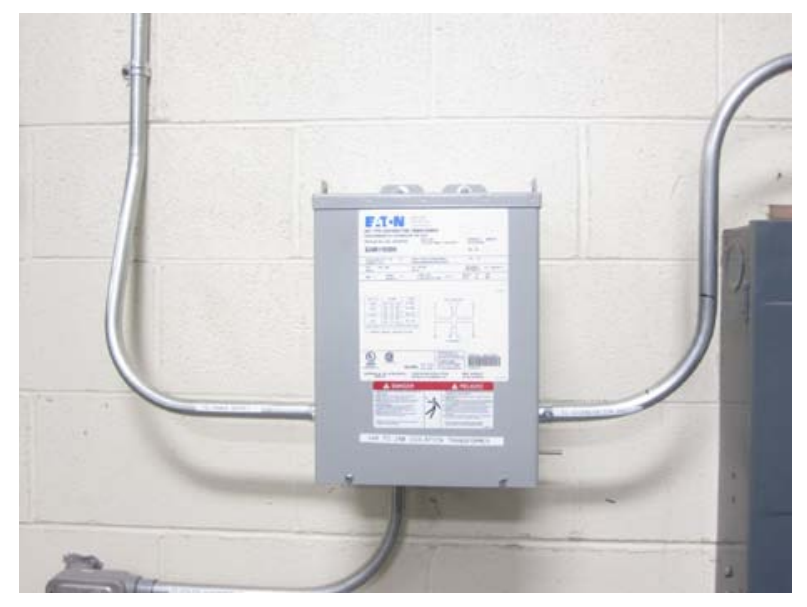

Figure 3.14.b: Isolation Transformer installed inside AERB 
3.8.3.4. Heavy Duty Safety Switch -2 (Utility side): A heavy duty safety switch is installed on the outside wall of the AERB so that the Utility company can have access to the switch in case of emergency. Utility company personnel will switch off this switch before conducting any maintenance activity on the local grid. Picture of Utility side heavy duty safety switch is shown in figure 3.15.

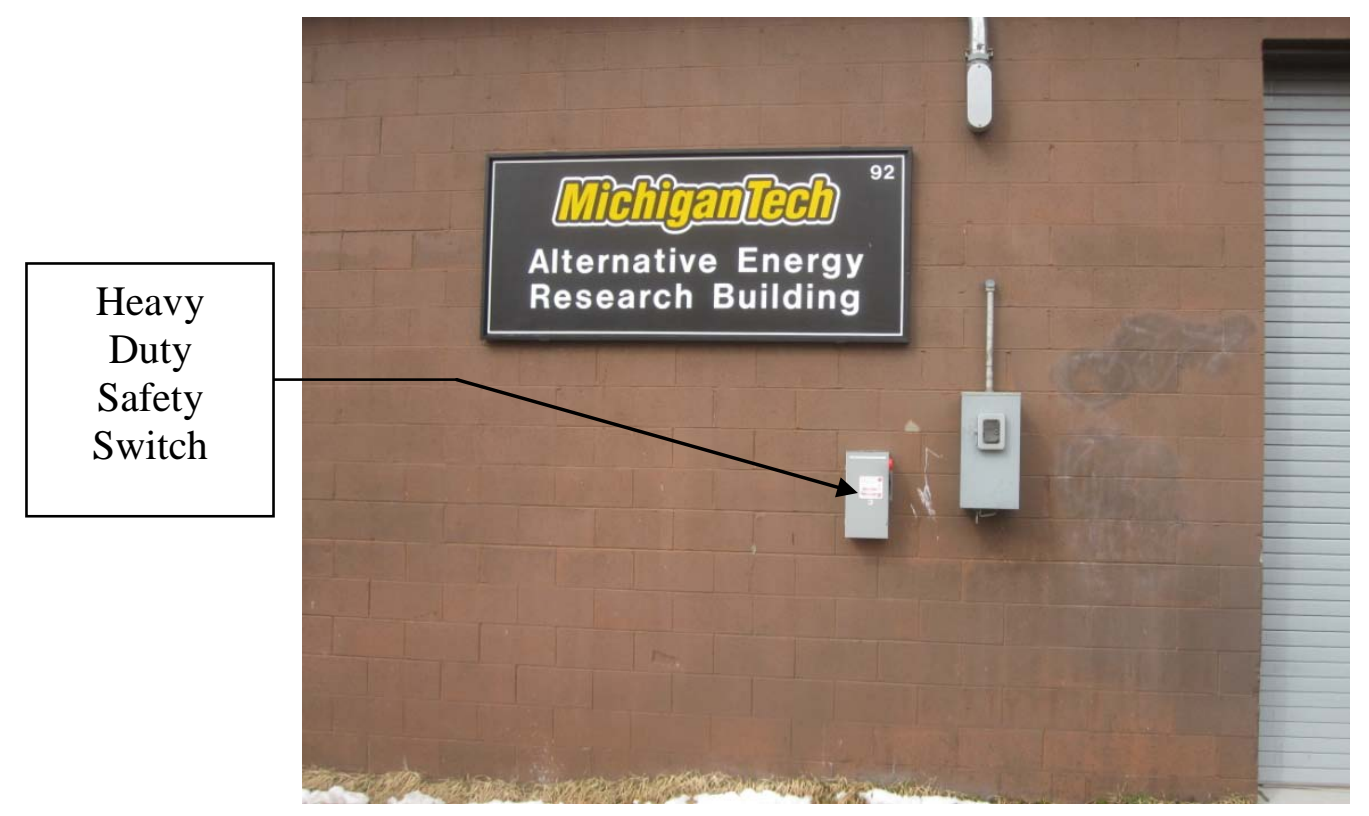

Figure 3.15: Heavy Duty Safety Switch installed on outside wall of AERB 


\subsubsection{Thermal loop connections}

The thermal loop design as shown in figure 3.1 is assembled in and above the cold room in the AERB. Complete assembly of the thermal loop can be seen in figure 3.16.

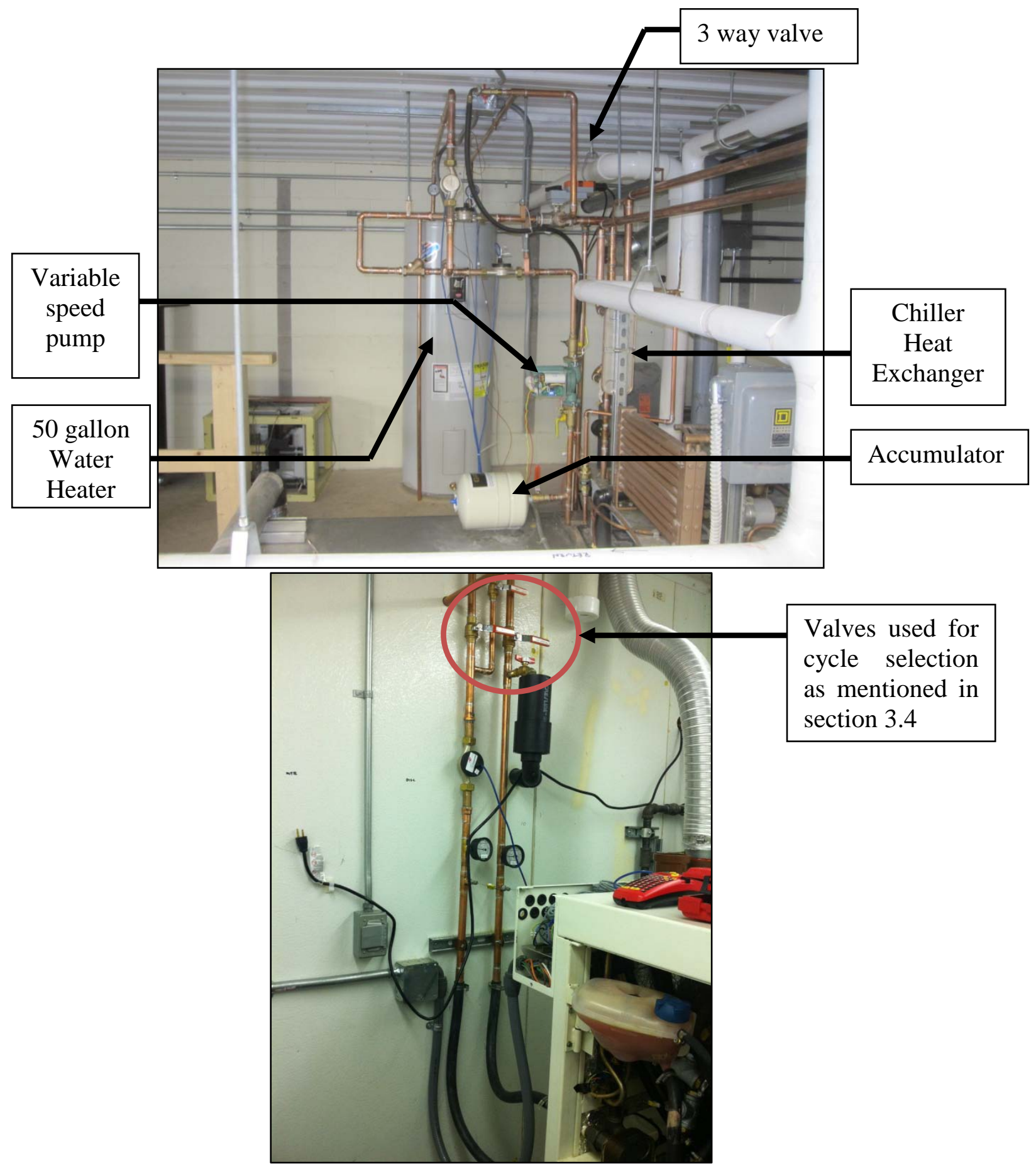

Figure 3.16: Thermal loop assembly 
3.8.4.1. Pump: For the thermal loop design, a variable frequency drive (VFD) pump was initially considered. VFD saves energy and helps regulate the flow rate of water precisely. However due to unavailability of VFD for smaller HP motor, we had to opt for a microprocessor based variable speed pump. The pump selected for the application is Taco 0013. Specification of this pump is given in the Appendix C and a picture of the pump is given in figure 3.17.

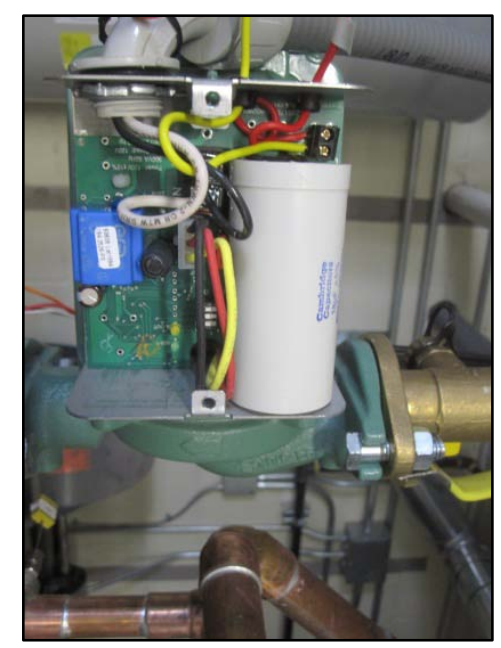

Figure 3.17: Taco microprocessor controlled variable speed pump

This pump can be controlled using $2-10 \mathrm{Vdc}$ or $0-10 \mathrm{Vdc}$. To select the right mode, we need to select one of the three DIP switches on the pump as shown in figure 3.18.

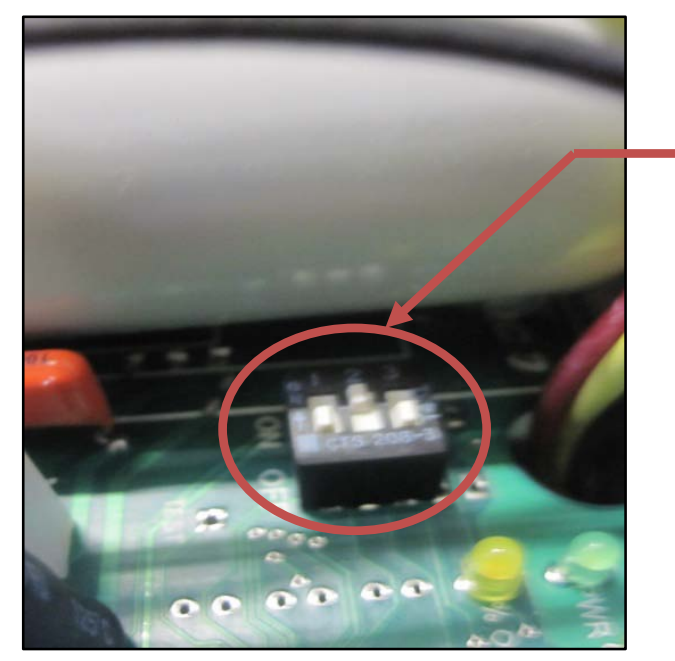

DIP switches to select mode of control of the pump (set at manual mode in the picture)

Figure 3.18: DIP switches on the Pump

DIP switch control is explained in the Appendix E.

3.8.4.2. Water Heater: A 50 gallon water heater is installed above the cold room as shown in figure 3.16 . The thermostat on the water is set at $120^{\circ} \mathrm{F}$. The temperature of water in the water heater can be set between $120^{\circ} \mathrm{F}$ to $155^{\circ} \mathrm{F}$, which is achieved by rotating the thermostat screw. 
3.8.4.3. Chiller Heat Exchanger: Chiller can be operated to reduce the water temperature to as low as $45^{\circ} \mathrm{F}$. Chiller temperature setting can be done on the touch pad on the chiller. Chilled water from chiller is circulated through the Chiller heat exchanger installed above cold room. Pictures of the Chiller and Chiller heat exchanger are shown in figure 3.19 .
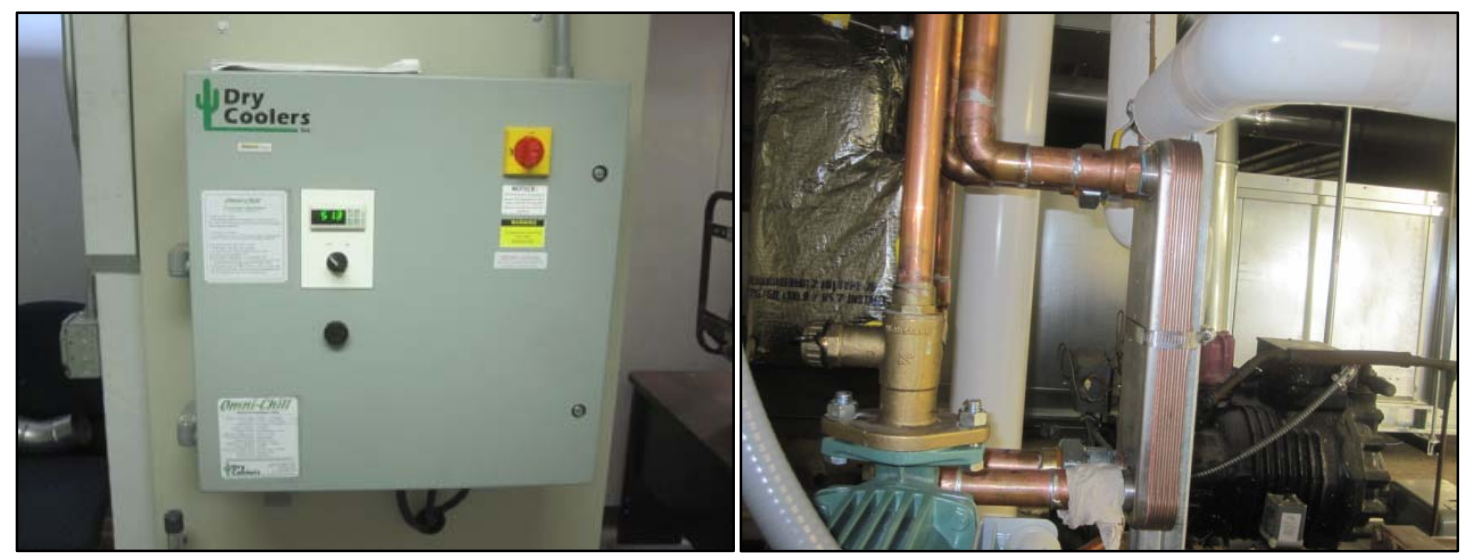

Figure 3.19: Chiller and chiller heat exchanger

3.8.4.4. Three way control valve: For splitting the water stream, we have a Belimo Electronic Characterized 3 way control valve. The wiring diagram of this valve is given in the Appendix F. Belimo three way control valve is shown in figure 3.20.

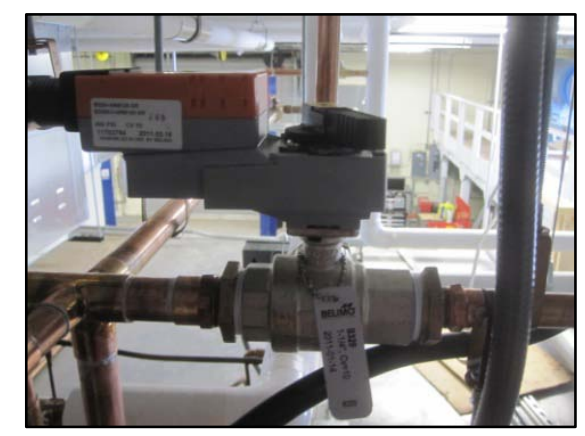

Figure 3.20: Belimo 3 way control valve

3.8.4.5. Thermocouples: $K$ type thermocouples are used for temperature measurement. Figure 3.7 shows a thermocouple. Specification of the $K$ type thermocouples is as follows:

- Sensitivity

- Temperature range $-328^{\circ} \mathrm{F}$ to $+2463^{\circ} \mathrm{F}$

- Wire color code Yellow= positive

Red= negative 
3.8.4.6. Pressure gauge: Liquid filled pressure gauge with a range of 0 to 100psi is installed at locations shown in figure 3.1. Picture of pressure gauge is shown in figure 3.21 .

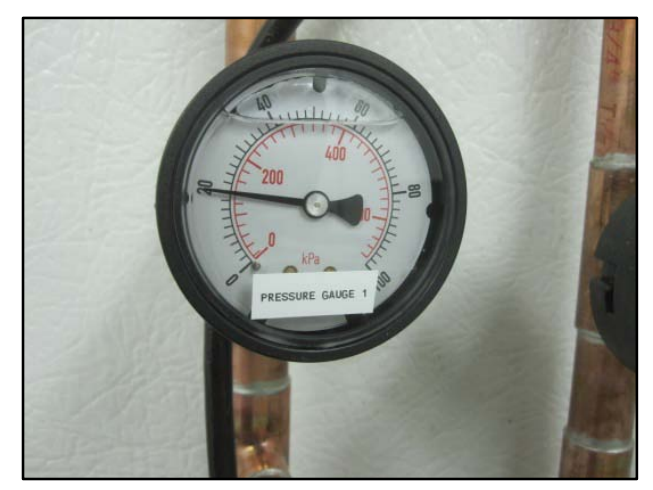

Figure 3.21: Pressure gauge

3.8.4.7. Flow meter: Seametrics low flow meters are installed in the locations shown in figure 3.1. Specification of the flow meters are as follows:

Sensor 5-30Vdc current sinking pulse

Max. temperature

$185^{\circ} \mathrm{F}$

Max. pressure 175psi

Standard K-Factor 330 pulses per gallon

Flow range

0 - 18 gallons per minute

Detailed specification and wiring diagram is given in Appendix. Picture of flow meter installed above cold room is shown in figure 3.22.

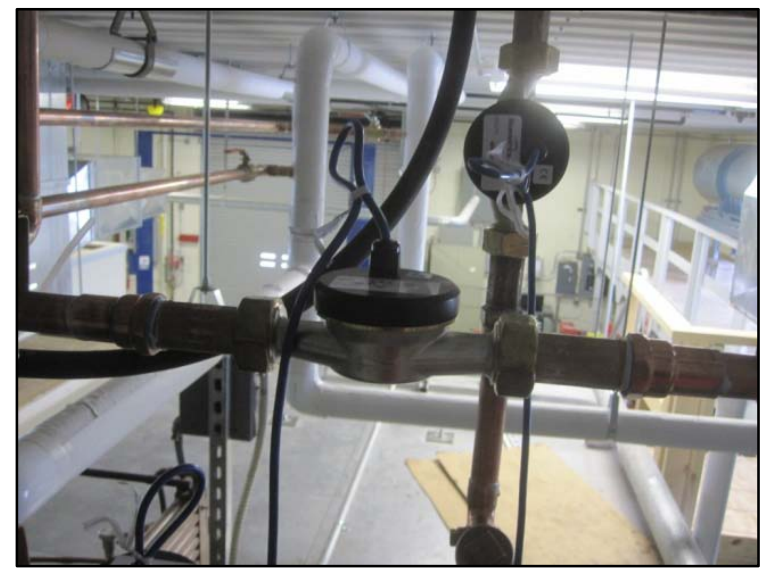

Figure 3.22: Seametrics flow meter

3.8.4.8. Relief Valve: A relief valve is attached to the thermal loop to safeguard the pipes from bursting. The relief valve is set to release pressure if the line pressure increases above 150 psi. Picture of relief valve is shown figure 3.23. 


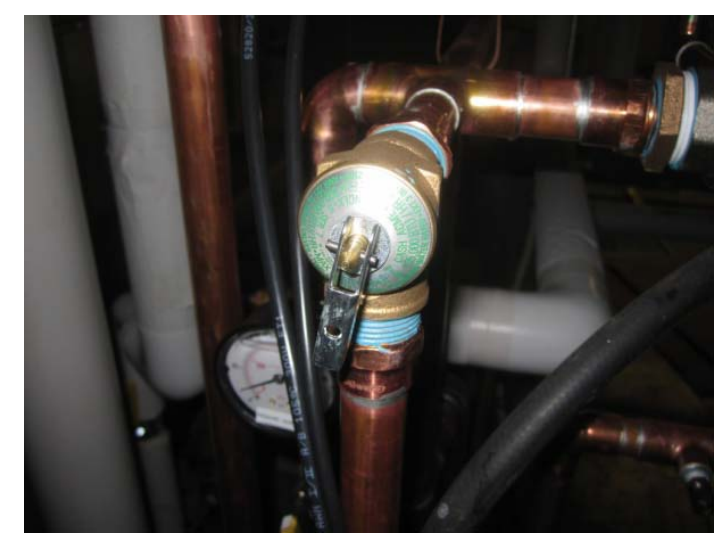

Figure 3.23: Pressure relief valve

3.8.4.9. Accumulator: An accumulator is used to dampen any sudden changes of pressure or flow rate of water in the thermal loop. A groco 1 gallon accumulator with 100psi working pressure is used in the thermal loop. Picture of the installed accumulator is shown in figure 3.24.

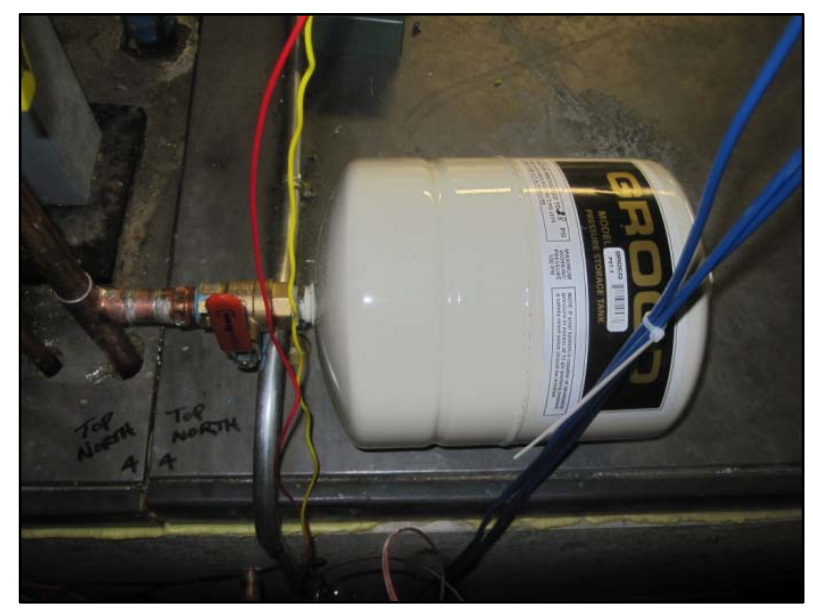

Figure 3.24: Accumulator

3.8.4.10. Check Valve: Check valve allows water to flow in only one direction. In the thermal loop, two check valves are installed to avoid the back flow of water to the 3 way valve. 
3.8.5. DAQ connections: NI compact DAQ Chassis is connected to a HP computer for control of the thermal loop. Picture of the DAQ system is shown in figure 3.25. Details the DAQ used is as follows:

Chassis: NI Compact DAQ 9178 Chassis (8 slots)

Table 3.1: Specification of DAQ modules

\begin{tabular}{|c|c|c|c|}
\hline Module Type & $\begin{array}{c}\text { Number of } \\
\text { channels }\end{array}$ & Specification & Quantity \\
\hline $\begin{array}{c}\text { ThI 9213 } \\
\text { module }\end{array}$ & 16 & $24 \mathrm{bit}$ & 2 \\
\hline $\begin{array}{c}\text { NI 9201 Analog } \\
\text { input voltage } \\
\text { module }\end{array}$ & 8 & $+/-10 \mathrm{~V}$ & 3 \\
\hline $\begin{array}{c}\text { NI 9401digital } \\
\text { input/output module }\end{array}$ & 8 & 12 bit & 1 \\
\hline $\begin{array}{c}\text { NI 9263 Analog } \\
\text { output voltage } \\
\text { module }\end{array}$ & 4 & $10 \mathrm{NS}$ & 1 \\
\hline
\end{tabular}

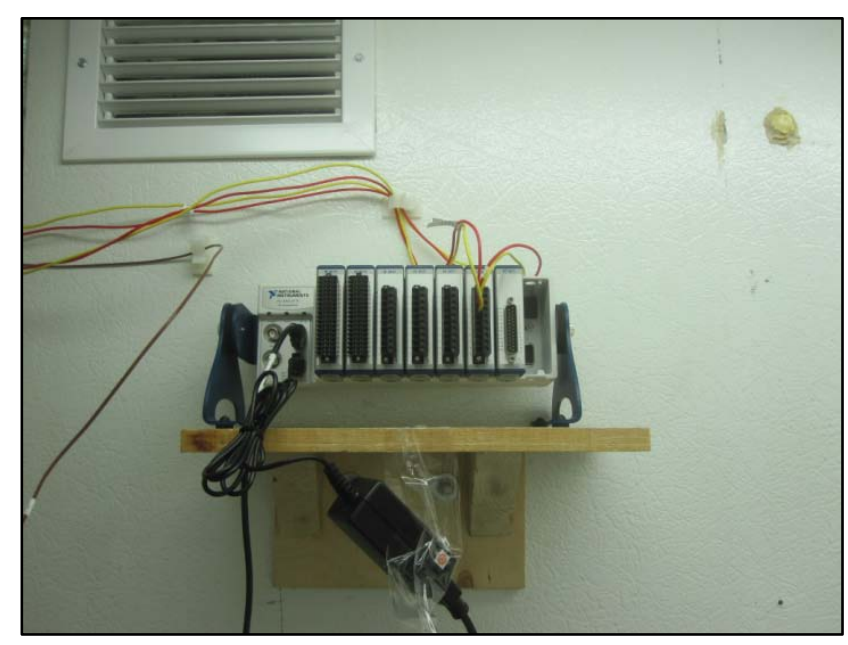

Figure 3.25: NI DAQ system 


\section{Simulation}

Micro-CHP system can be designed to run on various fuels. A simulation is done on an I.C. Engine based Micro-CHP system that can run on both Natural Gas and Syngas (produced by gasification of biomass). The advantage of this kind of Micro-CHP system is that we can use Syngas gas produced from waste wood which is freely available. Use of Syngas gas reduces the fuel cost and it is considered carbon neutral as the wood absorbs $\mathrm{CO}_{2}$ during its lifetime before it is cut down for fuel.

This simulation considers the operation of Micro-CHP unit in a residential property with cooling and heating needs. Cooling in summer is achieved with either adsorption chiller or electric chiller with priority given to adsorption chiller provided the heat source is Micro-CHP and not the Auxiliary Boiler. For building, thermal load and electric load specification is given in table 4.2.

\subsection{Design of Biomass run Micro-CHP system}

The design of the simulated biomass run Micro-CHP system is shown in figure 4.1. A biomass gasifier uses biomass like wood and forms Syngas. Syngas is used as primarily fuel for running the Micro-CHP unit. In case requirement of fuel goes over the maximum gasifier capacity, natural gas is used as a supplement fuel.

The fuel is supplied to the Micro-CHP's I.C Engine which is coupled to a generator that produces electricity. The thermal energy created due to combustion in the engine is captured by coolant and is transferred to water through a heat exchanger as shown in figure 4.1. The exhaust of the engine is passed through another heat exchanger to absorb the heat. If additional heat is required then an auxiliary boiler starts up to supplement with makeup heat. This auxiliary boiler can run on both Syngas and Natural Gas. If additional thermal energy is generated than the heat load then it is transferred to a thermal storage tank (buffer vessel). Specification of Micro-CHP system, gasifier, boiler and the fuel is given in table 4.1 .

Table 4.1: Specification of CHP, gasifier, boiler and fuel

\begin{tabular}{|l|c|}
\hline Specification & Value \\
\hline Micro-CHP electricity generation capacity & $5 \mathrm{~kW}$ \\
\hline Micro-CHP , electrical efficiency & $30 \%$ \\
\hline Syngas produced by biomass gasifier in kW & $5 \mathrm{~kW}$ to $15 \mathrm{~kW}$ \\
\hline Engine Exhaust Heat Exchanger efficiency & $95 \%$ \\
\hline Engine Coolant Heat Exchanger efficiency & $85 \%$ \\
\hline Biomass Gasifier efficiency & $93 \%$ \\
\hline Auxiliary boiler efficiency & $90 \%$ \\
\hline Parasitic power required to run Micro-CHP & $0.6 \mathrm{~kW}$ \\
\hline
\end{tabular}




\subsection{Assumptions and limitations of the Simulation}

\section{Assumptions:}

1. All of generator loss is in the form of heat, and is captured by the cooling system. Radiative heat losses are negligible.

2. All the coolant and exhaust pipes are well insulated, and loose no heat to the surroundings.

3. To simplify modeling the engine exhaust and flare gas boiler exhaust are assumed to pass through separate heat exchangers. In practice these may be combined to use a single heat exchanger.

4. If additional heating is required, and the gasifier is operating at full load, then NG will flow to the flare gas boiler.

5. Assume all combustion is stoichiometric

6. Assume all energy coming from biomass sources is $\mathrm{CO}_{2}$ neutral, so only the combustion of coal and NG produces $\mathrm{CO}_{2}$.

7. The thermal load is assumed constant at $40 \mathrm{BTU} / \mathrm{hr} / \mathrm{ft}^{2}$. This value varies from residential application to light commercial building. This value will be smaller for pure residential application.

\section{Limitations:}

1. The simulation does not account for net exporting of heat or power

2. It also does not account for source and kind of wood used for the gasifier and the $\mathrm{CO}_{2}$ emission associated with transporting the wood to the site.

3. In the simulation it is assumed that the Micro-CHP unit produces $5 \mathrm{~kW}$ of power using Natural Gas as well as Syngas. In reality Syngas will produce less power out of the same prime mover. 


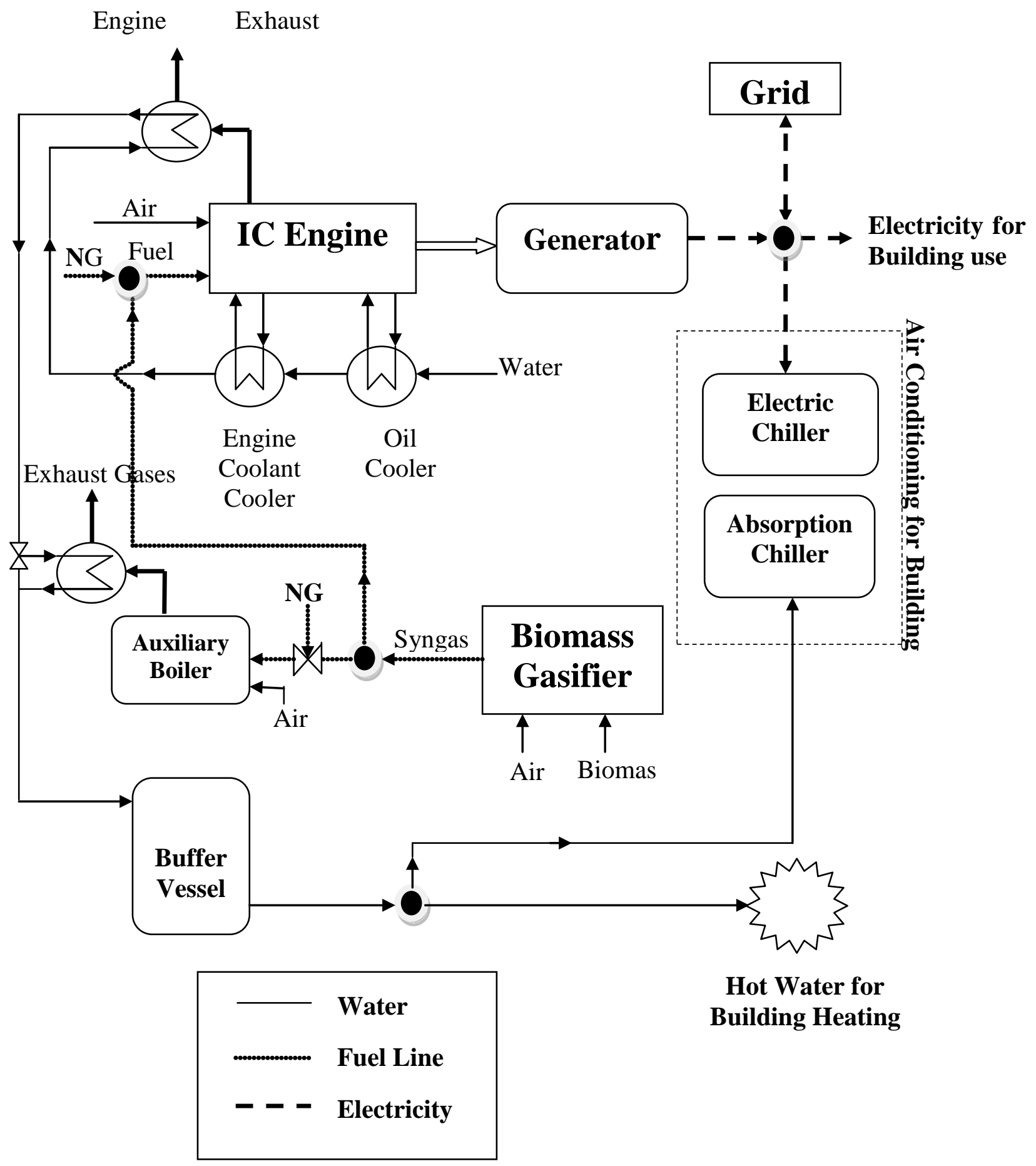

Figure4.1: Biomass powered Micro CHP design 
Table 4.2 Specification of building

\begin{tabular}{|c|c|}
\hline Specification & Value \\
\hline Building area & $2500 \mathrm{ft}^{2}$ \\
\hline Building electrical requirement & 0 to $6 \mathrm{~kW}$ \\
\hline Thermal demand in the building & $40 \mathrm{BTU} / \mathrm{hr} / \mathrm{ft}^{2}$ \\
\hline COP of electric Air Conditioner & 2 \\
\hline Efficiency of adsorption chiller & $70 \%$ \\
\hline
\end{tabular}

\subsection{Control logic}

The control logic used for the Micro CHP is shown in figure 4.2. Control logic for the simulation is designed to satisfy the electrical load first. Thermal load is subsequently satisfied using auxiliary boiler.

Following are the variables used to define different properties used in control logic:

Elec_req = Electrical load on the building

Therm_req $\quad=$ Thermal load on the building

Grid_pw = Grid power

Aux_boiler = Auxiliary boiler

CHP_max = Micro-CHP's maximum electrical power generation capacity

max_gas = Maximum power by the Syngas produced by biomass gasifier

min_gas = Minimum power by the Syngas produced by biomass gasifier

Pw_NG = Power produced using Natural Gas through CHP

Pw_gas = Power produced using Syngas through CHP

CHP_Pw = Power consumed by CHP to meet the electrical load

Th_gas = Thermal energy produced by Syngas through auxiliary boiler

Ht_ex = Total heat extracted from CHP and Boiler

Ht_CHP = Heat produced by the CHP

Ht_Boiler = Heat produced by the boiler

Boiler_makeup= Extra heat required to meet the thermal load 


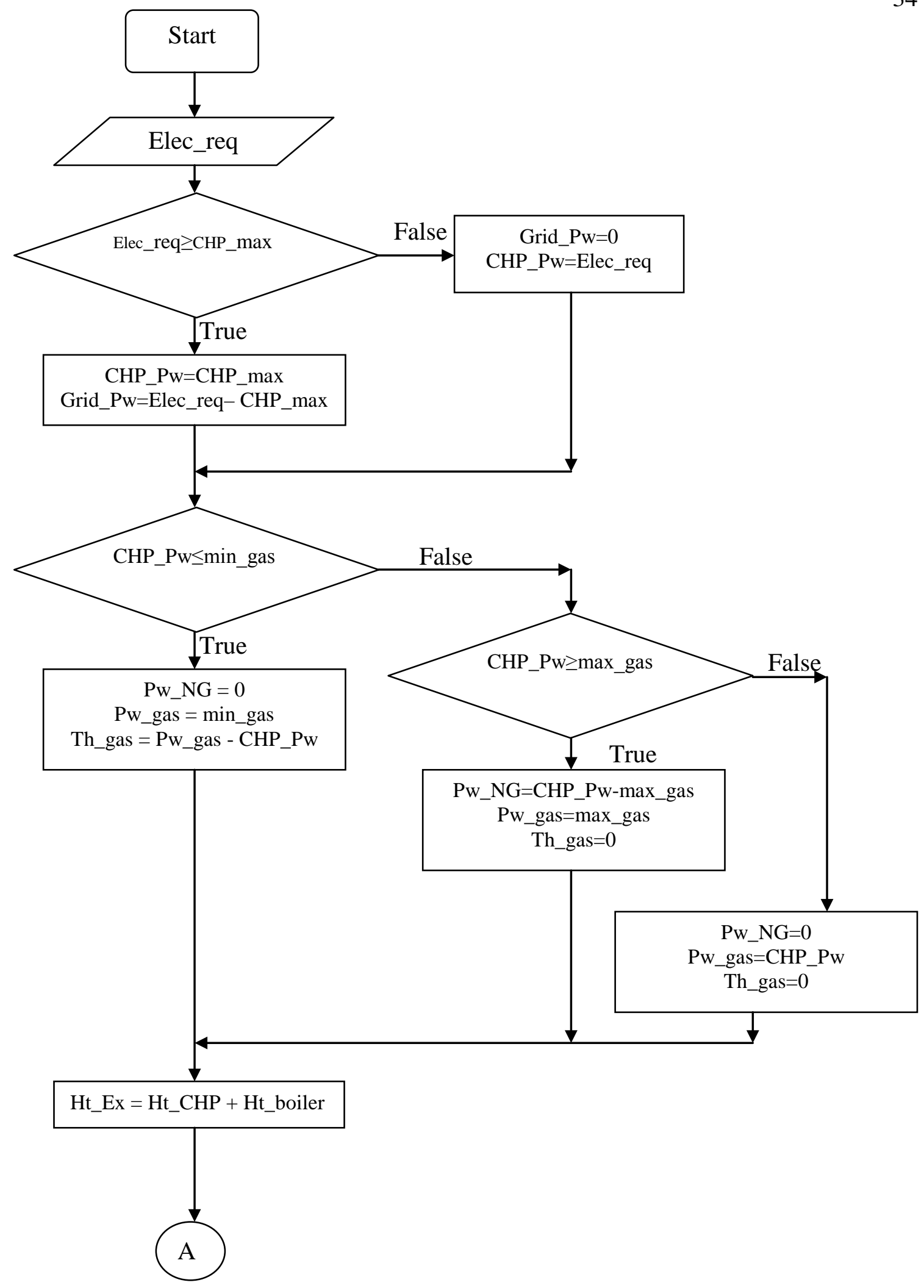




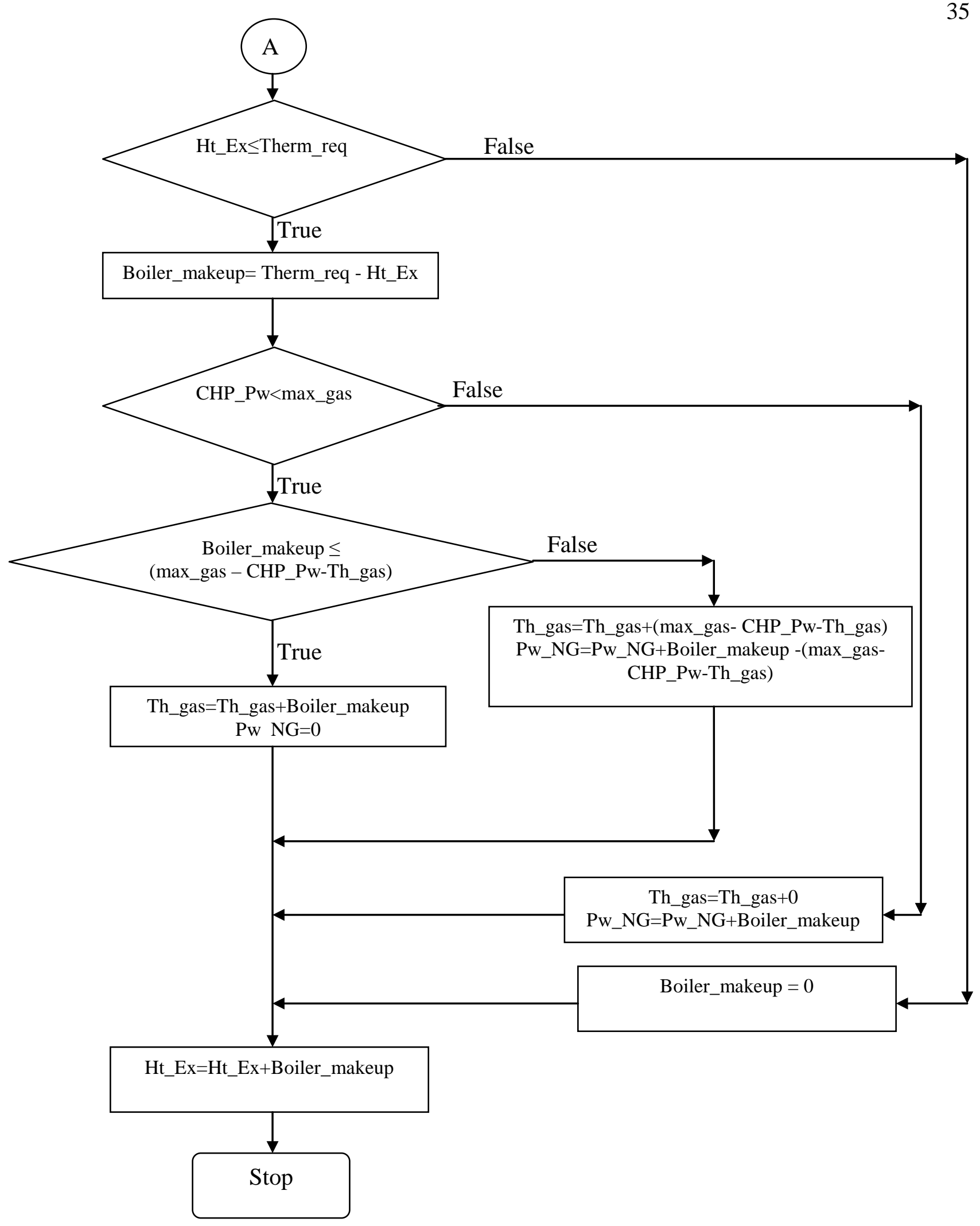

Figure 4.2: Flow chart showing the control logic for CHP simulation 


\subsection{Baseline - Building without Micro- CHP}

For the sake of comparison the same building was considered without the Micro-CHP unit. Here electrical power is assumed to be provided by coal fired power plants and thermal power is given by Natural Gas furnace. Table 4.3 shows the value considered for baseline simulation.

Table 4.3: Specifications for building without CHP

\begin{tabular}{|l|c|}
\hline Specifications & Value \\
\hline $\begin{array}{l}\text { Coal power plant efficiency (including } \\
\text { transmission losses) }\end{array}$ & $30 \%$ \\
\hline Natural Gas furnace efficiency & $93 \%$ \\
\hline
\end{tabular}

\section{5. $\mathrm{CO}_{2}$ Calculations}

$\mathrm{CO}_{2}$ emission values are determined for the Micro-CHP run building as well as for the building without Micro-CHP system. To calculate the carbon emitted by a fuel, we consider the number of Carbon atoms present in 1 molecule of fuel. The number of carbon present in a fuel can be given by:

$$
\text { Fuel }_{\mathrm{CO}_{2}}=\frac{\mathrm{C}^{*} M W_{\text {fuel }} * P}{L H V}
$$

Where, $\mathrm{C}=$ number of carbon present in one molecule

$$
\mathrm{MW}_{\text {fuel }}=\text { molecular weight of fuel }
$$

$\mathrm{P} \quad=$ Fuel consumed in $\mathrm{kW}$

LHV =Lower heating value of fuel

The fuel properties considered in the simulation is given in table 4.4.

Table 4.4: Fuel properties

\begin{tabular}{|l|l|l|l|}
\hline Fuel & $\begin{array}{l}\text { No. of carbons per } \\
\text { molecule }\end{array}$ & $\begin{array}{l}\text { Molecular weight } \\
\mathrm{kg} / \mathrm{moles}\end{array}$ & $\begin{array}{l}\text { Lower heating value } \\
\mathrm{kJ} / \mathrm{kg}\end{array}$ \\
\hline Coal & 100 & 286 & 33300 \\
\hline NG & 1 & 16 & 50000 \\
\hline $\begin{array}{l}\text { Wood } \\
\text { (carbon neutral) }\end{array}$ & - & - & 14900 \\
\hline
\end{tabular}




\section{Results}

\subsection{Results from the simulation}

\subsubsection{System efficiency comparison between CHP and baseline run system}

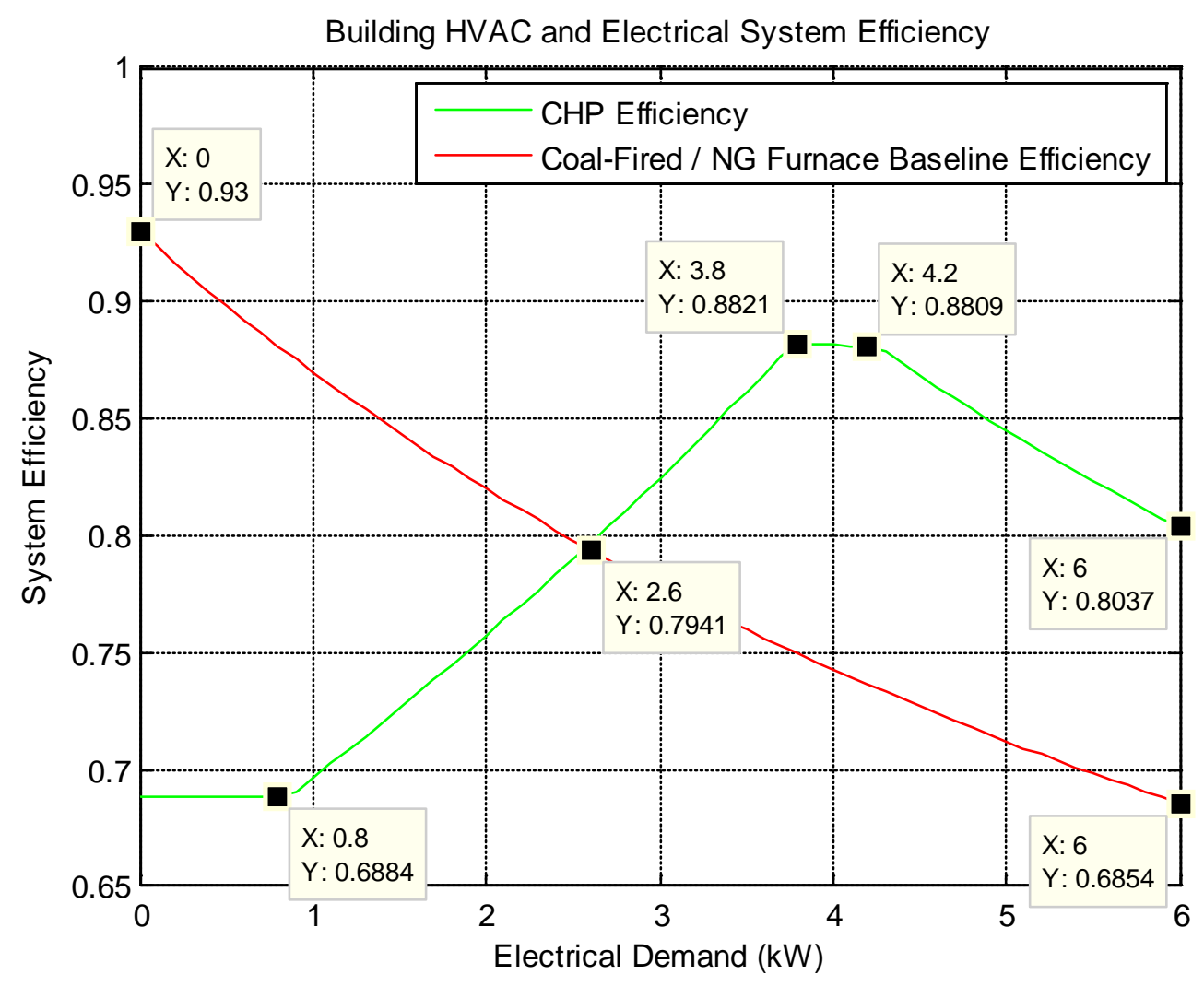

Figure 5.1: Building HVAC and Electrical System Efficiency

- As we see in figure 1 , The CHP run system gives steady increase in efficiency as the electrical demand increases

- Initially the efficiency of CHP system is constant at $68.84 \%$ because all the electrical power produced is used to overcome the parasitic losses

- After $4.2 \mathrm{~kW}$ mark, there is decline in overall efficiency because the system uses electricity from the grid.

- The CHP unit is rated at 5kW, but parasitic losses and transmission efficiency limits the uses of CHP power to $4.3 \mathrm{~kW}$. 


\subsubsection{Thermal power generation}

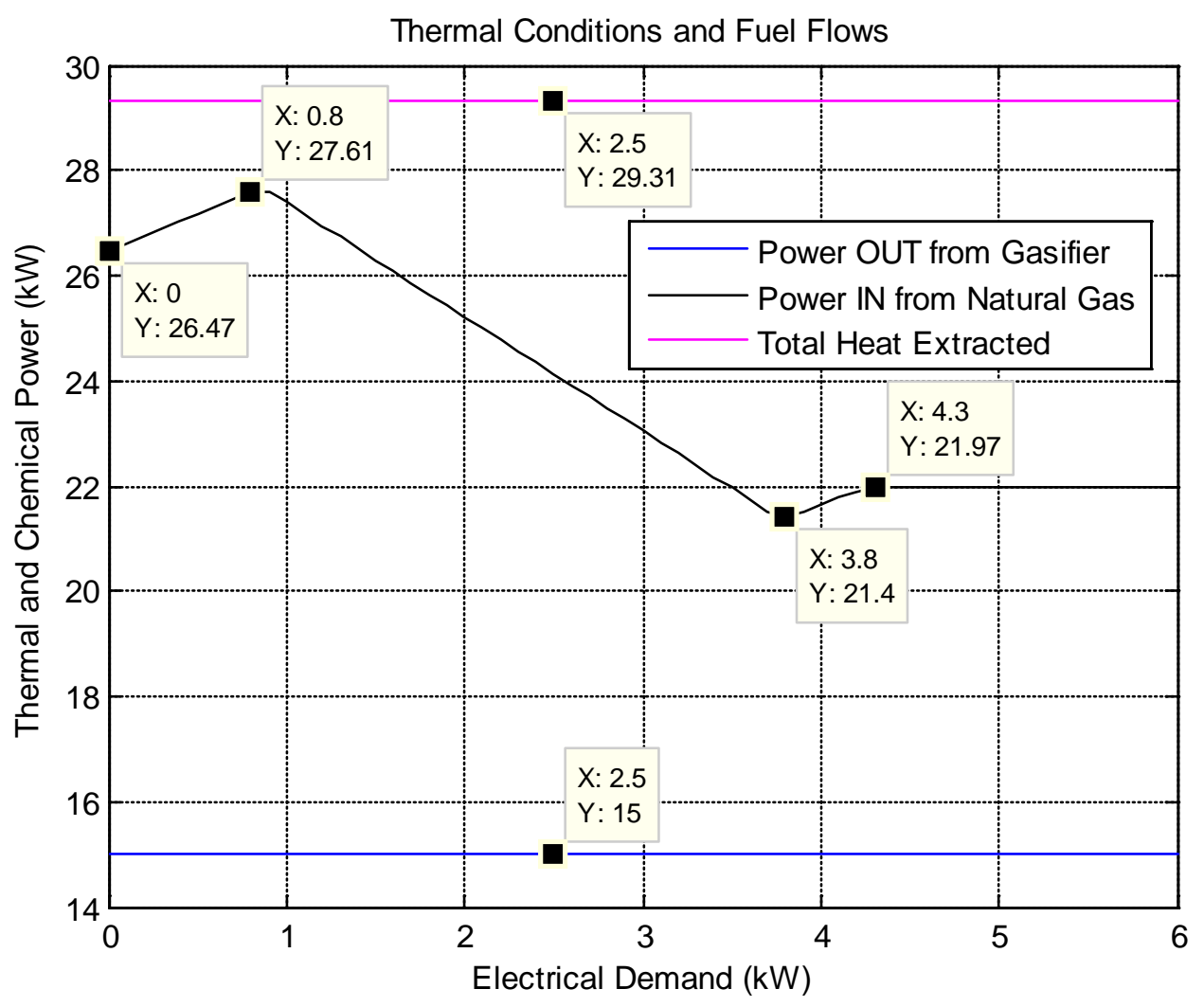

Figure 5.2: Thermal condition and fuel flow

- Total thermal requirement is at $29.3 \mathrm{~kW}$.

- This is met by a combination of thermal energy obtained from Syngas and Natural gas operated CHP unit and auxiliary boiler.

- The fluctuation in NG requirement is due to consumption of Syngas for electrical power generation through Micro-CHP unit. 


\subsubsection{Electrical Power supply}

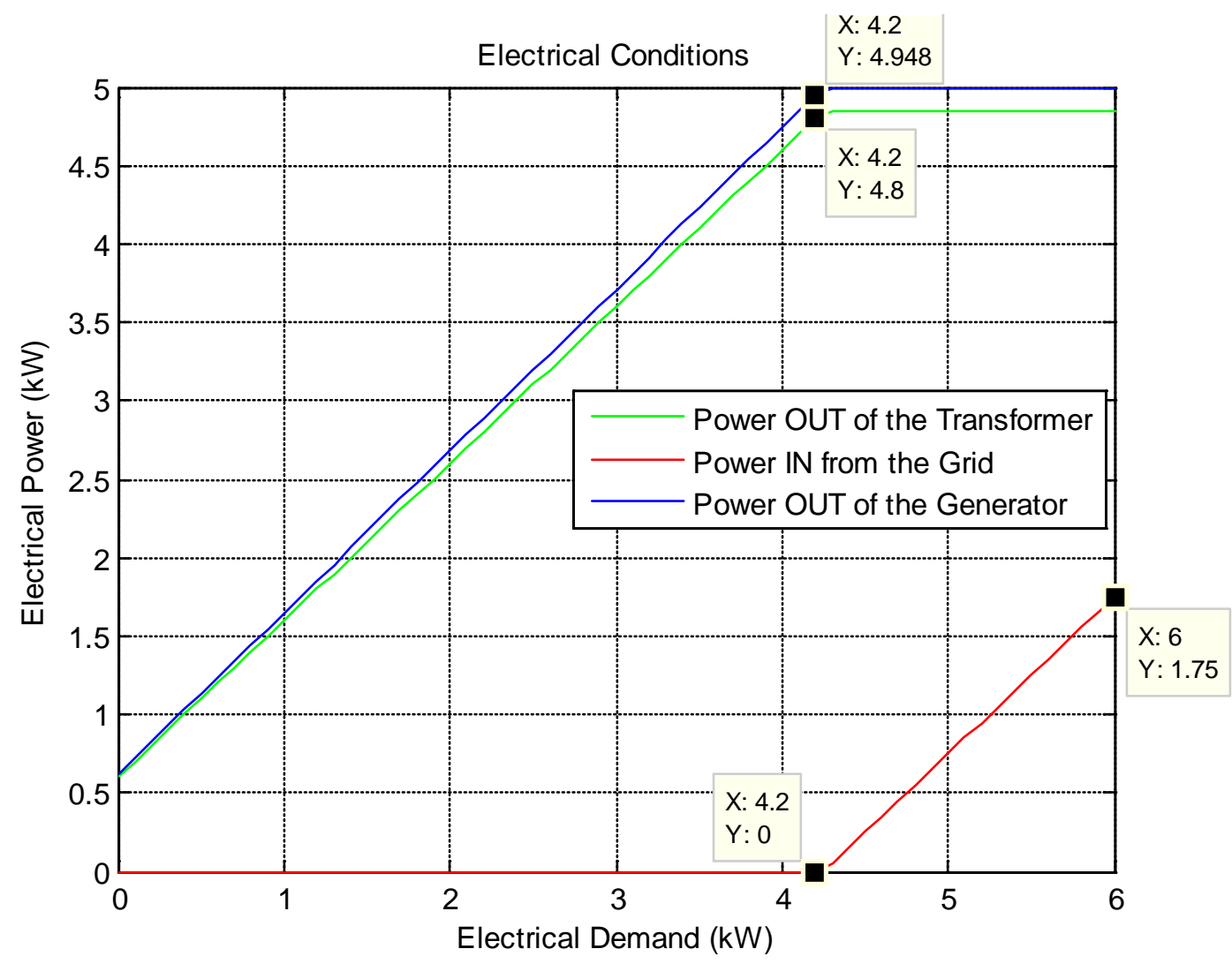

Figure 5.3: Electrical conditions

- Electrical demand varies from 0 to $6 \mathrm{~kW}$.

- The grid power does not kick in until $4.3 \mathrm{~kW}$ as the CHP acts as the primary power source.

- Change in slope between the transformer output and the generator power output shows the losses at the transformer. 


\subsection{4. $\mathrm{CO}_{2}$ emission comparison between a Syngas operated Micro-CHP system and a baseline system}

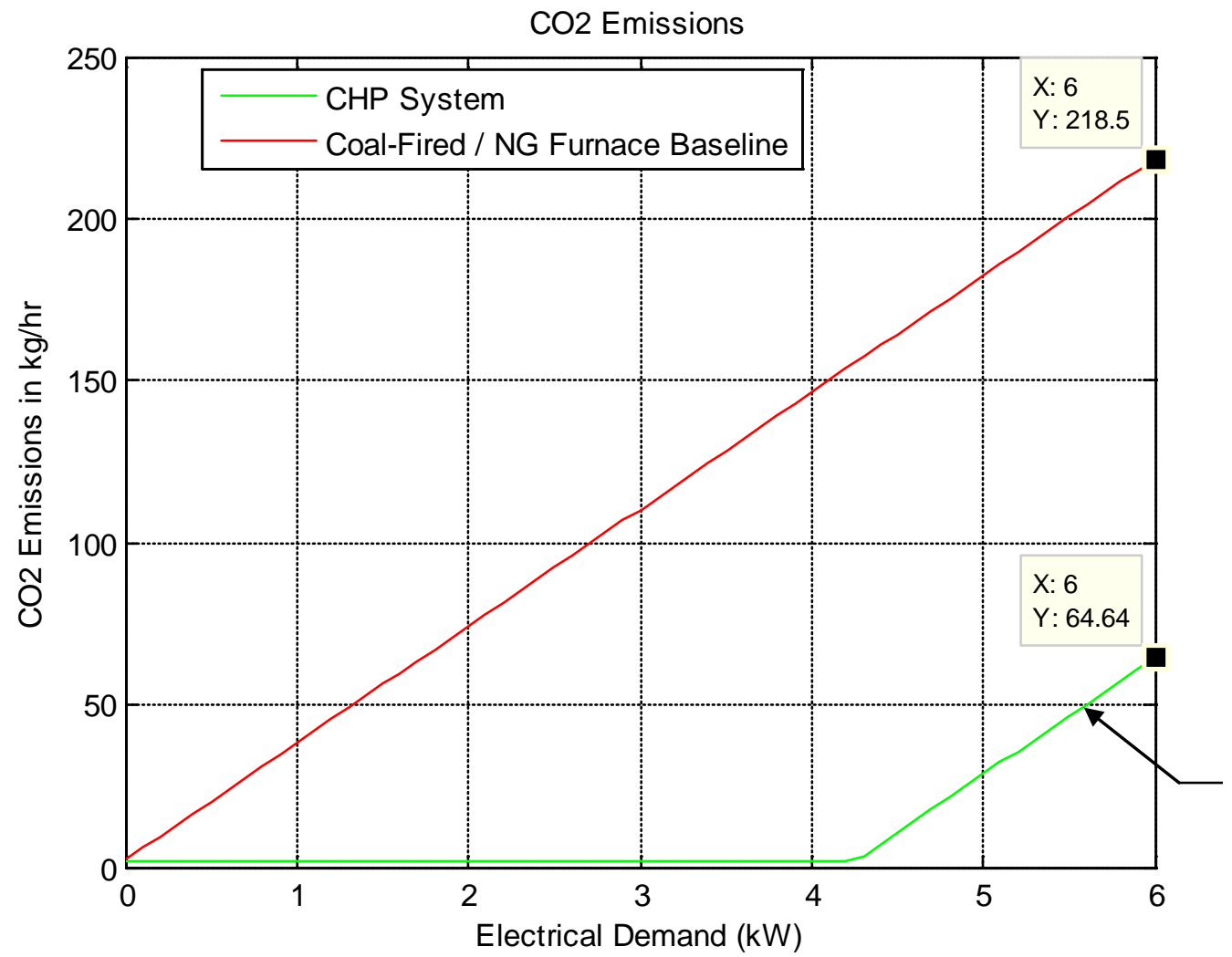

Emission due to power produced by grid as $\mathrm{CHP}$ has reached its maximum capacity at $4.2 \mathrm{~kW}$

Figure 5.4: $\mathrm{CO}_{2}$ emission comparison between Micro-CHP and Baseline system

- In figure 5.4, we can observe that $\mathrm{CO}_{2}$ emission from the Micro-CHP system is 0 until $4.2 \mathrm{~kW}$. This is because Micro-CHP uses Syngas produced from biomass as a fuel which is carbon neutral.

- Increase in $\mathrm{CO}_{2}$ emission in the Micro-CHP system line after $4.3 \mathrm{~kW}$ electrical demand is due to the fact that power in building above $4.3 \mathrm{~kW}$ is provided by the Grid. 


\subsubsection{Fuel mass flow rate for CHP system}

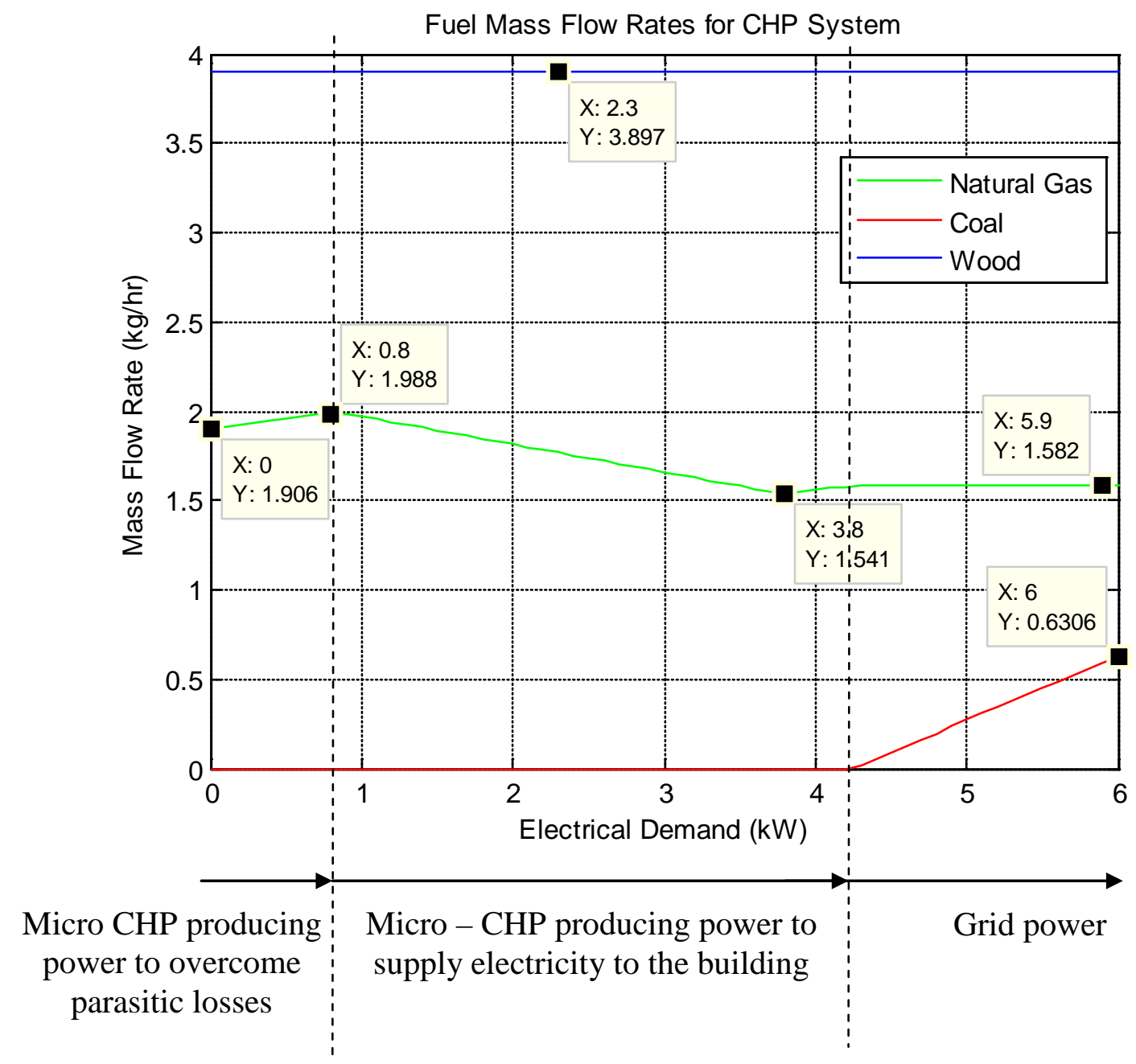

Figure 5.5: Fuel mass flow rate for CHP system

- As shown in figure 5.5, Micro-CHP unit runs on Syngas shown by the blue color line.

- Natural gas in this simulation is used in auxiliary boiler to meet the thermal demand

- The use of coal kicks in with the Grid power

- The fluctuation of natural gas consumption is due to the change in electrical power produced using Syngas run Micro-CHP system

- Fuel properties of all the fuel shown in figure 5.5 is given in table 4.4. 


\subsubsection{Fuel mass flow rate for Baseline System}

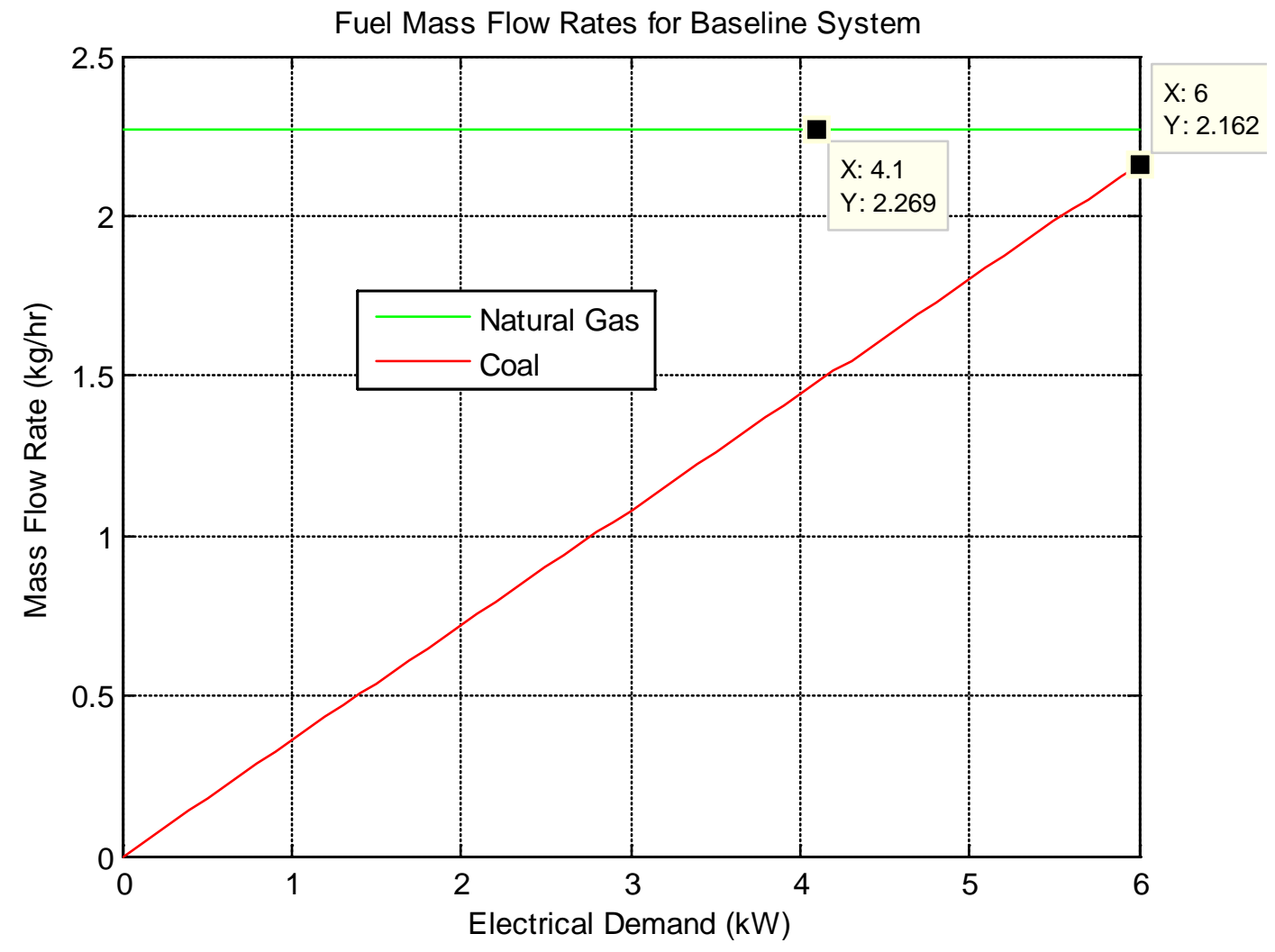

Figure 5.6: Fuel mass flow rate for baseline system

- Baseline system is where the electricity for the building is obtained from a grid based on coal based power plant.

- Mass flow rate of Natural Gas which is used to power a natural gas furnace is constant with varying electrical demand because we have taken constant thermal load in this simulation (refer table 4.2). 


\subsubsection{Energy Savings}

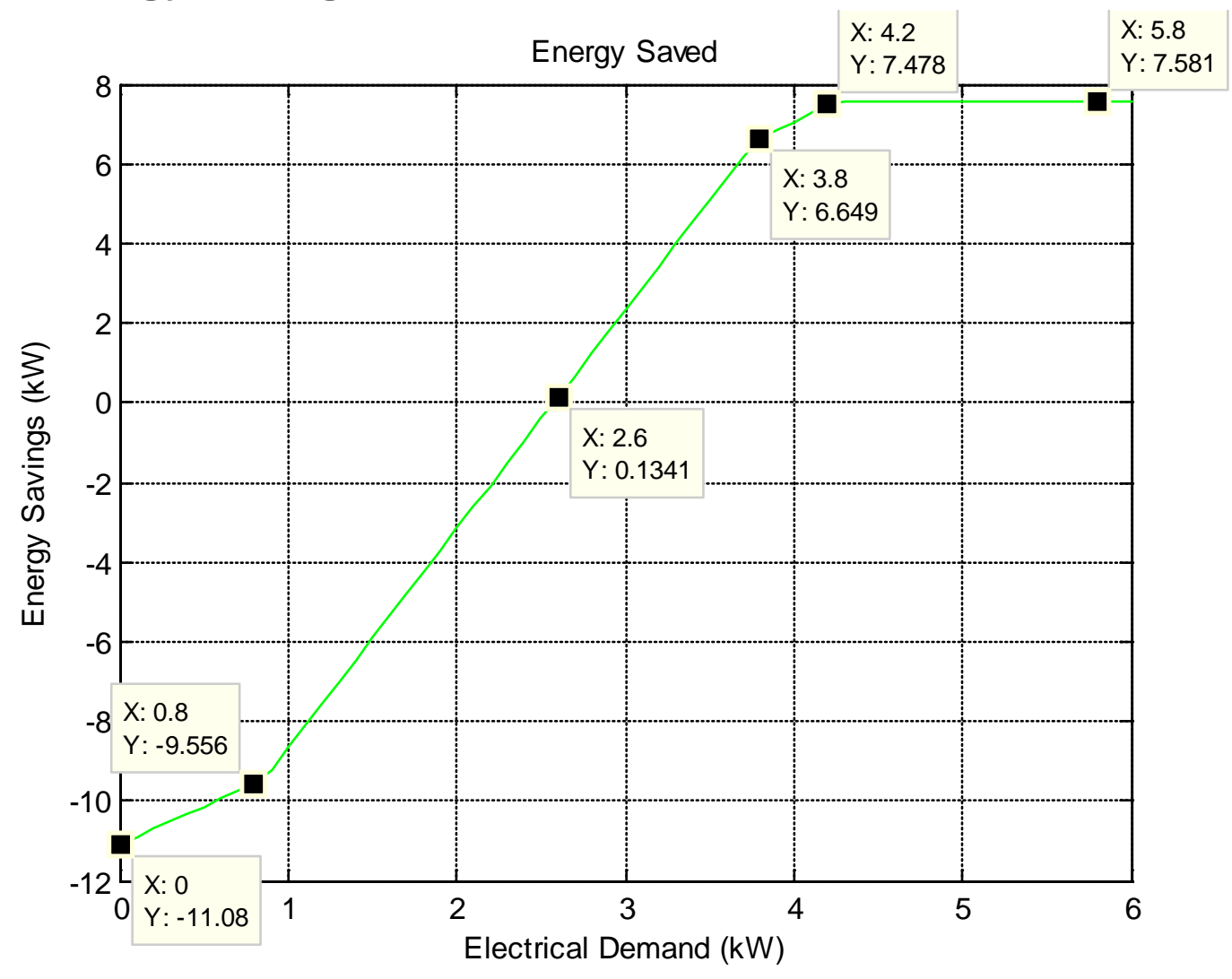

Figure 5.7: Energy Savings graph

- Energy Savings is the difference between the energy consumed for running the CHP system and the baseline system.

- For first $0.8 \mathrm{~kW}$ the CHP is utilizes all the electrical power to overcome parasitic losses. Thus we see that savings gradually increases till $0.8 \mathrm{~kW}$

- Energy savings below $2.6 \mathrm{~kW}$ of electric power is negative for Micro-CHP system. This is because superior efficiency of Natural gas furnace in the baseline system and the lack of Syngas on the Micro-CHP system for heating with increase in electrical power demand.

- At 4.2kW Energy Savings peaks because Micro-CHP reaches its maximum capacity. Even though Micro-CHP's maximum capacity is $5 \mathrm{~kW}$, we see the energy savings peak at $4.2 \mathrm{~kW}$ because of $0.8 \mathrm{k} \mathrm{W}$ parasitic losses 


\section{Conclusion}

In this Micro - CHP research project a test lab is designed and assembled which is capable of handling various tests including emissions, heat load optimization, adsorption chiller simulation etc. The simulation shown in chapter 4 allows us to understand application of Micro-CHP in residential building. It also compares the $\mathrm{CO}_{2}$ emissions and energy savings. Total energy saving (electrical and thermal) of $5.9 \mathrm{~kW}$ is obtained in the simulation using a $5 \mathrm{~kW}$ (electric) Micro CHP system. Also in the simulation, $\mathrm{CO}_{2}$ emission reduction of $153.9 \mathrm{~kg} / \mathrm{hr}$ is achieved by the Micro-CHP system as compared to a baseline system running on coal powered grid and natural gas powered furnace.

\subsection{Future work}

Following future work can be conducted on the Micro-CHP test setup:

- California emissions standard for CHP: Testing the Ecopower unit for emissions at different load cycles and if required modify the CHP to meet California standards for emissions.

- CHP System with Integrated Adsorption Cooler: Study the effect of adsorption chiller on the Ecopower unit. Adsorption chiller can be replicated using the thermal loop designed in chapter 3.

- Alternative fuels - Combustion, emissions and efficiency: Examination of gaseous fuels (e.g., biogas, syngas, landfill gas) and alcohol blends on the Ecopower unit.

- Lean / Dilute Combustion - Combustion, emissions and energy balance (thermal, mechanical): Lean combustion in SI system has shown improved performance primarily due to reduce heat-transfer and exhaust enthalpy albeit at the cost of lower power density. This may be an alternative load control for the system.

- Systems Level Real-Time Optimization: Implement model based control logic that optimizes the balance between electrical, coolant, and exhaust energy based on real-time utility pricing and thermal and electrical demands and storage capacity.

- Integration with Smart Metering and Micro Grids: Integration of CHP into home and community based microgrid systems. Optimization of electrical resources within system that include renewables (such as wind, solar) and electric vehicle charging.

- Benchmark testing of commercially available products: Conduct benchmark testing relative to performance, emissions, and fuel consumption of various micro-CHP products including other ICE based products like Honda ECOWILL and Baxi SenerTec, as well as Stirling and Rankine cycle products. Current Micro-CHP test setup has provisions to remove the Ecopower unit and install other Micro-CHP devises in the future. 


\section{Reference}

1. Çengel, Y.A. and M.A. Boles, Thermodynamics : an engineering approach. 6th ed. McGraw-Hill series in mechanical engineering. 2008, Boston: McGraw-Hill Higher Education. xxxi, 1018 p.

2. Meckler, M. and L.B. Hyman, Sustainable on-site CHP systems : design, construction, and operations. 2010, New York: McGraw-Hill. xx, 444 p.

3. Kavvadias, K.C., A.P. Tosios, and Z.B. Maroulis, Design of a combined heating, cooling and power system: Sizing, operation strategy selection and parametric analysis. Energy Conversion and Management, 2010. 51(4): p. 833-845.

4. Ren, H., W. Gao, and Y. Ruan, Optimal sizing for residential CHP system. Applied Thermal Engineering, 2008. 28(5-6): p. 514-523.

5. Cho, H.J., et al., Cost-optimized real-time operation of CHP systems. Energy and Buildings, 2009. 41(4): p. 445-451.

6. Peacock, A.D. and M. Newborough, Controlling micro-CHP systems to modulate electrical load profiles. Energy, 2007. 32(7): p. 1093-1103.

7. Zhao, X.L., et al., Performance improvement of a $70 \mathrm{kWe}$ natural gas combined heat and power (CHP) system. Energy, 2010. 35(4): p. 1848-1853.

8. De Paepe, M., P. D'Herdt, and D. Mertens, Micro-CHP systems for residential applications. Energy Conversion and Management, 2006. 47(18-19): p. 3435-3446.

9. Thomas, B., Benchmark testing of Micro-CHP units. Applied Thermal Engineering, 2008. 28(16): p. 2049-2054. 


\section{Appendix A: Matlab code for simulation}

\% Program created by Thomson Varghese. \%This program is based on Jeremy Worm's simulation of HEV CHP system with syngas.

\%Program to compute system efficiencies, emissions, and other operating \%parameters for biomass powered CHP system.

\%See the end of this editor file for assumptions

$\%$ Input

close all

clear all

clc

\%operating Condition

demand_electric = 0:.1:6; \%Electrical demand from the

building in $\mathrm{kw}$

demand_thermal_occupied $=40 ; \quad$ \%Thermal demand from the building in BTU / hr / ft^2 (a light commercial / industrial building is 20 -

60 )

season $=1 ; \quad$ \%1=Winter, $\odot=$ Summer

\%System specifications

building_area $=2500$;

max_gen = 5;

be generated from the $\operatorname{HEV}(\mathrm{s})$

Pout_gasifier_mean $=10$;

the gasifier in $\mathrm{kw}$

turndown $=.5$;

be reduced or increased as a percentage of the nominal output

\%Subsystem Efficiencies

eff_gen $=.903$;

$\%$ Area of the building in $\mathrm{ft}^{\wedge} 2$

\%The maximum power in $\mathrm{kw}$ that can

\%The nominal calorific output of

efficiency

eff_transformer $=.97 ; \quad$ \%Eff of the transformer that cleans

the AC power before exporting to the grid

eff_EngExhHeatExch = .95; \%from Scott \%Eff of the heat

exchanger that removes heat from the engine exhaust and the exhaust of the flare gas boiler. This is an air to liquid heat exchanger.

eff_boiler = .9; $\quad$ \%from Gregg \%Eff of the flare

gas boiler

eff_CoolantHeatExch = .85; \%from Scott\%Eff of the heat

exchanger that removes heat from the various liquid cooled sources

eff_chiller $=.7$; $\quad$ \%from scott \%The cop of the

absorption chiller. COP = refrigeration effect / heat input, therefore I'm treating this as an efficiency

eff_AC $=2.0$; $\quad$ \%from scott \%The cop of the

electric AC unit for the baseline configuration. COP = refrigeration

effect / heat input, therefore I'm treating this as an efficiency

eff_gasifier $=.93$;

\%Eff of the gasifier in converting

biomass to syngas on a fuel calorific basis.

eff_eng_BrakeThermal = .333;

\%The Brake Thermal Efficiency of

the engine 
eff_eng_coolant_fraction $=.333 ; \quad$ \%The fraction of fuel energy that goes to the coolant

eff_Coal_to_Power = .3; \%The efficiency of the "Baseline" power generation scenario for a coal fired power plant, from the point of coal already at the power plant, to useable electrical energy at the end users building.

eff_NG_Furnace $=.93 ; \quad$ \%The efficiency of a conventional

Natural Gas furnace

\%Energy Inputs

power_fan_liquid $=.1 ; \quad$ \%The power in $\mathrm{kw}$ to run the fan to blow air accross the liquid heat exchanger.

power_fan_gas $=.1$; $\quad$ \%The power in $\mathrm{kw}$ to run the fan to

blow air accross the gaseous heat exchanger.

power_controller $=.05 ; \quad$ \%The power in kw to run the

controller network, including actuators, sensors, etc.

power_gasifier $=.1$; $\quad$ \%The power in $\mathrm{kw}$ to run the

gasifier including pumps, feeders, ash removal, etc.

power_pump $=.25$; $\quad$ \%The power in kw to run any

required liquid or gasous pumps.

\%Fuel Properties

C_coal = 100;

molecule of coal

C_NG = 1;

molecule of Natural Gas

LHV_coal $=33300$;

$\mathrm{KJ} / \mathrm{Kg}$

LHV_NG $=50000$;

Gas in $\mathrm{KJ} / \mathrm{Kg}$

LHV_wood = 14900;

$\mathrm{KJ} / \mathrm{Kg}$

MW_coal = 286;

MW_NG $=16$;

\author{
\%The number of Carbon atoms in 1 \\ \%The number of Carbon atoms in 1 \\ \%The lower heating value of coal in \\ \%The lower heating value of Natural \\ \%The lower heating value of wood in \\ \%Molecular weight of coal \\ \%Molecular weight of Natural Gas
}

$\%$ Conversions

demand_thermal_occupied $=$

demand_thermal_occupied*1.055*building_area/60/60;\%Converting the

thermal load from BTU/hr/ft^2 to kw

Pout_gasifier_min = Pout_gasifier_mean - Pout_gasifier_mean*turndown;

\%The minimum power level out of the gasifier in kw of syngas

Pout_gasifier_max = Pout_gasifier_mean + Pout_gasifier_mean*turndown;

\%The maximum power level out of the gasifier in kw of syngas

$\%$ Determine the appropriate thermal demands

if season == $1 \%$ Winter

demand_thermal = demand_thermal_occupied;

\%Demand thermal occupied is the thermal demand of the occupied space. Demand_thermal is the thermal demand coming out of the heat exchangers demand_electric_AC $=0$;

\%The electricity demand in the baseline case specifically for electric

air conditioning

elseif season $==0 \%$ Summer

$\%$ Requires correction... need to consider radiation from engine into $\%$ account.

demand_thermal $=$ demand_thermal_occupied / eff_chiller;

\%This computes the thermal demand out of the heat exchangers 
demand_electric_AC = demand_thermal_occupied / eff_AC;

\%The electricity used in the baseline configuration to cool the building

end

$\%$ Energy Calculations

\%compute total parasitic power that is needed to run the system parasitic_power = power_fan_liquid + power_fan_gas + power_controller + power_gasifier + power_pump;

\% Preallocating memories to variables total_heat_extracted $=$ zeros $(1$, length $($ demand_electric $))$;

\%Just initializing this parameter

Pin_electric=zeros(size(demand_electric));

Pout_trans=zeros (size (demand_electric));

Pin_conv=zeros (size(demand_electric));

heat_TransInvertConvert=zeros(size(demand_electric));

Pout_bat=zeros(size(demand_electric));

Pout_gen=zeros (size (demand_electric));

Pin_gen=zeros(size (demand_electric));

heat_BatGen=zeros(size (demand_electric));

Pout_eng=zeros (size(demand_electric));

Pin_eng=zeros (size (demand_electric));

heat_EngLiq=zeros(size(demand_electric));

heat_EngExh=zeros (size (demand_electric));

Pout_gasifier=zeros(size(demand_electric));

heat_boiler=zeros (size(demand_electric));

heat_boiler_exh=zeros(size(demand_electric));

Pin_gasifier=zeros(size(demand_electric));

heat_gasifier=zeros(size(demand_electric));

total_heat_available_liquid=zeros(size(demand_electric));

total_heat_available_exh=zeros(size(demand_electric));

total_heat_available_radiated=zeros (size(demand_electric)) ;

total_heat_available=zeros(size(demand_electric));

heat_gasifier_additional=zeros(size(demand_electric));

heat_boiler_additional=zeros(size(demand_electric));

eff_sys=zeros (size (demand_electric));

total_energy_in=zeros(size(demand_electric));

total_energy_in_btu=zeros(size(demand_electric));

Pin_coal_base=zeros (size (demand_electric));

Pin_NG_base=zeros(size (demand_electric));

Pin_NG =zeros(size(demand_electric));

eff_sys_baseline=zeros (size (demand_electric) );

total_energy_in_base=zeros(size(demand_electric));

total_energy_in_base_btu=zeros(size(demand_electric));

Pin_flare=zeros(size(demand_electric));

for $\mathrm{n}=1$ :length(demand_electric) \%This crazy little loop is used to determine when the building starts using grid power, if it is not at the point where the CHP is at it's max generation capability.

\%Energy flow through the Isolation Transformer subsystem

Pout_trans $(\mathrm{n})$ = demand_electric $(\mathrm{n})+$ demand_electric_AC + parasitic_power;

Pout_gen $(n)=$ (Pout_trans(n)/eff_transformer);

if Pout_gen $(n)>=$ max_gen

Pout_gen $(n)=$ max_gen; 


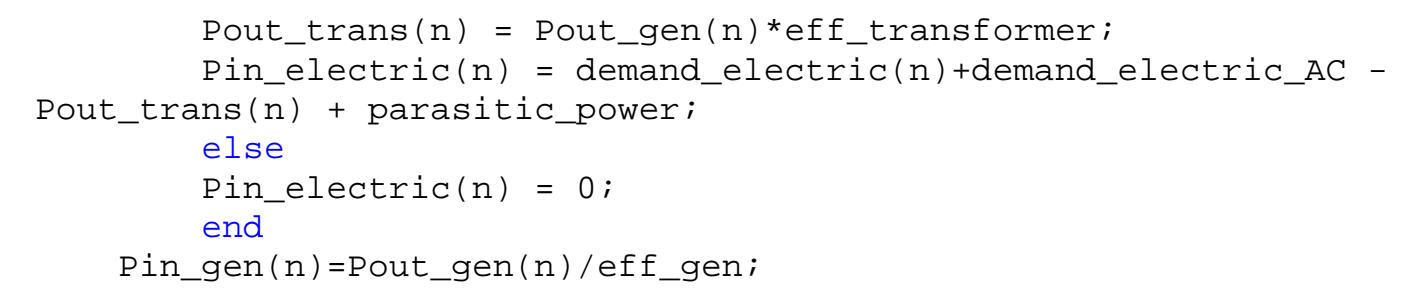

\%Energy flow through the Engine subsystem

Pout_eng $(n)=$ Pin_gen $(n)$;

Pin_eng $(n)=$ Pout_eng $(n) /$ eff_eng_BrakeThermal;

heat_EngLiq $(n)=$

(Pin_eng $(n){ }^{*}$ eff_eng_coolant_fraction)*eff_CoolantHeatExch ;

heat_EngExh $(n)=$ Pin_eng $(n) *(1$ - eff_eng_coolant_fraction -

eff_eng_BrakeThermal)*eff_EngExhHeatExch;

\%Determining the supplimental or excess fuel quantities on the

electrical production side

if Pin_eng $(n)<$ Pout_gasifier_min

Pin_NG $(n)=0$;

Pout_gasifier $(n)=$ Pin_eng $(n)$;

Pin_flare $(n)=$ Pout_gasifier_min - Pin_eng $(n)$;

heat_boiler $(n)=$ Pin_flare $(n)^{*}$ eff_boiler;

heat_boiler_exh $(n)=$ (Pin_flare $(n)$ -

heat_boiler $(n))^{*}$ eff_EngExhHeatExch;

elseif Pin_eng $(n)>$ Pout_gasifier_max

Pin_NG $(n)=$ Pin_eng $(n)$ - Pout_gasifier_max;

Pout_gasifier $(\mathrm{n})$ = Pout_gasifier_max;

heat_boiler $(n)=0$;

heat_boiler_exh(n) $=0$;

else

Pin_flare $(n)=0$;

Pout_gasifier $(n)=$ Pin_eng $(n)$;

Pin_NG $(n)=0$;

heat_boiler $(\mathrm{n})=0$;

heat_boiler_exh $(\mathrm{n})=0$;

end

Pin_flare $(\bar{n})=0$;

\%First cut at Total heat extracted

total_heat_available_liquid(n) = heat_EngLiq(n) + heat_boiler $(n)$;

total_heat_available_exh $(n)=$ heat_EngExh(n) + heat_boiler_exh $(n)$;

total_heat_extracted $(n)=$ total_heat_available_liquid $(n)+$

total_heat_available_exh(n);

\%Determining the supplimental fuel quantities on the thermal

production side

if demand_thermal > total_heat_extracted(n)

heat_boiler_makeup $=$ (demand_thermal - total_heat_extracted $(n))$;

if Pin_eng $(n)$ < Pout_gasifier_max \%Additional syngas is

available for boiler

if heat_boiler_makeup/eff_EngExhHeatExch <=

Pout_gasifier_max - Pin_eng(n)-Pin_flare $(n)$;

Pin_flare $(n)=$ Pin_flare $(n)$ theat_boiler_makeup /

eff_EngExhHeatExch;

\%Note, this will also add NG heat in

the summer for chilling, but this could be done much more efficiently 


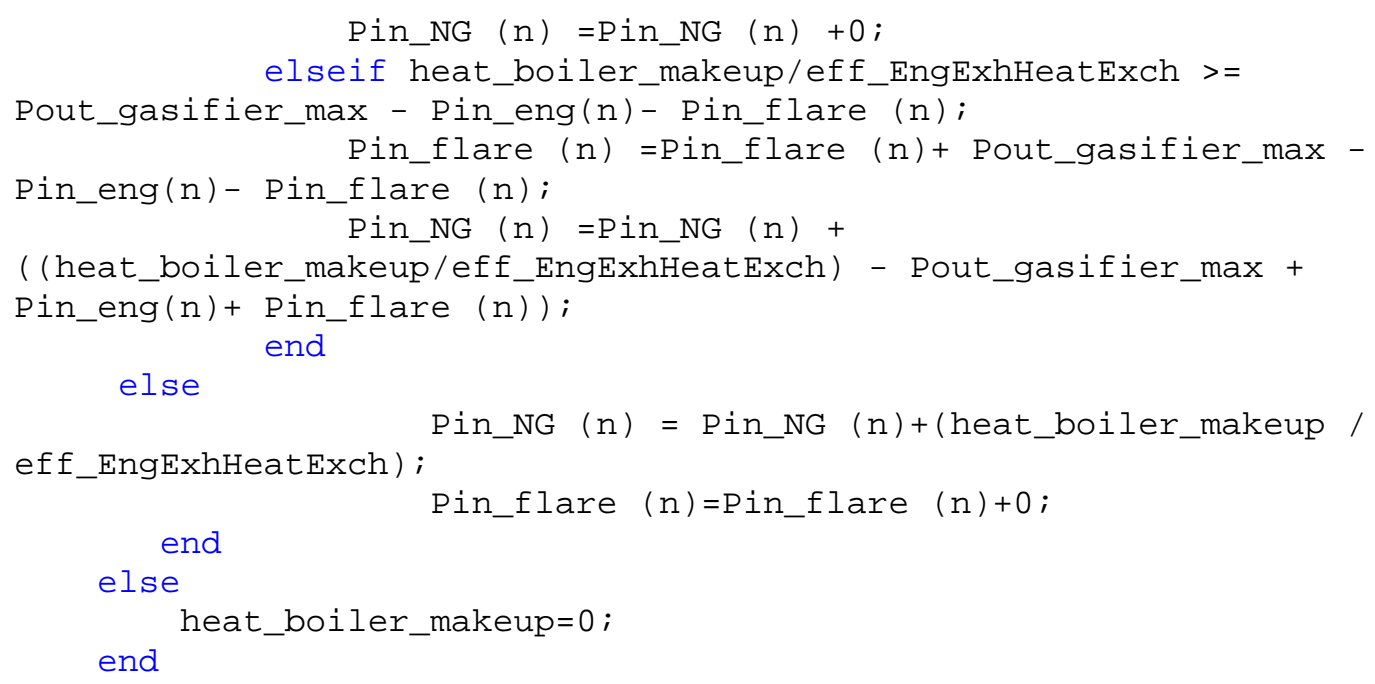

end

end 


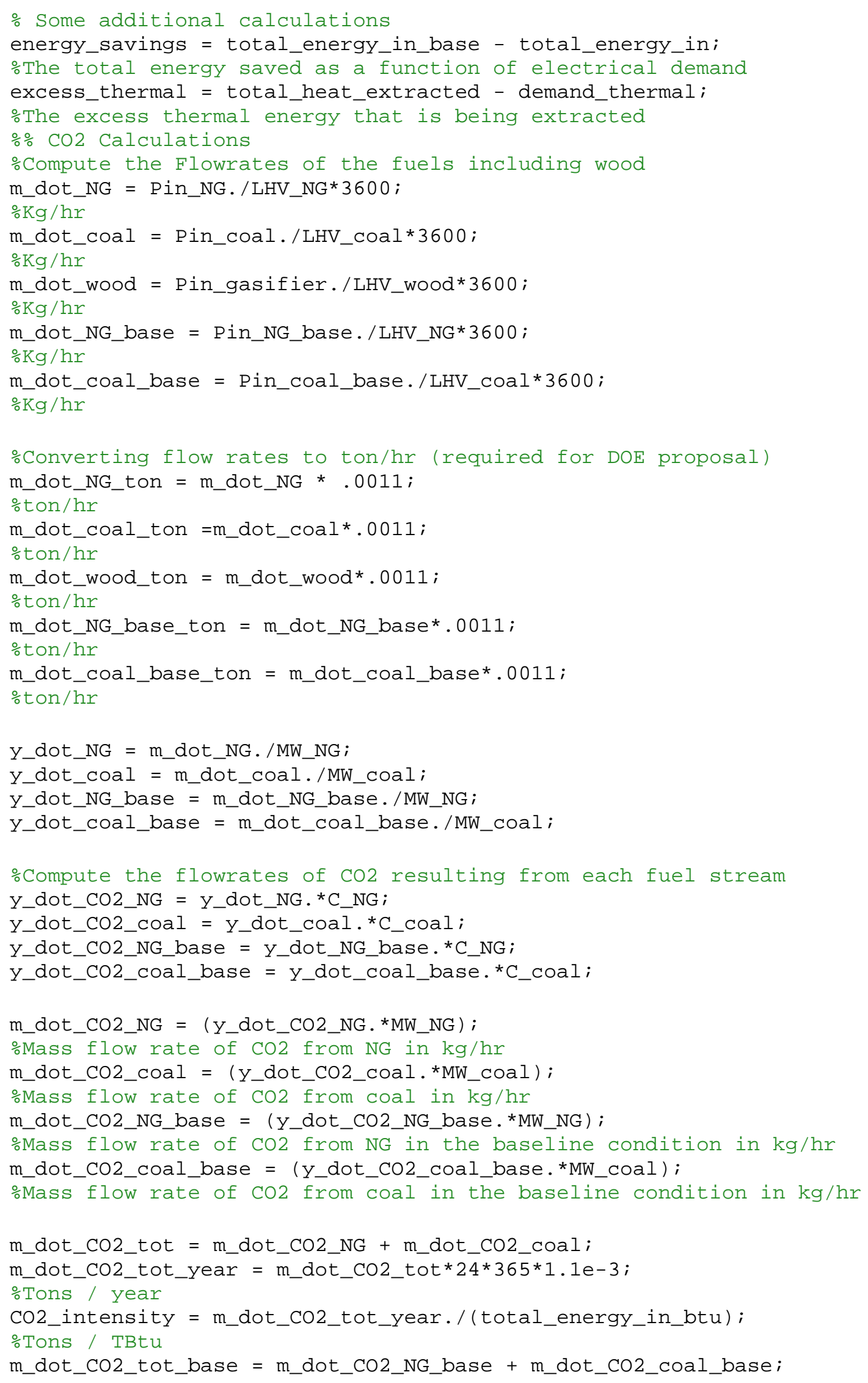




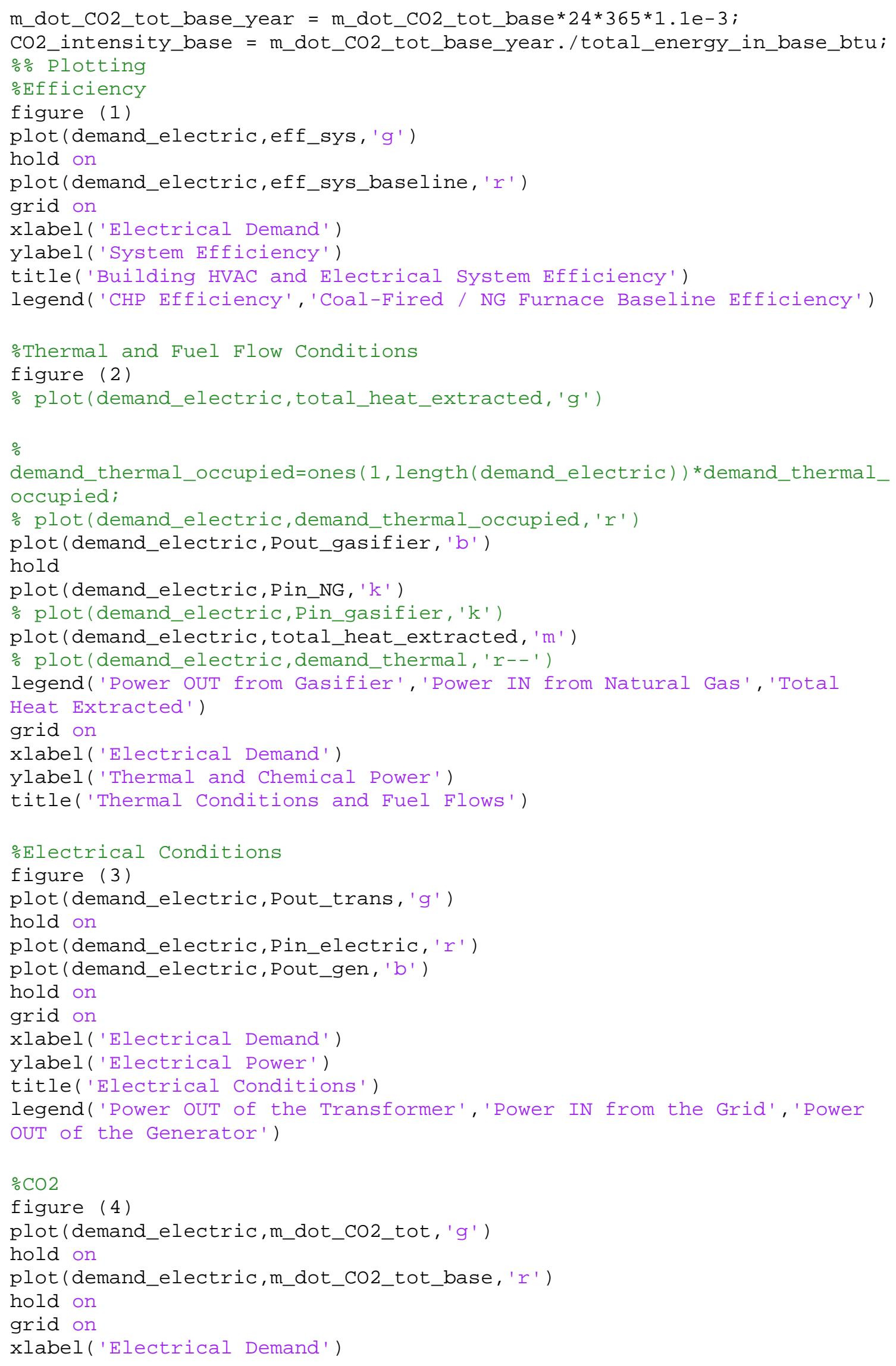




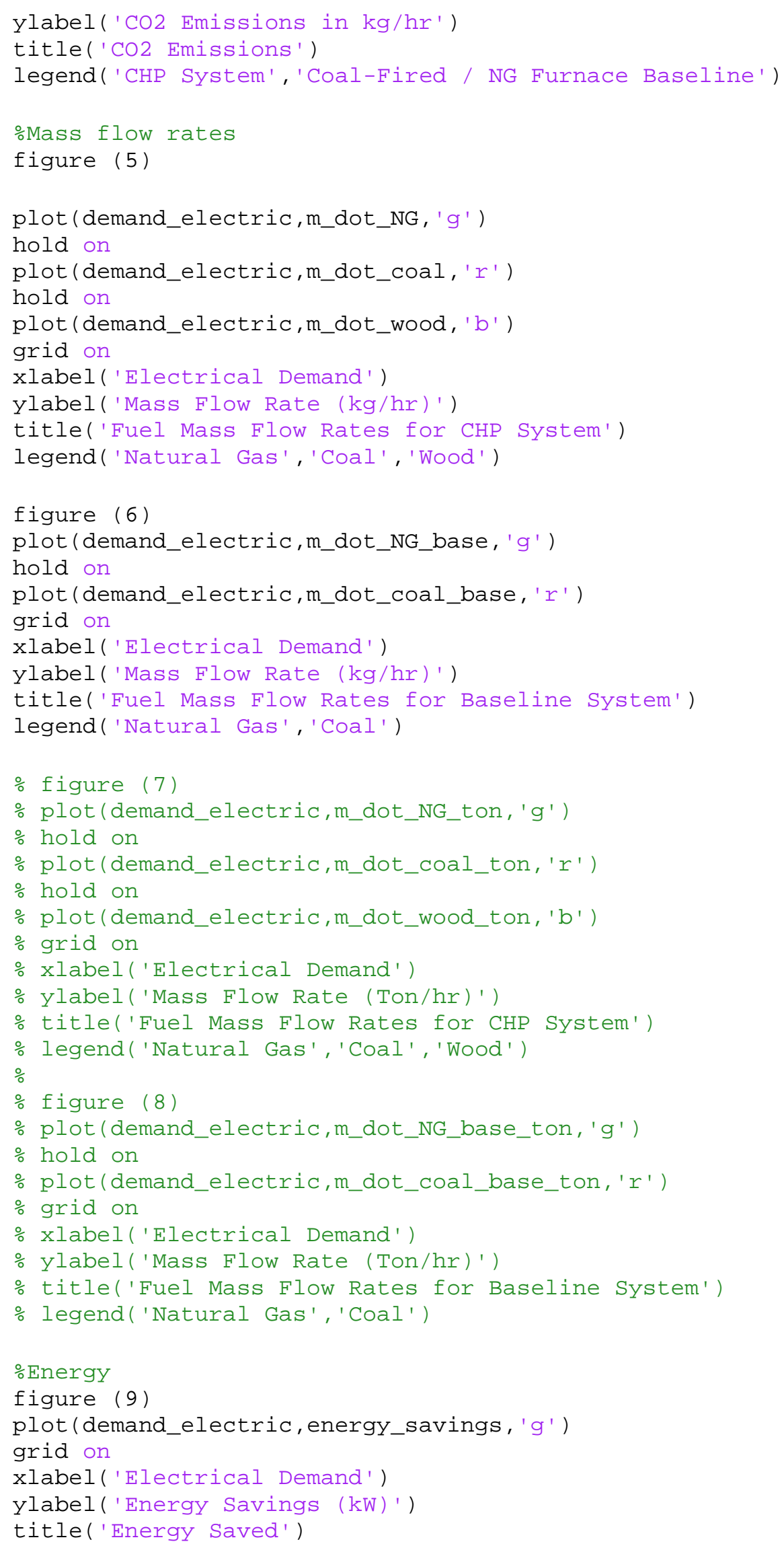


$\%$ Limitations

$\%$ this code currently does not account for any net exporting of heat or $\%$ power

\%this code does not currently have control logic to determine if the system

\%should be operated differently to make more or less heat or power. $\%$ Assumptions

\%1. All of generator loss is in the form of heat, and is captured by the

\%cooling system... radiative heat losses are negligible.

\%3. All coolant and exhaust pipes are well insulated, and loose no heat to \%the surroundings.

\%4. To simplify modeling the engine exhaust and flare gas boiler exhaust

\%are assumed to pass through separate heat exchangers. In practice these

\%may be combined to use a single heat exchanger.

\%6. If additional heating is required, and the gasifier is operating at \%full load, then NG will flow to the flare gas boiler.

\%7. Assume all combustion is stoichiometric

\%8. Assume all energy coming from biomass sources is c02 nuetral, so only

\%the combustion of coal and NG produces $\mathrm{C0} 2$. 


\section{Appendix B: EES program for thermodynamic analysis of the Thermal Loop}

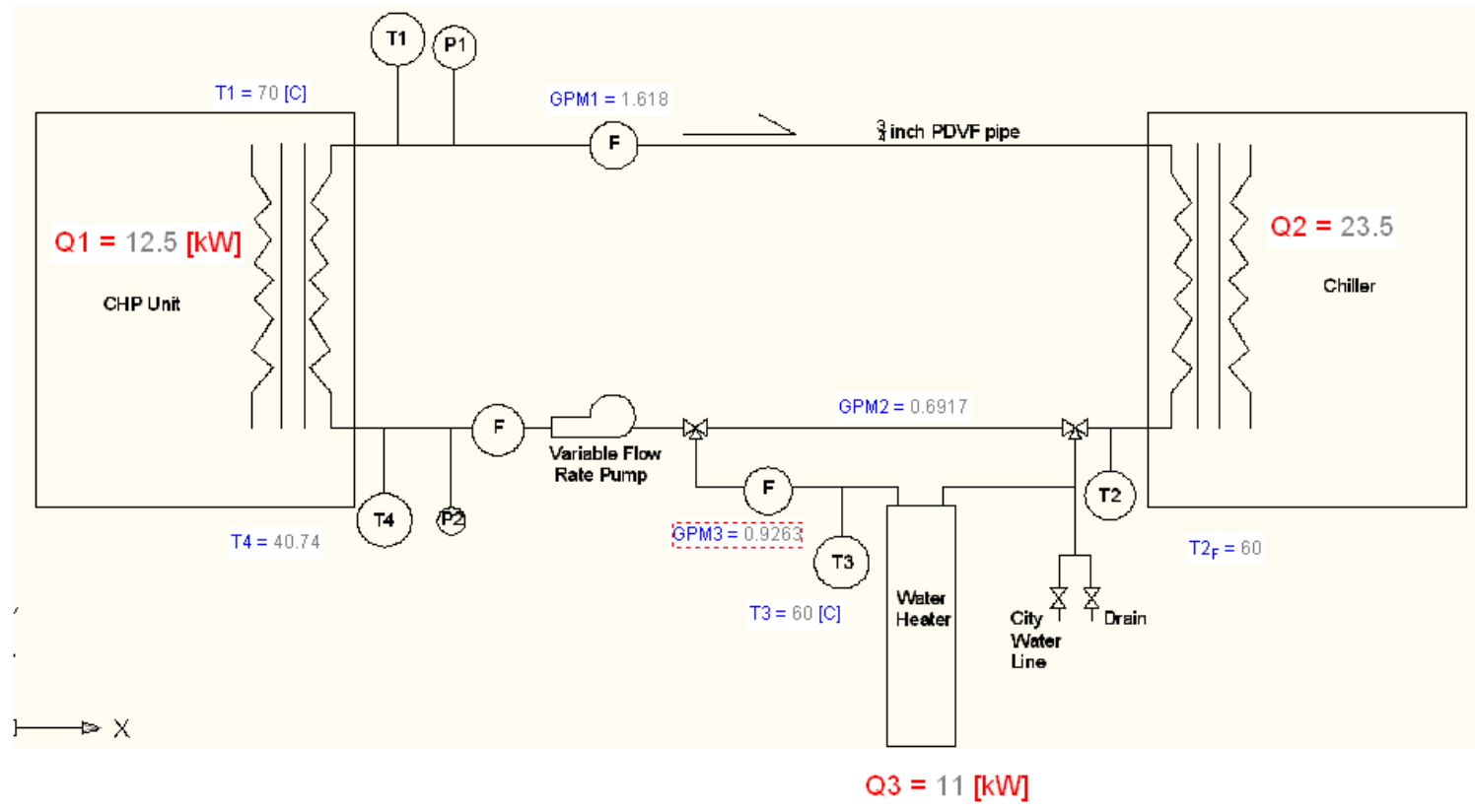

Figure 7.1: EES Diagram Window

EES Equation Window is as follows:

\{Final model of thermal loop for micro-CHP project in EES

"General equations governing the flow through the thermal loop"

"Intial Values"

Q3=11[kW]

$\mathrm{Q} 1=12.5[\mathrm{~kW}]$

"Standard Water heater capacity"

$\mathrm{C}=4.18\left[\mathrm{~kJ} / \mathrm{kg}^{*} \mathrm{C}\right]$

"CHP thermal o/p value"

Ploop $=300[\mathrm{kPa}]$

"specific heat of water"

"Temp Calculations"

T3=60 "T3 temperature can be set at the water heater. Due to 50 gallon capacity of the water heater and relatively low flow rate of water into the water heater, water coming out of the heater will have a constant temperature preset at the water heater."

T2=15 "T2 temperature can be set at Chiller, since chiller is $30 \mathrm{~kW}$ and CHP produces only $12.5 \mathrm{~kW}$, we will have all the heat produced by the chiller absorbed at chiller heat exchanger"

T1=70 "Desired temperature at entry of the CHP HE. This value is set by the user"

"mass balance"
$\mathrm{m} 3+\mathrm{m} 2=\mathrm{m} 1$

"Power calculations" 
$\mathrm{Q} 1=\mathrm{m} 1 *(\mathrm{~h} 1-\mathrm{h} 4)$

$\mathrm{Q} 2=\mathrm{m} 1 *(\mathrm{~h} 1-\mathrm{h} 2)$

$\mathrm{Q} 3=\mathrm{m} 3^{*} \mathrm{c}^{*}(\mathrm{~T} 3-\mathrm{T} 2)$

$\mathrm{Q} 2=\mathrm{Q} 1+\mathrm{Q} 3$

\author{
"Enthalphy Calculations" \\ h1=enthalpy(water, $\mathrm{T}=\mathrm{T} 1, \mathrm{P}=\mathrm{Ploop})$ \\ $\mathrm{h} 2=$ enthalpy(water, $\mathrm{T}=\mathrm{T} 2, \mathrm{P}=$ Ploop) \\ h4=enthalpy(water, $\mathrm{T}=\mathrm{T} 4, \mathrm{P}=\mathrm{Ploop}$ ) \\ "Converting flowrates from $\mathrm{kg} / \mathrm{s}$ to GPM" \\ GPM1 $=m 1 * 15.8402[\mathrm{GPM}]$ \\ $\mathrm{GPM} 2=\mathrm{m} 2 * 15.8402[\mathrm{GPM}]$ \\ $\mathrm{GPM} 3=\mathrm{m} 3 \star 15.8402[\mathrm{GPM}]$
}

h3=(Q2+m3*h2)/m3"Applied energy balance on CV water heater" 


\section{Appendix C: Pump description}

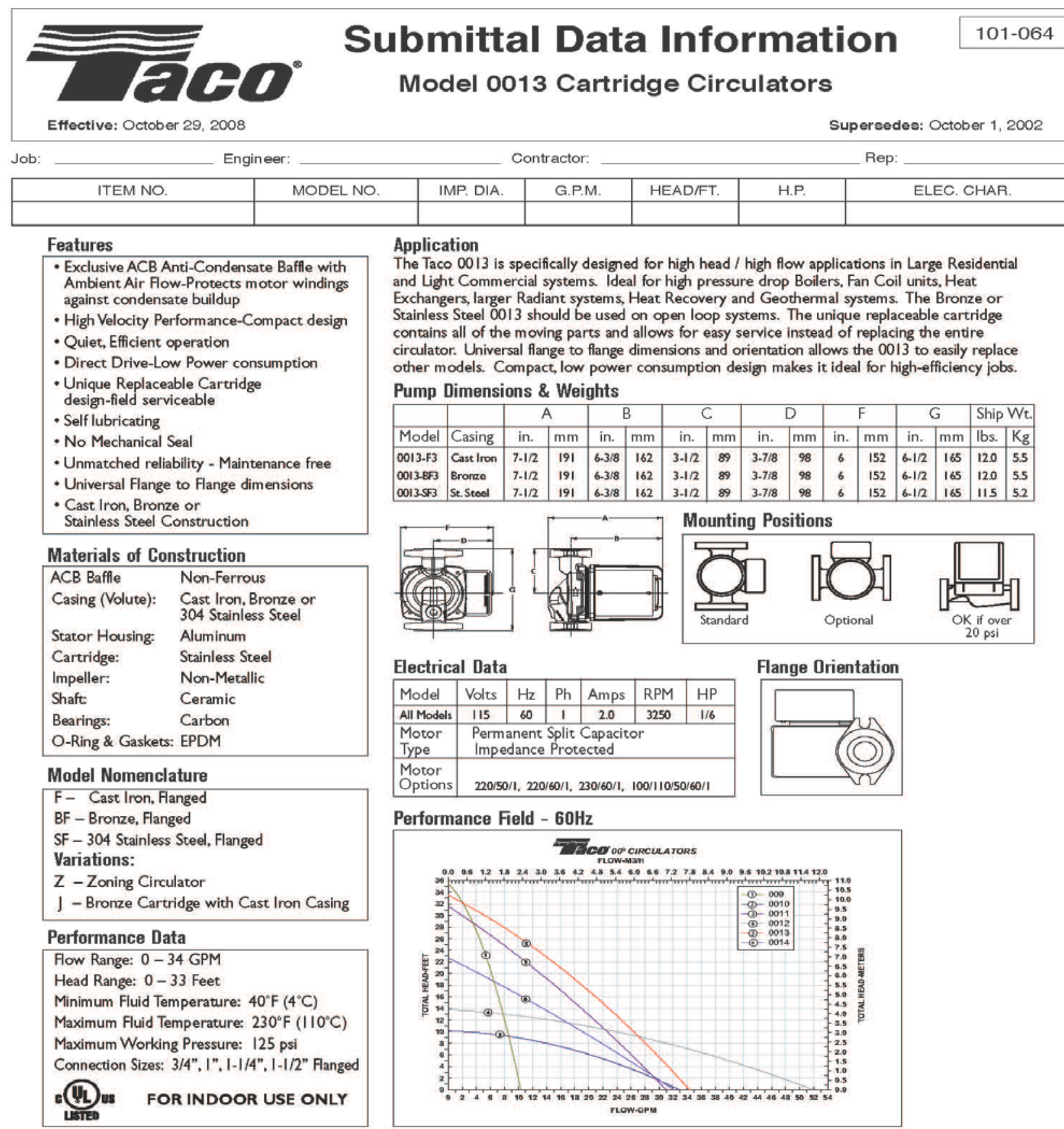

\section{Do it Once. Do it Right. ${ }^{\circledR}$}

TACO INC., 1160 Cranston Street, Cranston, RI 02920 Telephone: (401) 942-8000 Fax: 942-2360 Visit our website at: www.taco-hvac.com 


\section{Appendix D: Lambda Sensor technical data}

Lambda Measurement Modules

LA4 - Lambda Meter

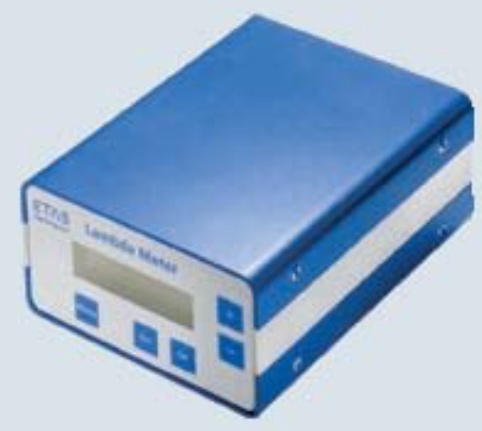

Lambata Meter LA4

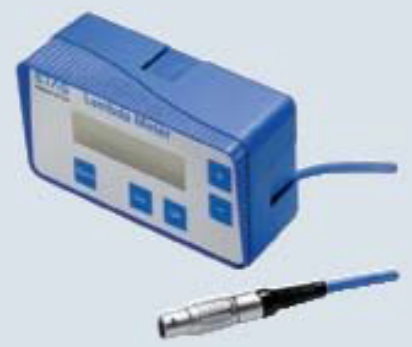

External LC-Dispby for Lambda Meter

\section{Applications}

The Lambda Meter LA,4 is ETAS' high-precision measuring device for emission levels. It perm its cost-effective exhaust gas measurements on gasoline, diesel, and gas engines - each optimized by using fuetspecific cha racteristic curves.

The Lambola heter is optimized for use with the Bosch broad-band Lambda Sercor LU. The LU sensor is in stalled as an additional measurement sensor in the exhaust system. This lets you determ ine la mbda values, oxygen content, and A.f ratio as well as internal resis. tance, pump cument, and heater voltage of the Lambda Sersor.

The La.4 allows connection to the senso rs LSU 4.2, LSU 4.7 and LU 49 . The different sensors a re easily adapted using switchable intemal resistances. LUU sersors with manufacturer-specific connectors areeasy to integrate. You can order the La.4 including the La mbda Sersor LU 4.2 or with the Lambda Sensor LUU 49.
Functionsat a Glance

- Uofide measurement range of lambda, oxygen content and air/ fuel ratio

- Fast measurement-readines thanks to the sensor's short warm-up time

- Rapid resporse of the measurement system to exhaust gas changes

- Analog output of the physical value iparameter setting

- Supported by the INCA measurement and calibration system

- Download of characteristic curves for specific fuek

- Analytic cakulation

- Uke of different fuek iH,,$O C$ ratiol

- Adapts to air pressure, air temperature, and air humidity

- Compensation for sensor diffusion or aging

- Suitable for usewith BOSCH LSU 4.2, LSU4.7, and

LU 4.9

Additional display awailable 
Technical Data

LA4 - Lambda Meter

\section{Block Diagram}

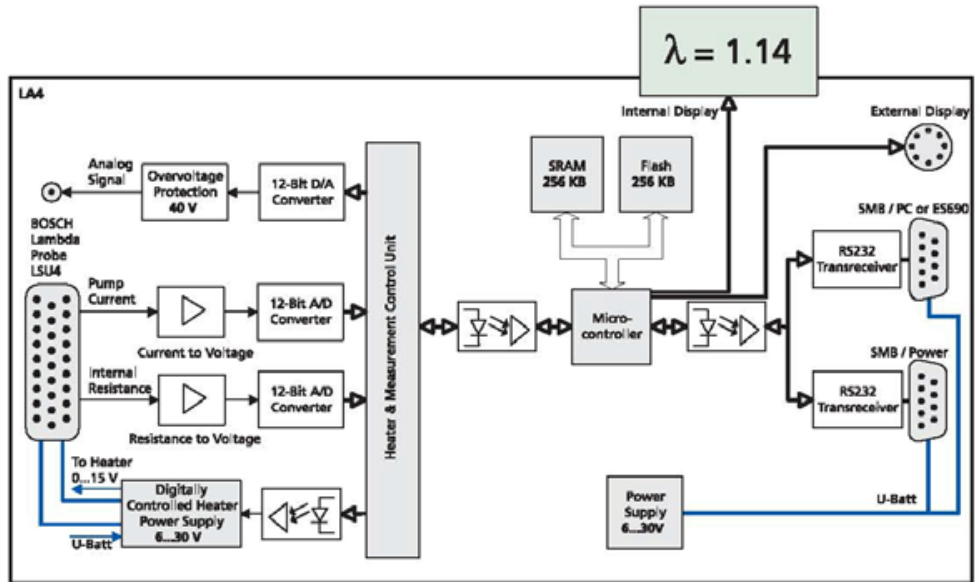

\begin{tabular}{lll}
\hline Item & Characteristics & Features \\
\hline General & Dimensions (H/W/D) & $60 \times 120 \times 155 \mathrm{~mm} / 2.4 \times 4.7 \times 6.1 \mathrm{in}$ \\
& Weight & $1125 \mathrm{~g} / 2.48 \mathrm{lbs}$ \\
& Temperature range & $-40^{\circ} \mathrm{C}$ to $+80^{\circ} \mathrm{C} /-40^{\circ} \mathrm{F}$ to $+176^{\circ} \mathrm{F}$ \\
& & $-25^{\circ} \mathrm{C}$ to $+75^{\circ} \mathrm{C} /-13^{\circ} \mathrm{F}$ to $+167^{\circ} \mathrm{F}$ (display) \\
\hline Power supply & Operating voltage & $6 \mathrm{~V}$ to $30 \mathrm{VDC}$, reverse voltage protected \\
& Current consumption & $400 \mathrm{~mA}$ at $12 \mathrm{~V}$ \\
\hline Lambda Sensor & Input voltage & $6 \mathrm{~V}$ to $30 \mathrm{~V} \mathrm{DC}$, reverse-voltage protected \\
heating & Max. current consumption & $5 \mathrm{~A}$ \\
& Heating & Integrated heating control via digital PID controller \\
\hline Sensor connection & Supported sensor types & $80 \Omega, 100 \Omega, 200 \Omega, 250 \Omega$ and $300 \Omega$ \\
& Sensor cable & Universal code 1 plug, K113 (other types available \\
& & on request) \\
& Pumped reference (LSU 4.9) & $0 \mu \mathrm{A}$ to $100 \mu \mathrm{A}$ \\
\hline Inputs & Lambda Sensor LSU; Measuring & $\pm 1.5 \%$ (depending on sensor) \\
& accuracy &
\end{tabular}




\title{
Technical Data
}

\author{
LA4 - Lambda Meter
}

\begin{tabular}{|c|c|c|}
\hline Item & Characteristics & Features \\
\hline \multirow[t]{5}{*}{ Measuring ranges } & Lambda & $\begin{array}{l}\text { LSU } 4.2 \text {, LSU } 4.7: 0.7 \text { to } 32.767 \\
\text { LSU } 4.9(300 \Omega): 0.65 \text { to } 16\end{array}$ \\
\hline & $\mathrm{O}_{2}$ & $0 \%$ to $24.41 \%$ \\
\hline & Air/Fuel ratio & $\begin{array}{l}\text { LSU } 4.2 \text {, LSU } 4.7: 10.29 \text { to } 327.67 \\
\text { LSU } 4.9(300 \Omega): 9.56 \text { to } 235.2\end{array}$ \\
\hline & Internal resistance of $\lambda$-sensor & $0 \Omega$ to $1 \mathrm{k} \Omega$ \\
\hline & Transient time measuring system & 2 ms cycle time \\
\hline \multirow[t]{2}{*}{ Outputs } & Analog output & $\begin{array}{l}0 \mathrm{~V} \text { to } 8.2 \mathrm{~V} \text { (parameter setting), Short-circuit-proof } \\
\text { and extraneous-voltage protected up to } 40 \mathrm{~V} \\
\text { Output resistance } 2 \mathrm{k} \Omega\end{array}$ \\
\hline & Serial interface & $\begin{array}{l}\text { V24 (RS232), } 38400 \text { Baud, cascadable with other } \\
\text { devices }\end{array}$ \\
\hline User interface & $\begin{array}{l}\text { Display } \\
\text { Membrane keyboard }\end{array}$ & $\begin{array}{l}\text { 8-digit back-lit LCD with contrast control } \\
\text { Configuration of module's options }\end{array}$ \\
\hline \multirow{2}{*}{$\begin{array}{l}\text { External display } \\
\text { (optional) }\end{array}$} & Dimensions (H/W/D) & $62 \times 119 \times 48 \mathrm{~mm} / 2.4 \times 4.7 \times 1.9 \mathrm{in}$ \\
\hline & Weight & $230 \mathrm{~g} / 0.51 \mathrm{lbs}$ \\
\hline
\end{tabular}




\section{Appendix E: Pump wiring and DIP switch settings}

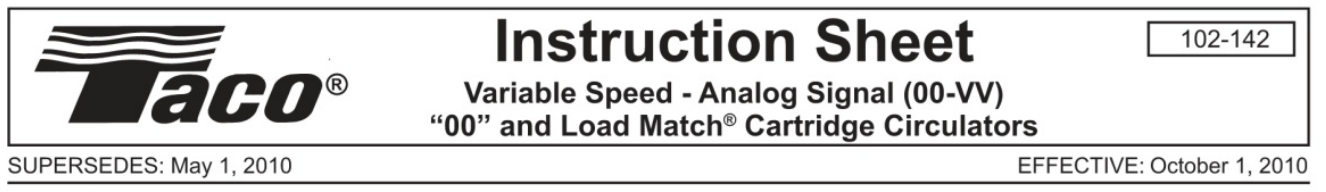

Plant ID\# 001-3810

The Variable Speed - Analog Signal "00" Cartridge Circulator (00-VV) is a microprocessor-based pump designed to operate at different speeds based on an analog voltage signal input. Its ease of installation and operation allows for a wide variety of HVAC applications, such as maintaining a pressure differential or a setpoint temperature.

\section{Sequence of Operation}

Whenever the $00-\mathrm{VV}$ is powered up, the green power LED turns on and the pump operates based on an analog input signal. The percent output (\% OUT) LED flashes at different rates based on the speed of the pump. As the \% OUT LED flashes faster it indicates a faster speed of the pump. A fully on LED indicates the pump is at $100 \%$ capacity.

\section{Output Characteristic (DIP switch 1)}

The 00-VV accepts an analog signal in order to drive the pump at different speeds. The pump speed may be selected to change linearly or based on equal percentage characteristic. The output characteristic is selected via DIP switch 1.

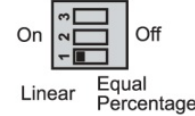

Linear Characteristic

The linear output characteristic assumes there is a linear relationship between percent of flow of the pump and heat output of the terminal unit. Linear operation is typically used in applications in which the pump injects into a constant circulating loop, which includes the terminal unit.

Equal Percentage Characteristic

The equal percentage output characteristic assumes there is a non-linear relationship between percent of flow of the pump and heat output of the terminal unit. In order to achieve the desired linear output, the 00-VV provides an equal percentage output. Equal percentage operation is typically used in applications in which the pump injects directly into the terminal unit.
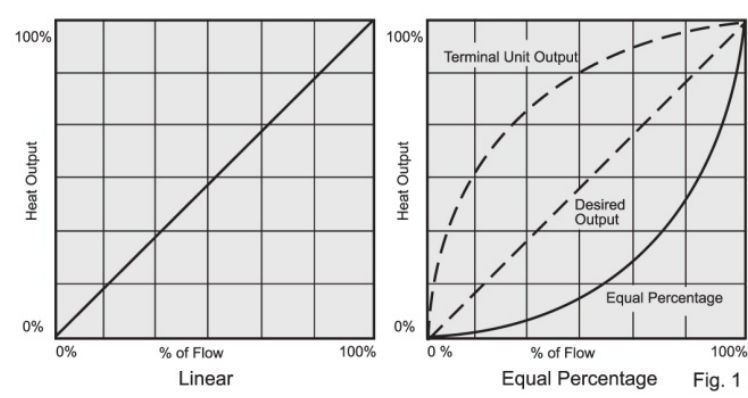

\section{Analog Signal (DIP switch 3)}

The control accepts either a 0-10 V (dc) or 2-10 V (dc) signal. The signal range is selectable via the DIP switch number 3 . Once a signal is applied, the pump speed varies based on the selected output characteristic.

$0-10 \mathrm{~V}(\mathrm{dc}) / 0-20 \mathrm{~mA}$

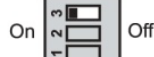

$2-10 \vee(d c) \quad 0-10 \vee(d c)$ when a $10 \mathrm{~V}(\mathrm{dc})$ signal is present.

If a 0-20 mA signal is used, install the $500 \mathrm{ohm} 1 / 4 \mathrm{~W}$ resistor across the (+) and (-) terminals as shown in figure 2 . Whenever the signal is $0 \mathrm{~mA}$, the percent speed output of the pump is $0 \%$, and it increases to $100 \%$ when a $20 \mathrm{~mA}$ signal is present.

2-10 V (dc) / 4-20 mA

Whenever $2 \mathrm{~V}(\mathrm{dc})$ is present, the control operates the pump at $0 \%$ and it increases to $100 \%$ whenever $10 \mathrm{~V}$ (dc) signal is present. If a 4-20 mA input signal is used, install the $500 \mathrm{ohm} 1 / 4 \mathrm{~W}$ resistor across the (+) and (-) terminals as shown in figure 2 . Whenever a 4 $\mathrm{mA}$ signal is present the pump operates at $0 \%$ output and it increases to $100 \%$ whenever $20 \mathrm{~mA}$ signal is present.

Manual / Automatic Operation (DIP switch 2)

The 00-VV allows the user to manually turn on the pump at full flow without an analog signal. This function is enabled by switching the DIP switch number 2 on.

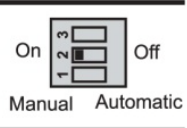

\section{Exercising}

Manual Automatic

During long periods of no operation, the $00-\mathrm{V}$ is designed to exercise for 10 seconds every 3 days of no operation in order to prevent precipitate build-up in the pump. The \% OUT LED turns on during the exercising function. 
Wiring and Troubleshooting

WARNING: Wiring connections must be made in accordance with all applicable electrical codes.

CAUTION: To prevent electrical shock, disconnect electric power to system at main fuse or circuit breaker box until installation is complete. When a service switch is installed, more than one disconnect switch may be required to deenergize this device for servicing.

\section{Powering the Pump}

Insert the line voltage wires through the knockout of the enclosure and connect the Live wire to the $\mathrm{H}$ terminal and the Neutral wire to the $\mathrm{N}$ terminal. Ensure that no power is present during this process.

For your safety and protection of permanent damage to the microprocessor, this PC board includes a fuse wire. If the fuse wire blows, contact a Taco representative. Once power is applied, the power LED is turned on.

\section{Analog Signal}

$0-10 \mathrm{~V}(\mathrm{dc})$ or $2-10 \mathrm{~V}(\mathrm{dc})$

Connect the positive line of the analog signal into the $(+)$ terminal and the negative wire into the $(-)$ terminal.

To test the voltage input signal place a voltmeter between the $(+)$ and (-) terminals.

0-20 mA or 4-20 mA

Connect the positive line of the analog signal into the $(+)$ terminal and the negative wire into the (-) terminal. Connect the $500 \mathrm{ohm} 1 / 4 \mathrm{~W}$ resistor across the $(+)$ and $(-)$ terminals.

To test the current input signal, place an ammeter in series between the

$(+)$ terminal and the positive wire from the signal control.

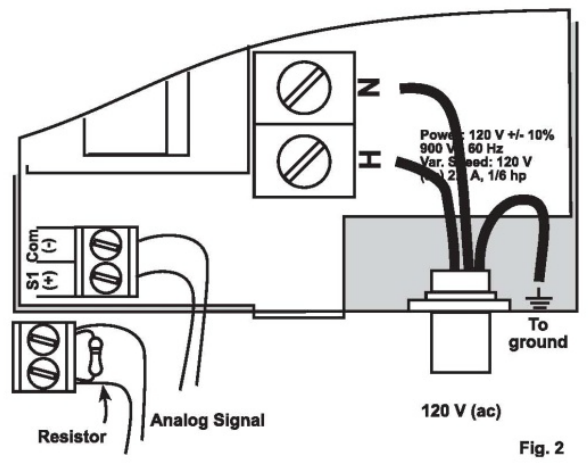

\section{APPLICATION}

1. Maximum operating pressure: $125 \mathrm{psi}(862 \mathrm{kPa})$ on all " 00 " Series Circulators, 200 psi (1379 kPa) on all LoadMatch Circulators.

2. Maximum water temperature not to exceed nameplate rating

3. Cast iron circulators are to be used for closed loop systems. Bronze circulators are to be used for open loop, fresh water, or potable water systems.

4. Taco Cartridge circulator pumps are for indoor use only - employer uniquement a l'interieur.

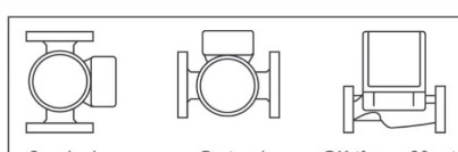

Optional

\section{INSTALLATION}

1. Mounting position - Circulator must be mounted with the motor in a horizontal position. It may be mounted vertically with the motor up, provided that the system pressure is at least $20 \mathrm{psi}(138 \mathrm{kPa})$.

2. Rotating body - Body has an arrow on the front that indicates direction of flow. To rotate body, remove the four body bolts, rotate body and replace bolts. Make sure that the junction box is NOT located underneath the circulator. (The junction box must NOT be located in the 6 o'clock position, as viewed from the motor end.)

3. Electrical connections - Observe all applicable codes when connecting to power supply. The motor is impedance protected, and does not require overload protection. The pump cannot run backwards.

WARNING: Do not use in swimming pool or spa areas; pump has not been investigated for this application.

WARNING: In the event the retaining screws have been pulled out of the housing, DO NOT replace them. Use of any other screw may short out the stator windings, creating a risk of electrical shock.

CAUTION: When installing electrical connections, do not apply mechanical loads to the capacitor box; otherwise, retaining screws may be pulled out of the housing, making circulator unusable.

CAUTION: Installations at higher elevations over $\mathbf{5 0 0 0}$ feet must have higher fill pressure of $\mathbf{2 0}$ psi to prevent pump cavitation and flashing. Premature failure may result. Adjust expansion tank pressure to equal fill pressure. A larger size expansion tank may be required. 
4. Fill system with tap water - The system must be filled before operating the circulator. The bearings are water lubricated and should not be allowed to operate dry. Filling the system will result in immediate lubrication of the bearings. It is always good practice to flush a new system of foreign matter before starting the circulator.

5. Circulator operation - Operate the circulator for 5 minutes immediately after filling system to purge remaining air from the bearing chamber. This is especially important when installing the circulator during the off-season.

\section{CAUTION: 1. The addition of petroleum based fluids or certain chemical additives to systems utilizing TACO equip- ment voids the warranty. \\ 2. Use supply wires suitable for $90^{\circ} \mathrm{C}-\mathrm{ATTENTION}$ : Employer des fils d'alimentation adequats pour $90^{\circ} \mathrm{C}$. \\ WARNING: To avoid electrical shock, disconnect the power supply to the circulator and the main electrical unit.}

\section{REPLACING CARTRIDGE ASSEMBLY}

1. Disconnect the electrical supply.

2. Reduce system pressure to $0 \mathrm{psi}$ and allow system to return to room temperature. Isolate the circulator by closing the service valves or draining the system.

3. Remove the body bolts and swing motor assembly away from the body.

4. Pull cartridge out of the motor housing.

5. Install replacement cartridge, making sure that the cover plate is between the cartridge flange and motor.

6. Make sure the replacement cartridge corresponds to the full circulator product number. A complete parts list is available from your local plumbing supply wholesaler.

7. Reassemble the circulator using the new gasket and bolts supplied.

8. Follow the "Installation" procedure to start up the circulator.

REPLACING INTEGRAL FLOW CHECK (IFC) ASSEMBLY (if applicable)

1. Disconnect the electrical supply.

2. Reduce system pressure to $0 \mathrm{psi}$ and allow system to return to room temperature. Isolate the circulator by closing the service valves or draining the system.

3. Remove the body bolts and swing motor assembly away from the body.

4. Remove IFC, using needle nose pliers.

5. Install replacement IFC by pressing valve into casing until it is firmly seated.

6. Reassemble the circulator using the new gasket and bolts supplied.

7. Follow the "Installation" procedure to start up the circulator.

REPLACING CIRCUIT BOARD

1. Disconnect the electrical supply and all field wiring to the circuit board.

2. Unplug the 3-pin plastic connector that connects the motor to the circuit board

3. Bend the lip of the capacitor base to ease the removal of the circuit board. Pull the circuit board up and out.

4. Reverse directions to install the new circuit board.

\section{Notes}




\section{Appendix F: Belimo Three way, Characterized Control Valve}

BELIMO

B3 Serles, Three Way, Characterlzed Control Valve

Stalnless Steel Ball and Stem

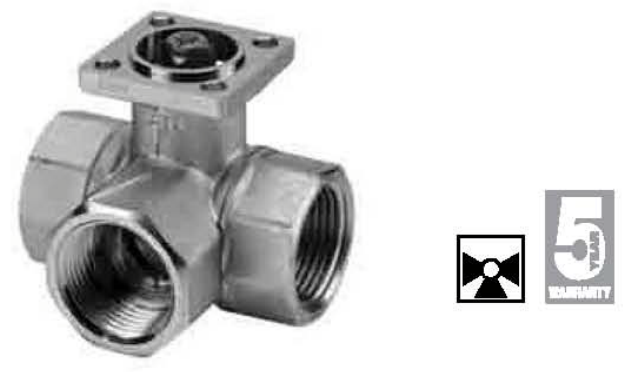

\section{Toctinleal Data}

Service

Flow characterlstlo

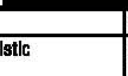

chilled or hot water, $60 \%$ glycol

A-port equal percentage

B-port modified for constant common port

\begin{tabular}{l|l} 
& flow \\
\hline Actlon & $90^{\circ}$ rotation \\
\hline Sizes & $12^{\prime \prime}, z^{\prime \prime}, 1^{\prime \prime}, 14^{\prime \prime}, 1 K^{\prime \prime}, 2^{\prime \prime}$ \\
\hline Type of end fitting & NPT fomale ends \\
\hline Materlals: &
\end{tabular}

Materlal

Body
Ball
Stem
Seats

Seats

Characterlzing disc

Packlng

Body Pressure rating

$600 \mathrm{psi}$

Medla temp. range

Close off pressure

200 psi

Maximum different

pressure $(\Delta P)$

Leakage

Cr rating

TotzeP is a regicterad trad amark of DuPont

\section{Dimerelare}
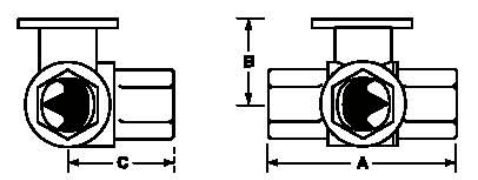

Valve Nominal siza

Vahe Bady Inehes DK [mm]

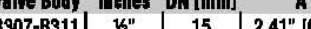

\begin{tabular}{l|l|l|} 
B312-B315 & $y_{2 \prime \prime}^{\prime \prime}$ & 15 \\
B317-B320 & $y_{4 \prime \prime}$ & 20 \\
& & 25
\end{tabular}

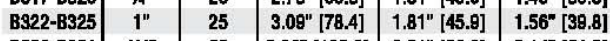

\begin{tabular}{l|l|l|l|l|l} 
B329-B331 & $1 K^{\prime \prime}$ & 32 & $3.96^{\circ}[100.6]$ & $2.21^{\prime \prime}[56.2]$ & $2.14^{\prime \prime}[54.3]$
\end{tabular}

\begin{tabular}{|c|c|c|c|c|c|}
$B 338-B 341$ & $11 \kappa^{\prime \prime}$ & 40 & $4.39^{\circ}[111.6]$ & $2.45^{\prime \prime}[62.2]$ & $2.33^{\prime \prime}[59.1]$ \\
\hline
\end{tabular}

\section{Application}

This valve is typically used in air handling units on heating or cooling coils, and fan coil unit heating or cooling coils. Some other common applications include Unit Ventilators, VAV box re-heat coils and bypass loops. This valve is suitable for use in a hydronic system with variable or constant flow.
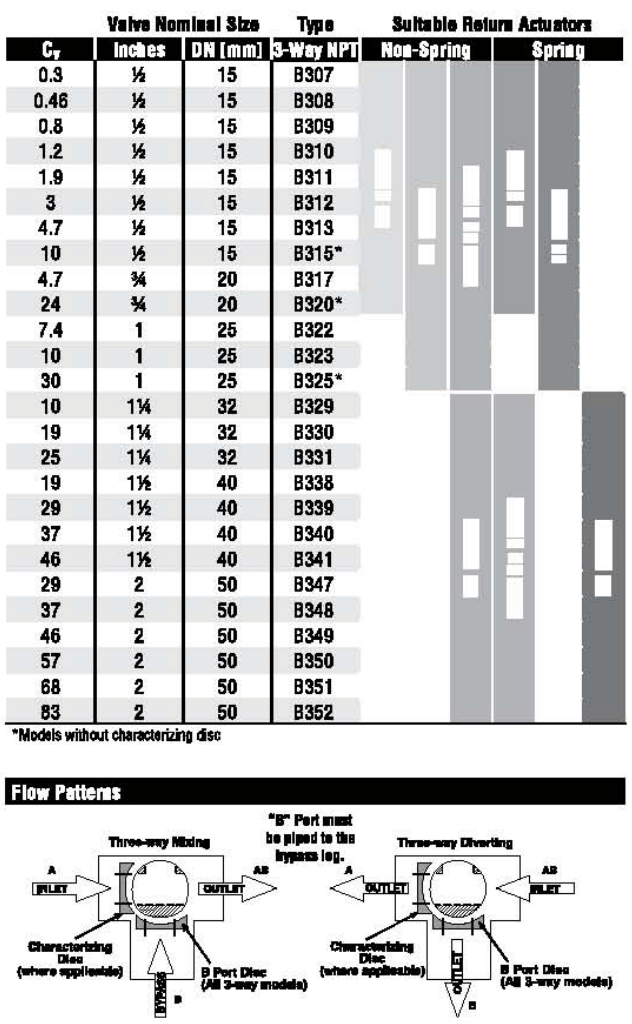


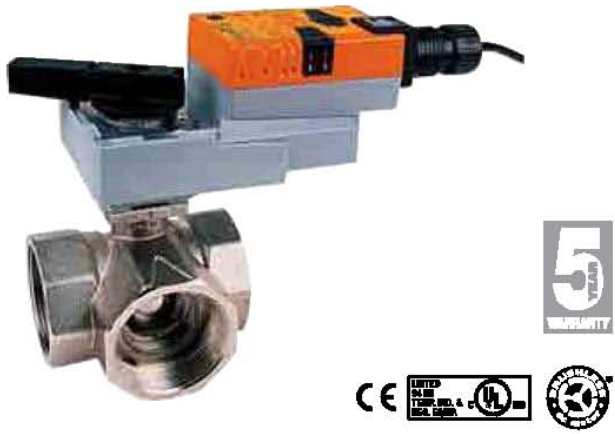

Models

ARB120-SR

ARX120-SR Flexible Version

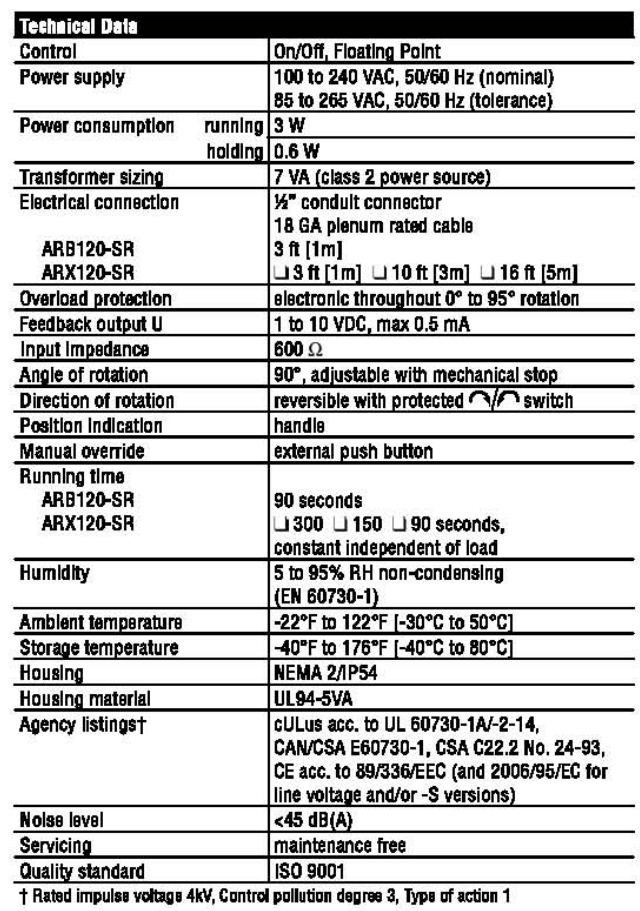

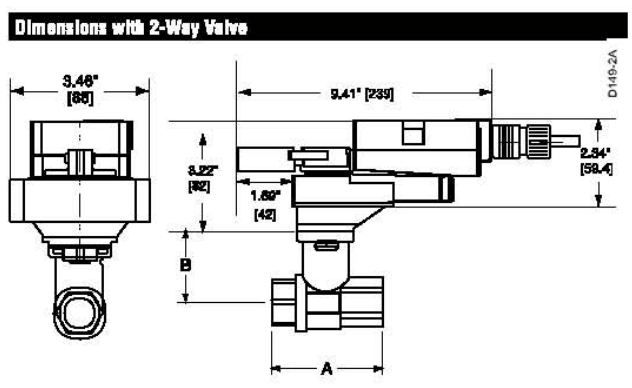

\begin{tabular}{|c|c|c|c|c|}
\hline & \multicolumn{2}{|c|}{ Yahre Mominal Size } & \multicolumn{2}{|c|}{ Dimensions (lnches [mm]) } \\
\hline Valve & Inches & DN [mm] & $\mathbf{A}$ & B \\
\hline B231- & $14^{\prime \prime}$ & 32 & $3.72^{\prime \prime}[94.6]$ & $1.98 "[50.4$ \\
\hline & $1 \kappa^{\prime \prime}$ & 40 & $3.88^{\prime \prime}[98.5]$ & $1.98 "[50.4]$ \\
\hline B248- & 2" & 50 & $4.21^{n}[107.0]$ & $2.21 "[56.2]$ \\
\hline
\end{tabular}

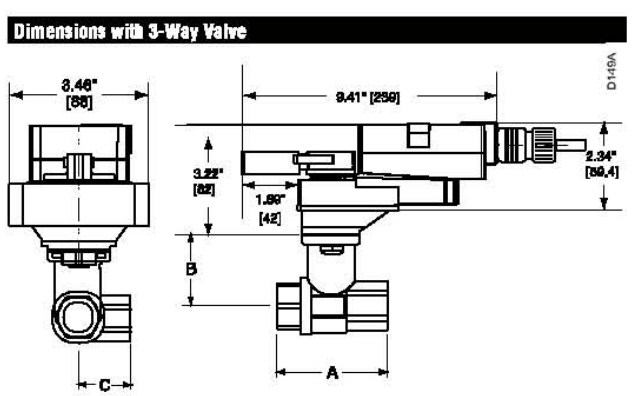

Valve Nominal 81zo Dlmensions (Inches [mm])

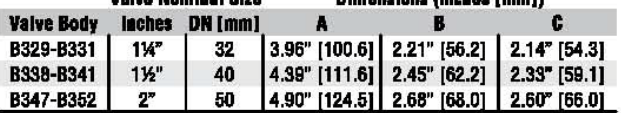


Wiring Diagrams

× installation notes

(2) CAUTION Equipment damage!

Actuators may be connected in parallet.

Power consumption and input impedance must be observed.

5. Only connect common to neg. ( - ) leg of control circuits.

$\triangle$ APPLCATION NOTES

The ZG-R01 $500 \Omega$ resistor converts the 4 to $20 \mathrm{~mA}$ control signal to

2 to $10 \mathrm{VDC}$, up to 2 actuators may be connected in parallel.

Meets cUL Us or UL and CSA requirements without the

need of an electrical ground connection.

A WARNING Live Electrical Components!

2. During installation, testing, servicing and troubleshooting of this product, it may

be necessary to work with live electrical components. Have a qualified licensed electrician

perter in

electrical components could result in death or serious injury.

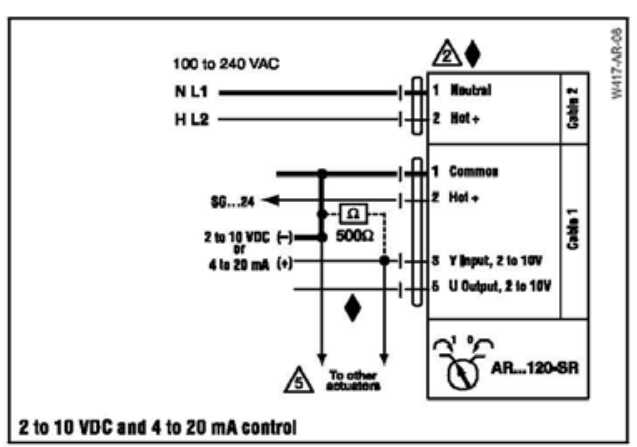

2 to 10 VDC and 4 to 20 mA control 


\section{Appendix G: Micro CHP Project spending report}

\begin{tabular}{|c|c|c|c|c|}
\hline Date & Description & Retailer & $\begin{array}{l}\text { Cost } \\
\text { in } \$\end{array}$ & Note \\
\hline \multicolumn{5}{|c|}{ Micro-CHP Account No. E49246 } \\
\hline $5 / 20 / 2010$ & Castors for Trolley & Castor City & 150.69 & \\
\hline $6 / 12 / 2010$ & Safety Glasses & MEEM Dept & 4.5 & \\
\hline $6 / 25 / 2010$ & Machine Shop Work & Marty & 59.8 & \\
\hline $7 / 1 / 2010$ & Silicone based water seal & McGann Building Supply & 5.19 & \\
\hline $7 / 6 / 2010$ & Black Paint - 2 bottles & Walmart & 1.92 & \\
\hline $7 / 16 / 2010$ & Black Paint - 2 bottles & McGann Building Supply & 8.98 & \\
\hline $8 / 4 / 2010$ & $3 / 4 " G a l v$ Tee and 2 reducers & McGann Building Supply & 4.83 & \\
\hline $8 / 4 / 2010$ & Teflon Tape & Fastnel & 0.89 & \\
\hline $8 / 4 / 2010$ & Funnel and Oilflex & Walmart & 1.37 & \\
\hline $8 / 5 / 2010$ & NI Daq System & $\mathrm{NI}$ & 2507.38 & \\
\hline $8 / 6 / 2010$ & Drain Pan and Oilflex & Walmart & 8.42 & \\
\hline $8 / 11 / 2010$ & Thermocouples & Temprel & 663.04 & $202.98+460.0$ \\
\hline $8 / 17 / 2010$ & Galv Nipple and Coupling & True Value, Hancock & 5.28 & \\
\hline $8 / 20 / 2010$ & Thermocouples-female adapters & Temprel & 100.14 & \\
\hline $8 / 20 / 2010$ & Crow feet set & Auto Value,Houghton & 19.56 & $\begin{array}{l}\text { Charged } \\
\text { under AERB } \\
\text { Account }\end{array}$ \\
\hline $8 / 20 / 2010$ & $3 / 4$ to $1 / 8$ th bushing-30Nos. & J.O. Galloup & 39 & \\
\hline $8 / 23 / 2010$ & Super grip coat glove & ACE Hardware & 2 & \\
\hline $8 / 23 / 2010$ & Hose Barb 3/4 x 3/4 & ACE Hardware & 10.98 & \\
\hline $8 / 24 / 2010$ & 18 mm Boss Fitting Qty=2 & Summit Racing & 24.33 & \\
\hline $8 / 25 / 2010$ & Hose Barb 3/4 x 3/4 & ACE Hardware & 126.27 & \\
\hline $9 / 17 / 2010$ & $\begin{array}{l}11 \text { Galv Tee,10 Hose clamps and } \\
5 \text { 'hose }\end{array}$ & True Value, Hancock & 47.04 & \\
\hline $9 / 27 / 2010$ & Lambda Module & Etas & 2497.5 & \\
\hline $9 / 28 / 2010$ & $1 / 8$ and $1 / 4$ th black wrot steel & Swift Hardware & 2.23 & \\
\hline
\end{tabular}




\begin{tabular}{|c|c|c|c|c|c|}
\hline & coupling & & & & \\
\hline $10 / 6 / 2010$ & Machine Shop Work & Marty & 22.56 & & \\
\hline $10 / 12 / 2010$ & $\begin{array}{l}\text { Copper gasket maker and coolant } \\
\text { density marker }\end{array}$ & Auto Value,Houghton & 11.32 & & \\
\hline $10 / 21 / 2010$ & $10 \mathrm{~mm}$ wrench & NAPA & 3.8 & & \\
\hline $11 / 3 / 2010$ & $8 \mathrm{~mm}$ cap screw and nut $\times 6$ Nos. & Auto Value,Houghton & 1.92 & & \\
\hline $11 / 4 / 2010$ & $\begin{array}{l}\text { M8-1.25x20mm SS Cap screw and } \\
\text { flat washer } \times 4 \text { Nos. }\end{array}$ & Fastnel & 2.84 & & \\
\hline & NG,Exhaust and water drain piping & Facilities & 2300 & $\begin{array}{l}\text { Need } \\
\text { varify }\end{array}$ & to \\
\hline $12 / 3 / 2010$ & 2-Check Valves \& 7 pressure gauge & mcmaster-carr & 203.06 & & \\
\hline $1 / 29 / 2011$ & 1 Groco Accumulator Tank & CLR Marine LLC & 140.27 & & \\
\hline $2 / 1 / 2011$ & 1 Seametrics Flow meter & Instrumart & 935.77 & & \\
\hline $2 / 19 / 2011$ & HP Computer & Office Max & 379.99 & & \\
\hline $2 / 24 / 2011$ & AOC Monitor & Office Max & 129.99 & & \\
\hline $3 / 16 / 2011$ & $\begin{array}{l}3 / 4 \text { gal. } 90 \text { elbow and SS hose } \\
\text { clamps }\end{array}$ & True Value, Hancock & 14.91 & & \\
\hline $3 / 16 / 2011$ & $\begin{array}{l}3 / 4 \text { gal. } 90 \text { elbow and SS hose } \\
\text { clamps }\end{array}$ & True Value, Hancock & 15.9 & & \\
\hline $3 / 16 / 2011$ & $3 / 4$ x 3/4 MPT Barb Inserts Qty=3 & Swift Hardware & 9.69 & & \\
\hline $3 / 19 / 2011$ & $1 / 4$ x 3/4 MPT Barb Inserts Qty=2 & Swift Hardware & 6.46 & & \\
\hline $3 / 21 / 2011$ & $\begin{array}{l}\text { USB extension cable } \times 2 \text { and USB to } \\
\text { serial portable }\end{array}$ & Office Max & 96.97 & & \\
\hline $3 / 23 / 2011$ & 1 NI 9263 module - Voltage o/p & $\mathrm{NI}$ & 356.43 & & \\
\hline $4 / 1 / 2011$ & 1 Null Modem DB9 F/F 6ft cable & Buy.com & 4.59 & & \\
\hline $4 / 5 / 2011$ & 1 Heater Hose, wires and hose clamps & True Value, Hancock & 65.41 & & \\
\hline 4/6/2011 & $\begin{array}{l}\text { 18" heavy cable tie, normal cable tie } \\
\text { and Release clamp }\end{array}$ & True Value, Hancock & 20.96 & & \\
\hline $4 / 6 / 2011$ & $\begin{array}{l}\text { Fiber Gasket martial and 1/4" galv } \\
\text { plug }\end{array}$ & True Value, Hancock & 5.98 & & \\
\hline $4 / 7 / 2011$ & 15VDC power supply & TRC Electronics & 28.28 & & \\
\hline $4 / 8 / 2011$ & 1 Null Modem DB9 F/F & Amazon.com & 5.88 & & \\
\hline
\end{tabular}




\begin{tabular}{|l|l|l|r|r|}
\hline & Thermal loop installations & Facilities & 4450 & \\
\hline & Electrical connections to the grid & Facilities & 3268 & \\
\hline $4 / 15 / 2011$ & Starting fluid & Facilities & 75 & \\
\hline $4 / 18 / 2011$ & Carburetor cleaner & Car Quest & 2.43 & \\
\hline $4 / 20 / 2011$ & Mercury Power tune-Engine cleannertion application fee & vices.com & 2.49 & \\
\hline $4 / 26 / 2011$ & Seal Lead Acid baterry & Car Quest & 22.22 & \\
\hline & & Total: & 48.89 & \\
\hline & & Remaining Balance & 5976.65 & \\
\hline
\end{tabular}




\section{Appendix H: Instructions to run Micro-CHP Lab}

1. Switch on the power supply to Ecopower unit by turning on the heavy duty switch inside the cold room (Make sure the on/off switch on left side of Ecopower is off).

2. Switch on the Natural Gas supply by opening the valve.

3. Switch on power for DAQ and Computer to collect the data

4. For city water cycle follow instruction 4 to 8 , for water recirculation follow steps 6 to14

5. Slowly turn the city water line valve and drain valve simultaneously till the desired pressure is reached. Make sure the pressure of water does not exceed 80psi

6. Check all the instrument readings on computer for safety

7. Turn on the switch on the left side of Ecopower

8. Now system is ready for conducting the desired experiment with Ecopower.

9. Switch on pump and water heater breakers present on the front wall of Cold Room

10. Power the 3 way control valve

11. Vary the flow of pump and 3 way valve to check the thermal loop is working fine

12. Turn on the switch on the left side of Ecopower

13. Now system is ready for conducting the desired experiment with Ecopower.

14. After completing the experiment, make sure to power off everything. 


\section{Appendix I: Lesson's learnt}

- $\quad$ Ecopower error reset code used on touchpad: 1995

- $\quad$ CHP Maintenance password used on the touchpad: 1291

- In case of trouble with engine, contact Ken Stupar at Marathon Engines

- In case of trouble with computer communication with Ecopower, contact Phil at Marathon Engines

- To tighten the rocker arm assemble on the intake and exhaust valve use 180 inch pound of torque on the bolts

- City line water pressure varies between 80psi to 140psi. Opening the city line suddenly can cause water hammer and destroy the piping and pressure gauges

- If the engine looses compression check for carbon deposits on the exhaust valve 